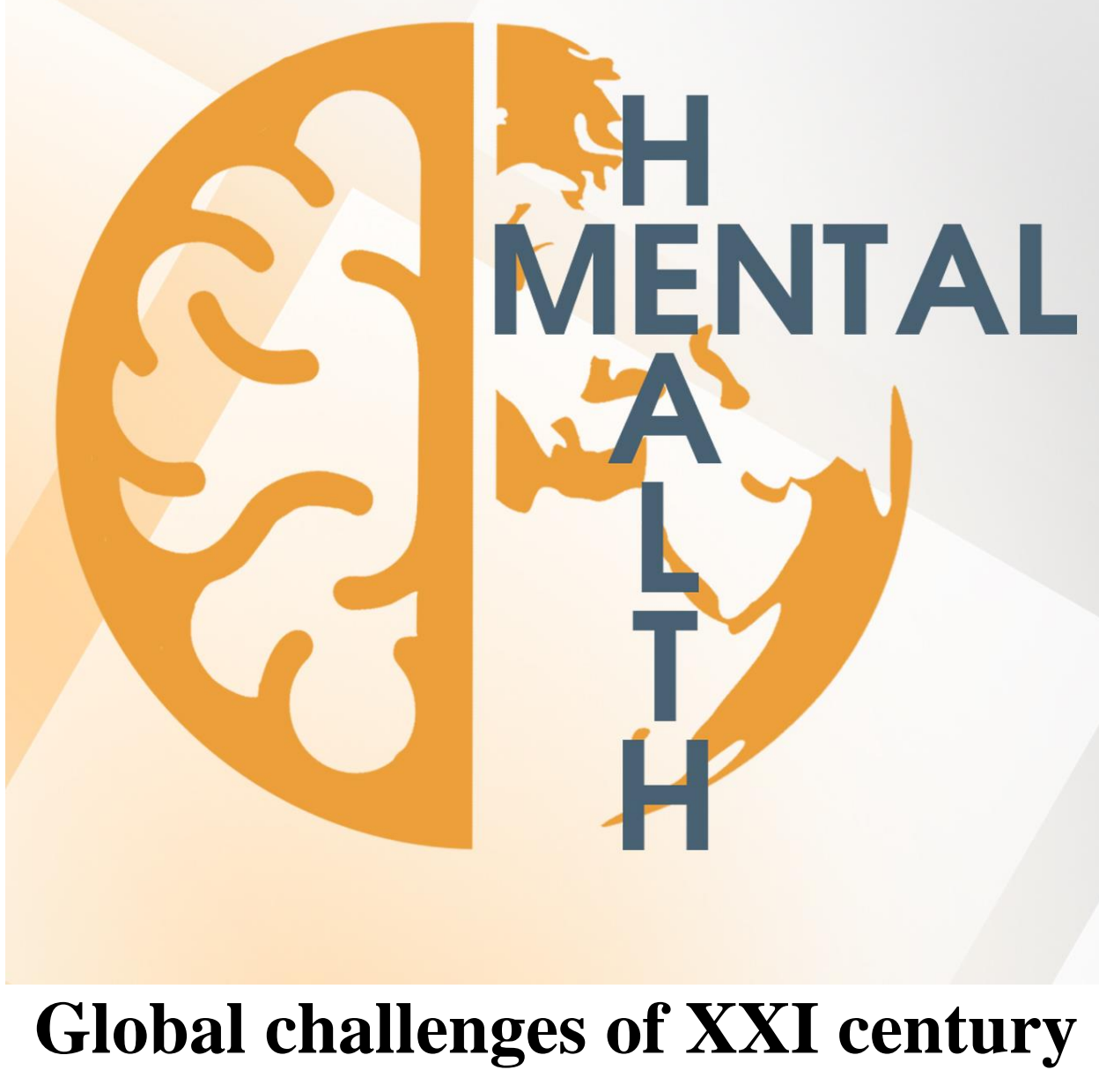

MHGC PROCEEDINGS

Rome 2018 
Published from

the year 2017
Publication frequency

1 issue/year
Issue status

National/International

\section{Founders}

The MHGC Proceedings was originally founded by NDSAN Network (MFC Coordinator of the NDSAN)

\section{Issue languages}

English

\section{Media environment}

International

\section{Abbreviation key title MHGCP}

\section{Target audience}

Scientists/researchers (medical, social, educational fields and etc.), mental health $(\mathrm{MH})$ practitioners, policy-makers, researchers, lawyers.

\section{Major objectives}

- to attract attention of researchers and policy-makers to urgent problems of mental health care (MHC)

- to provide a platform for dissemination of ideas and development of academic and non-academic network of MHC researchers, practitioners and policy-makers

- to promote high quality research most specifically on $\mathrm{MH}$ in developing countries and countries in transition

- to investigate multi-disciplinary, transdisciplinary and multicultural aspects and solutions related to MHC

\section{Field of study and special focus}

Medicine, Social Sciences, Education, Economics, Law, Inter- and Transdisciplinary studies

\section{Topics}

- MHC systems in the context of global social challenges:

- Mental health and migration:

- Mental health in times of military conflicts

- Mental health and community

- Specific issues of MHC: child neuropsychiatry; support for people with disabilities, work with elders related to mental health; MHC in rural areas; addictive behavior

- Higher Education and MHC: Research and Innovations:

\section{How to cite:}

Author (2018). Title of the paper, MHGC Proceedings (pp.). Rome, Italy. International Support

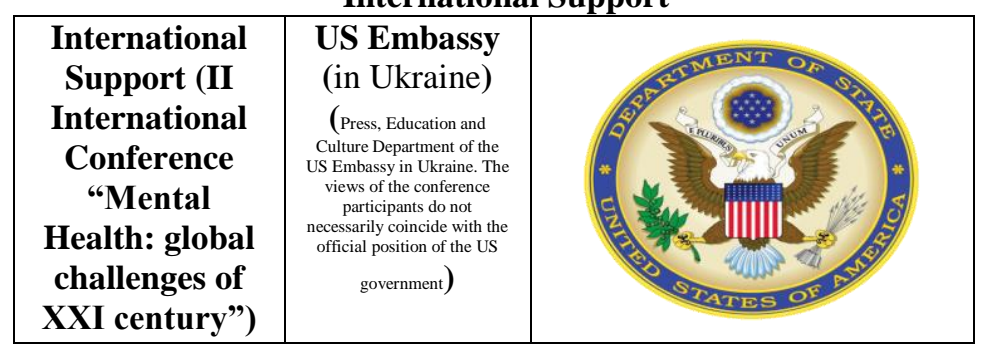

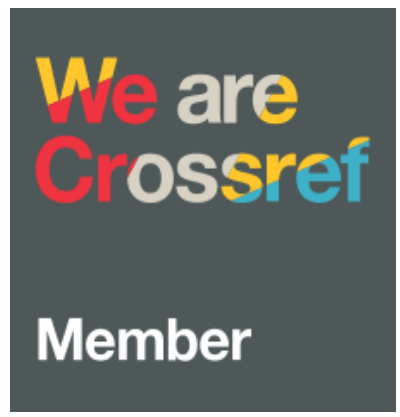

The MHGC Proceedings contain research papers on multidisciplinary aspects of Mental Health Care system in globally 
UDK 159.922.27:316.33(811.111)

DOI: http://doi.org/10.32437/MHGCProceedings.Issue-2018

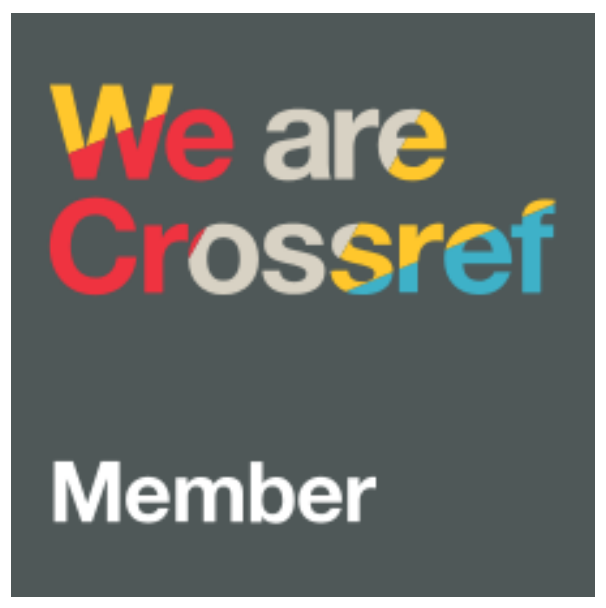

\section{Indexed in CrossRef}

The MHGC Proceedings contain research papers on multidisciplinary aspects of Mental Health Care system in globally.

\section{UDK 59.922.27:316.33(811.111)}

The authors are responsible for validity of data

(C) NDSAN (MFC - coordinator of the NDSAN), Italy, 2018 


\section{Contents}

Protecting Mental Health in an Epoch of Virtualization (Olena Andriienko).

Features of the Application of the Cognitive-Behavioral Therapy Techniques as the Method of Early

Intervention in Therapy of Psychotic Disorders (Oleksandr Avramchuk, Hrystia Shalak) 8

Emotional Characteristic of Personality Maturity of Teachers in Conditions of Social Transformation (Svitlana Baranova)

Acceptance of Own Corporeality as Sanogene Factor in the Development of the Marital Relationship (Halyna Bevz).

Preserving Human Mental Health through Control of Pathogenic Text in Mass Media by Means of Indexing and Marking (Olesya Bik)

Bulling as a Model of Systemic Deficit. Healing Strategies (Angela Borshchevska, Nataliya Ryshkovska) ....... 16

Explorative Study of Psychosocial Stress Factors that Cause Professional Burnout Among Teachers, Who Leave Near the Front-Line Zone in the East of Ukraine (Andriy Girnyk ${ }^{1}$, Yulia Donets ${ }^{2}$, Sergiy Bogdanov ${ }^{2}$, Victoriya

Solovyova ${ }^{2}$, Lyudmyla Romanenko ${ }^{3}$ )

Features of Psychosocial Support of Combatants' Wives (Nataliia Didyk).

The Mental Health between Epigenetics and Individual Beliefs (Marin Drămnescu, Vladimir Enăchescu, Monica Păduraru).

Role Models' Peculiarities of Women with Crisis Pregnancies (Natalie Heisonyuk, Yaroslava Andrieieva) ...... 27

Psychological Sense of Ownership: from Disorders to Norm (Iryna Hubeladze).

Nuclear Power Plant Disaster: Impact on Mental Health and Lifestyle of Liquidators (Olha Humeniuk) ........... 31

The Adaptability Factor of Young People with the Status of a Disabled Child in the Context of Medical and Social Expertise (Victoria Khramtsova, Yulia Honchar)

Changing Approaches to Dementia Management: How Relevant Is It for Ukraine? (Oleksandra Khudoba) ...... 35

Parental Competence with Autism's Children: Current and Perspective Research (Hanna Khvorova) ............... 37

The Research of the "Courage to Continue" Using Narrative and Ideographic Approaches (Zoia Kireeva, Olena Odnostalko)

On Solving the Problem of Mental Health Care with the Social Work Input (Liliya Klos, Larysa Klymanska, Nina Hayduk, Halyna Herasym)

The Narcissistic Ways to the Existential Self-Fulfillment (Maria Klymenko)

Multidisciplinary Approach to Research of the Adherence to Treatment Phenomenon in Patients with Diabetes Mellitus (Anna Kogut ${ }^{1}$, M. Bobryk ${ }^{1}$, O. Potapov ${ }^{2}$, I. Frankova ${ }^{1}$, J. Komisarenko ${ }^{1}$, O. Khaustova ${ }^{1}$, O. Chaban ${ }^{1}$ ) 45

The Influence of the Emotional Intelligence Features on the Intensity of the Loneliness Experience in Adolescence (Lyudmyla Kolisnyk).

Group Support for Vulnerable Groups as a Prerequisite for Mental Health (Olha Korobanova)

Public Health Strengthening in the Context of Community Adaptation to the Consequences of a Military

Conflict: Salutogenic Approach (Larysa Korobka).

Personality Features of Pet Owners (Eduard Krainikov ${ }^{1}$, Eugene Prokopovich ${ }^{1}$, Thais Bezkrovna ${ }^{2}$ ) ................... 56

Subjective dimension of mental health: Ukrainian adaptation of the Orientation to Happiness Scale (Iryna Kryvenko, Galyna Petryk)

Readaptation of ATO Veterans and their Wives: Experience of Psychosocial Assistance School (Borys Lazorenko ${ }^{1}$, Kateryna Kalnytska ${ }^{2}$ )

Reasons of Healthy Behaviour Disorders in Adolescence (Maryna Martseniuk)

Stress Resistance in the Structure of Individual Psychological Characteristics of Students (Iryna Martyniuk) ... 64 
East and West about Mental Health: Personal and Social Strategies for the Achievement (Sergei Naidenov) .... 71

Intersubjectness as a Resource to Maintain Mental Health (Maria Nakonechna).

Political and Legal Informing of Students in Conditions of Military Conflict Between Russia and Ukraine (Lyudmila Nikonenko).

Psychological Health of a Person: Theoretical Issues (Mykola Papucha)

Employee's Mental Health in the Service Organizations as the Object of Psychological Research (Igor Proshukalo)

The Quality of Social Functioning in Patients with Depression, as a Parameter of State Severity (Lyudmyla Rakhman, Oksana Plevachuk, Iaroslav Shpylovyi)

Are Extrovert People More Satisfied with Life? Case Study (Lena-Ramona Richițeanu-Năstase, Camelia Stăiculescu)

Pilot Study of Stigmatization of Mental Health Problems in the Ukrainian Educational Environment (Olha Savychenko, Natalia Portnytska)

Confession as a Psychotherapeutic Tool to Work with Ego Inflation (Iryna Semkiv)

Psycho-Information (Psychotronic) Technologies for Overcoming the Effects of Operative-Combat Mental Trauma: Addictive Disorders, Drug-Resistant Major Depression, Anhedonia and Alexithymia. First Report (Anatolii V. Sergiienko ${ }^{1}$, Taras A. Sergiienko ${ }^{2}$, Olesia O. Kovalyk ${ }^{3}$, Taras I. Kovalyk ${ }^{4}$ )

Attitude to Supervision as the Form of Professional Support: Survey Results of the Helping Professions' Specialists (Diana Shtryhol ${ }^{1}$, Larysa Spitsyna ${ }^{2}$, Victoria Melman ${ }^{3}$, Oleksii Vydysh ${ }^{4}$, Inese Stankus-Visa ${ }^{5}$, Zilvinas Gailius $\left.{ }^{6}\right)$

The Cognitive Methods of Protection the Adolescences' Mental Health in the World Wide Web (Oksana Strilchuk)

Is autism Spectrum Disorder (ASD) a Mind-and-Somatic State "Neuro-Managing" System Malfunction? About Some Possible Mechanisms of this Kind of Neurodevelopmental Disorder (Oleksii Tanasiienko ${ }^{1}$, Olena Tanasiienko ${ }^{2}$ )

Applying The Semantic Differential to Compare the Experiences of Existential Fears (Kateryna Titova ${ }^{1}$, Volodymyr Savinov ${ }^{2}$ )

Psychological Factors of the Formation of Victimization of Women in the Modern World (Vakulich Tetyana) 97

Media-Art-Therapy for Mental Health Care (Olena Voznesenska)..... .98

Traumafokus $^{\circledR}$ (TF) - Psychotherapy for Chronic Pain Regulation and Pain Syndromes (Thomas Ch. Weber) 100

Ethical Grounds of Psychological Help as a Means of Preserving Mental Health of a Person (Tetiana Yablonska, Natalia Bulatevych).

Neurofitness as a Method of Psychotherapy for Children with Psychoneurological Pathologies (Olga Yashna ${ }^{1}$, Olexandr Makarenko ${ }^{1}$, Alla Shapovalova ${ }^{2}$ ) 


\title{
Protecting Mental Health in an Epoch of Virtualization
}

(Olena Andriienko)

\author{
Legal Department of “CCM” SE (Publicis Groupe Ukraine), Kyiv, Ukraine
}

\begin{abstract}
Introduction. The huge amount of digital phenomenon stresses the permanently virtualizing character of our "way of being" (Rogers, 1994). It could be frightening, however, this is not the very first experience of virtualization as each transition to the next level of abstraction may by estimated as the virtualizing act (including development of natural languages, writing systems invention, book-printing and computation) (Nosov, 2000: Zhurba, 2016). The future steps on this way are hardly predicted, but all of them are united by the psyche, which may be defined as the independent physical force that creatively regulates the information-energy exchange in its movement between different levels of virtualization driven by meanings (Frankl, 2018; Gleiser, 2017).
\end{abstract}

Humanity is creating new realities with their own space-time in the digital sphere now. In language of physics (Wilczek, 2018) the new metric field is expanding, which gives rigidity to space-time and causes gravity on our individual mental maps and in this "brave new world" (Hucksley, 2014) as a whole. Therefore, virtualization gifts the both new threats and new opportunities including ideas of singularity and immortality connected with the cyber sphere. However, these ideas accentuate the search for an "answer to the ultimate question life the universe and everything".

Purpose. Any reality demands its own rules to exist. These rules or system of limitations (often called "laws" in physics and in social sciences) are the necessary precondition not for development and existence of liberty, responsibility, beauty, creativity only, but, first at all, they are the ground for state of well-being in physical, psychological and social aspects, in other words for the health. This is correct for any carrier of psyche including a separate person, the certain group or the global community, who acts in the corresponding virtual space-time.

The lack of verbalized socially agreed rules for the virtual digital reality provokes the feel of uncertainty and permissiveness and an extremal behavior, which causes the psychic instability (Holmes, 2016), deviation in different forms and very new forms of psychic disorders: from obsessive behavior, anxiety and neuroses related with gadget dependency, game and social network addiction until cybercrimes like incitement to suicide.

Thus, the purpose of the study is describing an effective instrument for the cyber sphere normative regulation as a precondition for the mental well-being.

Design/Methodology/Approach. The first step in any norm development is the differentiating as the simplest case of energy and information processing demands two poles. It could be 0 and 1 , good and evil, energy and information, etc. Even life is possible within a comparably narrow corridor of poles - in gravity, space-time, temperature, and infinite quantity of others. Thus, human psyche also mirrors this polarity and is highly effective in operating with them. The individual and social development pass through different poles: progress and traditionalism (conservatism), independence and globalization, etc.

However, polarization creates tension and may cause diseases on the individual and social levels. At the same time, this tension stimulates movement to the next level of virtualization, which may help to solve the poles of the previous level and heal by retrieving the wholeness. Then the new pair of polarities starts development on this new level of virtualization and process repeats with new degree of complexity. Thus, the key for treatment is overcoming the polarities and forming the wider field of conscious and responsible activity both on the individual and social levels.

In view of this, society needs a supranational instrument for fast-reacted self-regulation, especially in cyber space, including rules for virtual and alternate realities and interaction with artificial intellect or robots.

However, the most of governmental and private official institutions are too slow acting, often unduly politically and economically motivated, while their legal acts are overcomplicated for perception (for instants, EU GDPR or Facebook policies).

Results. For this reason, the wisdom and potential of collective consciousness may (and should) be used for creating a global crowd platform to self-regulate the fast-developing and weakly predictable virtual space.

The described platform may be effective for natural development and systematizing the customs as the source for the cyber sphere normative regulation.

Limitations and strengths of the study. Description of the approach is the very first, but necessary step in development of the global crowd platform for virtual space self-regulation.

The general advantages of the mentioned platform are following:

1) It combines the enthusiasm of Wiki projects (Isaacson, 2017; McGonigal, 2016) with laconism of Ten Commandments given to Moses.

2) It is fast-reacted sources of law for private (civil) relations known as custom in international and local jurisdictions (Polanski, 2007). 
3) It activates the power of self-enforcing agreement as any person may feel like co-creator through involving in corresponding discussion and decision-making (McGonigal, 2016; Ramo, 2018).

The programming means, which may be a basic for the development of the mentioned platform, are first at all wiki software, blockchain and artificial neural networks.

This paper makes a step to popularize the mention idea, develop it, and create the sensitive collective perception. The next steps are the project plan development; involving the like-minded theorists and practitioners, team development, and the pilot project realization.

Practical/Social value. Society receives the effective supranational instrument for fast-reacted self-regulation, especially in cyber space, including rules for virtual and alternate realities and interaction with artificial intellect or robots.

Originality/Conclusion. The described approach summarizes and develops theoretical ideas in many different fields of study, including psychology (Frankl, 2018; Rogers, 1994), law (Harvey, 2017; Polanski, 2007), physics (Deutsch, 2015; Wheeler, 1990; Wilczek, 2018), information theory (Hidalgo, 2016) and game theory (McGonigal, 2016), and, of course, everyday practice. This integrated approach is very natural for the new stage of the Anthropocene when all of us are creating the unitary social network with radically new characteristics (Isaacson, 2017; Ramo, 2018; Sloman, 2018).

As any joke, the popular Internet meme: "Save me!" - "As.jpg or.pdf?" reflects some deepest wisdom and is something more than a fun only. Thus, we have a unique opportunity to develop a new approach to creation of regulatory framework for the mental health protecting in any types of newly invented human world.

Keywords: virtual reality, digitization, mental health, collective activity, crowdfunding, self-regulation.

\section{References:}

1. Deutsch, D. (2015). The Fabric of Reality: The Science of Parallel Universes and Its Implications. Moscow: Alpina non-fiction. (In Russian).

2. Frankl, V. (2018). The Doctor and the Soul: From Psychotherapy to Logotherapy. Kharkiv: Family Leisure Club. (In Ukrainian).

3. Gleiser, M. (2017). The Island of Knowledge: The Limits of Science and the Search for Meaning. Saint Petersburg: Piter. (In Russian).

4. Harvey, D. (2017). Collisions in the Digital Paradigm: Law and Rule Making in the Internet Age. Oxford: Hart Publishing.

5. Hidalgo, C. (2016). Why Information Grows: The Evolution of Order, from Atoms to Economies. Moscow: Eksmo. (In Russian).

6. Holmes, J. (2016). Nonsense: The Power of Not Knowing. Kyiv: Nash Format. (In Ukrainian).

7. Hucksley, O. (2014). Brave New World. Moscow: AST (In Russian).

8. Isaacson, W. (2017). The Innovators: How a Group of Hackers, Geniuses, and Geeks Created the Digital Revolution. Kyiv: Nash Format. (In Ukrainian).

9. McGonigal, J. (2016). Reality Is Broken: Why Games Make Us Better and How They Can Change the World. Moscow: Mann, Ivanov and Ferber. (In Russian).

10. Nosov, N. A. (2000). Virtual Psychology. Moscow: Agraph. (In Russian).

11. Polanski, P. P. (2007). Customary Law of the Internet - In the Search for a Supranational Cyberspace Law. The Hague: T.M.C. ASSER PRESS.

12. Ramo, J. C. (2018). The Seventh Sense. Power, Fortune and Survival in the Age of Networks. Kyiv: Yakaboo Publishing. (In Ukrainian).

13. Rogers, C. (1994). On Becoming a Person: A Therapists View of Psychotherapy. Moscow: Progress. (In Russian).

14. Sloman, S., Fernbach, P. (2018). The Knowledge Illusion: Why We Never Think Alone. Kyiv: Yakaboo Publishing. (In Ukrainian).

15. Wheeler, J. A. (1990). Information, physics, quantum: The search for links. Complexity, Entropy, and the Physics of Information. Retrieved from http://cqi.inf.usi.ch/qic/wheeler.pdf on 2018-08-08.

16. Wilczek, F. (2018). The Lightness of Being: Mass, Ether, and the Unification of Forces. Saint Petersburg: Piter. (In Russian).

17. Zhurba, M. A., Pagava, O. V., Baidyk, V. V. (2016) Labyrinths of virtual: Theseus in search for Ariadne. Kharkiv: Tochka. 


\title{
Features of the Application of the Cognitive-Behavioral Therapy Techniques as the Method of Early Intervention in Therapy of Psychotic Disorders
}

\author{
(Oleksandr Avramchuk, Hrystia Shalak) \\ Ukrainian Catholic University, Lviv, Ukraine
}

Introduction. According to the National Institute of Mental Health in 2015, in the United States, about 100,000 people survived the first psychotic episode, and three in 100 people have at least one psychotic episode in their lives (National Institute of Mental Health, 2015).

According to World Health Organization, schizophrenia in the world affects about 21 million people. The onset of the disorder occurs in adolescents and early adulthood (15-29 years) (World Health Organization, 2012). People suffering from psychotic disorders, 2.5 times more often than others, died at a young age due to somatic causes - cardiovascular, metabolic and infectious disorders.

In 2015, according to official statistics of the Ministry of Health of Ukraine, the incidence of psychotic disorders (schizophrenia, schizotypal and delusion disorder) was 15.82 per 100,000 population. The prevalence of schizophrenia was 292.6 per 100,000 population, of which the working age was 355.4 per 100,000 of the population (Ministry of health of Ukraine, 2016).

Considering these statistics, it can be argued that psychotic disorders occupy an important place in the structure of the general morbidity of the population, affect quality and life expectancy, reduce working capacity and often cause disability. Psychotic symptoms cause significant distress in patients and lead to violations in important spheres of life, social functioning, may be the cause of suicidal or socially dangerous behavior, affective disorders. Therefore, the issue of effective treatment and prevention of these disorders, as well as social rehabilitation of patients, is relevant. Recent systematic reviews on cognitive-behavioral therapy (CBT) as a method of early intervention in psychotic disorders were implemented in 2010 (Early intervention services, cognitive-behavioral therapy and family intervention in early psychosis: a systematic review) and 2012 (Cognitive Behavioral Therapy in Prodromal Psychosis) years (Bird, Premkumar, 2010, Addington, 2012). Among the Ukrainian publications, these interventions don't enough highlights in comparison with medical therapy.

Purpose. The aim of the present research is to investigate the features of the use of cognitive-behavioral therapy techniques and their effectiveness in the treatment of psychosis in the early stages. This study complements already existing systemic literature reviews and meta-analyses on the topic of cognitive-behavioral therapy of psychotic disorders those devoted to CBT of the first psychotic episode. This review contains an analysis of new articles on this topic. In addition, it examines the effectiveness of the use of CBT not only in the prodromal stage of psychosis and during its manifestation, as well as in the remission period as a method for preventing recurrence.

Methods and organization of research. For review, we used the following the inclusion criteria:

- The research should be having been published no more than 10 years;

- The research should be having been related to the use of cognitive-behavioral therapy in the treatment of patients with psychotic disorders in the early stages. These include prodromal phase (high risk of developing psychosis), first psychotic episode, recovery, and remission after the first psychotic episode;

- The articles should be having been published in authoritative scientific research resources: PubMed, Medline, Web-of-Science, BIOSIS, Cochrane library and Research gate databases.

Results and Discussion. Most studies confirmed the effectiveness of CBT psychotic symptoms. For the most common is the inclusion in the therapy of psychoeducation, normalization of experiences and developing preventing relapse plan. The necessity of these components is confirmed by the theory and points to the importance of open presentation of information to the patient, interpretative work on the symptoms, their prevalence, possible causes and triggers in each case. Their effectiveness has been proved by the technique of teaching useful coping strategies about positive and negative symptoms, which is confirmed by the theoretical basis and proves the usefulness of the skills of adaptation and management of the symptoms of the disorder. Some studies also suggest that typical CBT protocols for comorbidities, such as depression, anxiety disorders, and low self-esteem, may be used for patients with psychotic disorders. The training of social skills and assertiveness helps in restoring social functioning. The effectiveness of the application has been demonstrated in both individual and group formats.

Limitations and strengths of the study. It should be noted that the one limitation of the present review is the paucity of randomized controlled trials included in a review. Some trials include CBT early interventions and 
addition antipsychotic courses in both trial group, that could impact the effects of early intervention. In addition, a small number of early intervention trials provided long-term data, limiting the comparison and review.

Practical/Social value. Based on this study, recommendations for the use of cognitive-behavioral therapy for the first psychotic episode as a method of choosing early psychotherapeutic intervention can be formulated. Given that the work contains a theoretical overview of the basic principles of cognitive-behavioral therapy of psychosis, the results of the study can be used in practice. The present review can be useful to psychiatrists, psychologists, social workers and anyone who works with people at high risk for a psychotic disorder, with people which were experienced the first psychotic episode or are in the recovery stage after it and need help in preventing relapse.

Conclusions. According to the data, CBT-techniques is an effective and scientifically based method in the integrated therapy of patients in the early stages of the course of psychotic illness. CBT early interventions reduce positive and negative symptoms severity, improve access to engagement with treatment, which also reduces hospital admission and relapse rates. Consequently, based on the results of the research, it is possible to recommend programs, techniques, and manuals based on CBT for use in the integrated therapy of psychotic disorders in the early stages.

Keywords: Psychiatry, psychology, mental health, mental illness.

\section{References:}

1. Bird, V. \& Premkumar, P. (2010) Early intervention services, cognitive-behavioural therapy and family intervention in early psychosis: systematic review. Br.J.Psychiatry, 197(5), 350-356. http://doi.org/10.1192/bjp.bp.109.074526

2. Addington, J. (2012) Cognitive Behavioral Therapy in Prodromal Psychosis. Current pharmaceutical design, 18(4), 558-565. http://doi.org/10.2174/138161212799316082

3. Ministry of health of Ukraine (2016) Notice on the publication of a draft order of the Ministry of Health of Ukraine "On approval and implementation of medical technology documents on the standardization of medical care for schizophrenia". Retrieved from: http://old.moz.gov.ua/ua/print/dn_20160702_0.html.

4. National Institute of Mental Health (2015) Fact Sheet: First Episode Psychosis. Retrieved from: https://www.nimh.nih.gov/health/topics/schizophrenia/raise/fact-sheet-first-episode-psychosis.shtml

5. World Health Organization (2012) Psychoeducation, family interventions and cognitive-behavioural therapy. Retrieved from: http://www.who.int/mental_health/mhgap/evidence/psychosis/q10/en/. 


\section{Emotional Characteristic of Personality Maturity of Teachers in Conditions of Social Transformation}

(Svitlana Baranova)

Institute for Social and Political Psychology of National Academy of Pedagogical Sciences of Ukraine, Kyiv, Ukraine

Introduction. Ukraine's coming into the Europianean Educational World determines the educational content modernisation in the context of its correspondence for modern demands of a society and a personality. Domestic system of education is experiencing a hard period which is conditioned by the socio-economic development of the country as well as social transformations. The Minister of Education and Science of Ukraine has commented the relevant situation in the country as "a chance for changes for the educational system", which is able to be seen as ".contribution in Ukrainian education and general development of the country".

In the period of transformation the responsibility of every society member for work results, the process of social changes increases and the importance of teachers' responsibility increases significantly because school provides the foundation for future social life of any country. In such a situation demands for not only qualities of pedagogical influence and implementing innovations are increasing but also there are big demands for a personality of a teacher who is mostly responsible for development of a pupil's personality. Such an approach can be ensured only by mature and responsible attitude of participants implementing educational innovations. In the process of implementing new innovations new demands are appearing in front of a teacher; except this, a high level of social tension in the period of social transformation in our country - all these factors add tension and can lead to experience of crisis situations and emotional states of a teacher, overcoming of which often causes demonstration of aggression. In such conditions the problem of understanding and analize of particularity of emotional state of teachers is actualized as a demonstration of personality maturity.

Purpose. In accordance with the mentioned above, the purpose of our research is to reveal features of aggression of pedagogical workers in the period of implementing educational innovations as emotional characteristics of personality maturity.

An optimisational process of a personality maturity formation in conditions of social transformation is a humanistic value of education. It is recognized in admitting unique and unrepeated value of everyone, his or her role in the society's development, strengthening the responsibility of a personality for building his/her life way and professional path. In scientific discussions emotional characteristic of personality maturity is seen through specified control of own emotional state and mature managing of own behaviour. Peculiarities of self-control, self-evaluation, an ability to suppress very strong and non-adaptive emotional reactions (V. Tatenko, 2014; E. Gejko 2016; S. Baranova, 2017).

The pedagogical profession contains a potential possibility of a higher emotional reaction and in many cases can lead to vicariousness and deformation of individual maturity and strengthen of a negative tendency in the structure of a teacher's personality. Except damage which is made by such an activity to the child's psyche, deconstructive emotional demonstrations of teacher's aggression are also able to influence teacher's own health. Such consequences as psychosomatic illnesses, professional burnout appear and they lead to a decrease in the effectiveness of pedagogical activities.

Methodology. 250 pedagogues in the age between 22 and 64 from Ukrainian secondary schools took part in the research of pecularities of appearing aggression in the pedagogical activity.

Methods of the research. Such methodologies which reveal qualities of a personality which are connected with a personality maturity and different emotional demonstrations have been used in the research, as test-questionnaire of personality maturity of Yu. Z. Gilbuha, Cattell test, 16 PF (form A), method of diagnostics of J. Rotter's subjective control (adapted by E. F. Bazhina, S. A. Golinkina, A. M. Etkinda), self-assessment methodology (S. A. Budassi), the questionnaire "Self-assessment of forms of aggressive behaviour" (modified version of the method A. Bassa - A. Darki), professional burnout questionnaire for pedagogical staff (adapted by N. E. Vodopianov).

Results. The analyse of results is the identification and substance of pecularities of emotional characteristic of pedagogue's personality maturity which is revealed in the connection between pedagogue's aggression and his/her individual psychological features which determine its demonstration in professional activity. In accordance with Bassa-Darki questionnaire the general profile of teachers' aggression form is characterized by low and average values for all scales. Such forms of aggression as feelings of guilty and irritation have been the most significant, the low indexes have been in scales of physical aggression, non-direct aggression, suspicion and verbal aggression.

The further analyse has revealed signs of teachers' aggression which depends on gender differences and work experience. The research has revealed that male pedagogues tend to physical aggression more that female 
pedagogues. According to the work experience, teachers with the experience between 11-25 years of work are more aggressive (it's based on all scales of the research) which can be explained, from our point of view, by a development of a professional deformation.

The sign of a self-assessment depends on a type of teacher's aggression. Non-aggressive pedagogues have an adequate self-assessment. The low self-assessment belongs to other types of teachers. So, the earlier determined regularity is confirmed, that a low self-assessment is not a positive factor in their professional activity. Moreover, we can stipulate, that the low self-assessment influences on the development of interaction with students, colleagues, and also influences the quality of professional duty.

Data, which has been obtained via the methodology of identifying the syndrome of "professional burnout", shows that the big quantity of teachers demonstrate signs of formed syndrome of "professional burnout". Except this, the dependence between the emotional exhaust, depersonalization and high sense of guilty has been revealed.

Conclusion. On the base of fulfilled researches we are able to reach the following conclusions:

1. Teacher's realizing of the importance of the situation of social transformation and the potential of educational innovations, the uniqueness of the moment "here and now" and a connection with all global processes which are going on in the world and also in Ukraine, has the fundamental value as from the ethical quality of a teacher as a search for ways of his/her development.

2. It has been identified that the strategy of teacher's professional behaviour is tightly connected with the teacher's emotional state. Negative emotions, which the teacher is experiencing, often reflect his/her attitude to his/her professional activity. Correlation relations between the demonstration of aggression and the pedagogical experience of teachers have been revealed. Different stages of professional development are characterized by different psychological pecularities of aggression which have a qualitative and quantitative originality at the stage of adaptation, the first and the second stage of professional development and professional excellence of a teacher.

3. In accordance with the research results, it has been revealed that in comparison with other forms of teachers' aggression the feeling of irritation and the sense of guilty appear more often. Pedagogues in general are characterized by a high and middle emotional level of exhaust, depersonalization and reduction of individual achievements, the low level of self-assessment, internal subjective control and a high level of personality maturity. In the gender aspect, as personality maturity in general as its individual components of a female teacher reduce a possible appearing of all forms and indicators of aggression. The biggest demonstration of destruction reveals a connection with verbal aggression. Male teachers have lower enough level of connection between personality maturity and aggression, although it is also negative. The connection between an indicator of achievements of personality maturity and a low level of an indicator of suspicion has been revealed among male teachers.

The prospect of further research is to development modern prevention programmes and form skills of mature control of own emotional state and management own behaviour taking into account pecularities of pedagogical activity and conditions of social transformation of the present.

Keywords: personality maturity, aggression, gender divergences, pedagogical activity, emotional exhaust.

\section{References.}

1. Zakon pro osvitu (2017). mon.gov.ua. (Закон «Про освіту» прийнято - «ЗА» проголосували 255 депутатів). Press. 2017. http://mon.gov.ua/usi-novivni/novini/2017/09/05/zakon-«pro-osvitu»-prijnyato---〈(za»progolosuvali-255-deputativ/

2. Baranova S. (2017). Theoretical analysis of responsibility as an integrative quality of personality maturity in conditions of transformation // Development and modernization pedagogical and psychological sciences: the experience of Poland and the prospects of Ukraine: Collective monograph. Vol.1. Lublin: Izdevnieciba "Baltija Publishing", 2017" Maria Curie-Sklodowska University. - P. 37- 53. Press. 2017. http://repositsc.nuczu.edu.ua/bitstream/123456789/6063/1/colmon\%20Lublin_ped_psyh_Часть\%201_новий.pd f

3. Gejko E.V. (2016). Psychology of integrity of personality (Гєйко Є.В. Психологія цілісності особистості). 4. Moldovanova A. (2008). Psychological determinants of aggression in the conditions of the teacher's professional activity (Молдованова А.О. Психологічні детермінанти агресії в умовах професійної діяльності вчителя). Actual problems of psychology: Psychology of training. Genetic Psychology. Medical psychology. V. 10, Ed. 6, 69-72.

5. Tatenko V. (2014). Psychology of intimate life (Татенко В. Психологія інтимного життя). 


\section{Acceptance of Own Corporeality as Sanogene Factor in the Development of the Marital Relationship}

(Halyna Bevz)

Institute for Social and Political Psychology of National Academy of Pedagogical Sciences of Ukraine, Kyiv, Ukraine

Introduction. In psychology, the category of corporeality is not a separate category of study and is explored mainly in the context of such concepts as: the phenomenon of femininity/masculinity, sexuality and gender psychology (T. Goworyn and O. Kikinerzdi, 1999); on issues of psychophysical development and psychosomatic states (K. Bondar, 2013; V. Nikolaeva, 2009), the development of "physical-Self" in the process of personal formation, as well as the concept of bodily identity and eating addiction (T. Khomulenko, 2016; V. Nikitin, 1998; V. Tatenko, 2014), as well of developing a healthy lifestyle (K. Bondar, 2013; L. Korobka, 2012).

In the scientific debate, "corporeality" appears in two dimensions: as the natural basis of the mentality and as a sociocultural. In the area of marriage scientific research corporeality matters mainly relate to the category of marital compatibility at the psychophysical level and to the issues of disorders in the sexual sphere of private life. It turns out that the intimate side of the life of the couple, which involves physical and mental closeness, is still not sufficiently studied by scientists, specifically for the category of "corporeality".

In our work we sought to reveal the peculiarities of the manifestation of acceptance of one's own body by men and women in the context of their marital life.

Purpose. The purpose of the research was to study the attitude to their own body of the representatives of married couples in the categories "acceptance-rejection" and its presentation in marital interaction through the concept of "criticism of the appearance from the partner's side" and "motivation to change one's own body."

Methodology. The research was conducted in Ukraine during 2015-2018. 300 persons married from one year and more (up to 55 years) and presenting themselves as a married couple (regardless of the existence/absence of legal registration of marriage) were enrolled in the study. The age of respondents varies from 19 to 75 years old. Investigations involved both men and women in equal shares.

The article states the biopsychosocial approach as providing an opportunity to cover different aspects of the psychology of corporeality in the sphere of marital interaction. Research methods. The survey was conducted by using the questionnaires (direct and on-line). A questionnaire of 15 questions was developed in order to reveal a positive body perception and the wish/motivation to change one's body as a sign of one's own dissatisfaction. To measure the indicator «unfavorable judgement of the respondent's appearance by his/her partner» as a sign of partner's dissatisfaction, a questionnaire of 5 questions was developed. Additional tools were also used to determine the strength of bonds in a married couple manifested by common values and interests, mutual support, as well as seclusion as an indicator of alienation and detachment in relationships. The developed toolkit was shaped into a single diagnostic unit including the following items: a questionnaire to identify common interests of married couples (a total of 33 items) based on the translated Oregon Avocational Interest Scales by Lewis Goldberg; Method of "Network of Support Relationships" (W. Furman, D. Buhrmester,); the Schwartz's Value Orientations Test adjusted by V. Karandashev and UCLA method (D. Russell, L. Peplau, M. Ferguson in the version of I. Ishmukhametov).

Results. The results of the study relate to the gender differences in the attitude of the married couples to their own body, in particular, in the categories of "acceptance-rejection" and its presentation in marital interaction through the concept of "criticism of the appearance of the partner" and "motivation to change one's own body." According to the results of the research, the antonymic nature of corporeality in the context of married life was confirmed, and it was statistically proved that positive attitude towards one's own body is a condition of positive perception of the world, prosociality and satisfaction with family life as a whole and with each one of its spheres. It is stated that the attitude towards one's own body is a situational characteristic that is variable throughout life. It was found that in situations of criticism of the appearance from the partner, the initially fixated positive attitude to one's own body undergoes a revision (up to its destruction). The reactive character of the motivation for changes in one's own body is being proved: conflicting, antagonistic and criticizing environment enhances the motivation to change one's own body and is more characteristic for women, whose probability of transformation of the body is determined also by the factor of childbirth.

The benefit of this study is the statistically established gender and age characteristics of changes in the attitude of adults towards their own body and the peculiarities of accepting their own corporeality as a life-giving potential for the development of marital life.

Conclusion. An important conclusion of the work is the statistically proved probable therapeutic effects of restoring a positive attitude to one's own body. They relate to situations of manifestations of sociability and 
support of the partner as a response to a request; development of the sphere of interests that are sociable and promisingly directed for environmentally friendly management of the living environment.It was proved that the positive attitude towards one's own body is based on the relationship of mutual support, interest in food and mode of life, thereby pointing to directions of development of the culture of marital relationships. This provides a study of the practical value and the potential for using in counselling of married couples and clinical practice. The prospect of further research is the study of the nature of corporeality as a systemic and cultural phenomenon, which reveals the marital potential of balanced functioning in the living environment.

Keywords: family, relationship, attitude to the body, psychology of corporeality.

\section{References.}

1. Bondar K. V. (2013) Theoretical and methodological approaches to the consideration of the phenomenon of corporeality. (Бондар К. В. Теоретико-методологічні підходи до розгляду феномену тілесності.) Scientific Journal of V.O. Sukhomlynskyy Nikolaev State University. Sir : Psychological sciences. V. 2, Ed. 10, 42-45.

2. Govorun T., Kikinezhdy O., (1999) (Говорун Т., Кікінежді О. Стать та сексуальність: психологічний ракурс) Sex and Sexuality: Psychological Perspective. 20-51

3. Ishmukhametov I. N. (2006) Psychometric characteristics of the loneliness scale ucla. (Ишмухаметов И. Н. Психометрические характеристики шкалы одиночества ucla.) Computer Modelling and New Technologies. Vol. 10. № 3, 89-95

4. Karandashev V. N. (2004) Sh. Schwartz's method for studying the values of the person. (Карандашев В. Н. Методика Ш. Шварца для изучения ценностей личности.)

5. Korobka L. М. (2012) Psychological health of a person in the context of a healthy lifestyle. (Коробка Л. М. Психологічне здоров'я людини в контексті здорового способу життя.) Education in the region: political science, psychology, communication. No. 2, 332-337

6. Nikitin V. N. (1998). Psychology of corporeal consciousness. (Никитин В. Н. Психология телесного сознания) P. 74-108

7. Psychosomatics. Corporeality and culture. (2009). Edited by V. V. Nikolaeva (Психосоматика. Телесность и культура. Под редакцией В. В. Николаевой)

8. Tatenko V. (2014). Psychology of intimate life (Татенко В. Психологія інтимного життя)

9. Khomulenko T. B., Kramchenkova V. O. (2016). Methods of prognostic diagnostics of corporeal Self. (Хомуленко Т. Б., Крамченкова В. О. Методика проективної діагностики тілесного Я). Scientific journal of Kherson State University. Series "Psychological Sciences”. Issue 5, 39-45.

10. Furman W Network of Relationships Questionnaire Manual / Wyndol Furman, Duane Buhrmester The University of Denver and the University of Texas at Dallas. http://www.midss.org/sites/default/files/network_of_relationships_questionnaire_manual.6.21.2010.doc

11. Goldberg L. R. Personality, Demographics, and Self-Reported Behavioral Acts: The Development of Avocational interest Scales from Estimates of the Amount of Time Spent in Interest-Related Activities. In C. R. Agnew, D. E. Carlston, W. G. Graziano, \& J. R. Kelly (Eds.), Then a miracle occurs: Focusing on behavior in social psychological theory and research (pp. 205-226). New York: Oxford University Press. 2010.http://projects.ori.org/lrg/PDFs_papers/Goldberg_2010_Avoc_Interests_Chapter.pdf 


\title{
Preserving Human Mental Health through Control of Pathogenic Text in Mass Media by Means of Indexing and Marking
}

\author{
(Olesya Bik) \\ Sociology and Social Work Department, National University "Lvivska Polytechnica”, Lviv, Ukraine
}

\begin{abstract}
Background: Subject of this research paper is problem of pathogenic text as method for manipulating human consciousness and its dissemination through mass media, which due to their specific, make such manipulation most effective. Mass media have mastered metaphoric language, which can flawlessly influence readers' imagination. According to the theory of psychic mechanisms (reflection - projection - objectification), described in this paper, humans can create, design, build, view objects and phenomena from known and realized elements (Maksymenko, 2008). Since one of characteristic feature of human psychology is transference, analogy, building of associative series, one of the questions analyzed in the paper is: what actions would be performed by the person, what she will be capable of creating or designing, imagining and realizing, if, with everyday information flow, her consciousness will be "consuming" descriptions of awful outcomes of catastrophes, detailed descriptions (photos) of bloodied corpses, details of sexual crimes, corruption cases of governmental officials, deliberations about total decay of its country. Such technologies are used today in psychological operations (PSYOPS) carried as part of informational wars. Work (first of all intellectual), as meaningful activity (including arts), requires that its results should first be visualized in form of vision, thought or feeling (Bila, 2014). This allows to compare it with subject of work, its transformation and result of work. This way vision, which drives person activity, is realized in object form.
\end{abstract}

Purpose: Define social responsibility for quality of disseminated information, considering potential psychosocial harm from consumption by auditorium pathogenic information due to lack of control over information flows, that becomes weapon in today's information warfare; review approaches to solving this problem in the world community and propose possible alternative solution.

Methods: We use theoretical research method to gather information about developments and results in research on psychology of linguistic influence and existing methods of overcoming influence of pathogenic texts. Then we applied method of inverse analysis and synthesis making assumption that Bayesian text classifier algorithm can be used to analyze level of pathogenic information, delivered by modern mass media. Using synergetic approach we developed system for filtering and evaluating texts based on level of pathogenic influence by feeding them into adaptive Bayesian classifier software.

Results: It is implied that there is direct dependency between demonstration of shows with negative content and anomalies in audience behavior. Scenes of violence should cause fights or murders, erotic scenes should trigger sexual activity of audience, commercials - urge to felony, etc. Usually extreme forms of social deviations crimes, are being highlighted as results of negative impact of information on humans.

There are other threats in consumption of pathogenic text: e.g. informational addiction. Once experiencing emotional reaction, e.g. interest, fear, shock, stress, after consuming information (text describing scandal, tragedy or sensation), person will seek to repeat experience. According to researchers, besides strong addiction to such informational drug and inability to exist without it, people exhibit:

- readiness to consume any, even very "dirty" informational drug;

- the need to increase the dose of consumption, as well as the use of stronger drugs. In the case of informational addiction, this is expressed, for example, in increasing the time spent watching TV or the attraction to texts of a pathological nature;

- narrowing of consciousness and vital interests;

- decreased insight, loss of will, responsibility and informational independence;

- the state of chronic exhaustion in the form of a syndrome of chronic fatigue.

Socially, information addiction is expressed in increased external control of people. Any addiction, including informational, is usually caused by temptation to get something with minimal efforts.

We need to separately highlight our interest in text-based mass media (printed or blogs) versus audio-visual mass media (broadcast and digital), where flow of negative information seems to be magnitudes larger. In particular, paper touches specifics of written information perception. Contrary to the TV, where information is served fragmented, creating illusion of real-time and diversity, in press and other text-based mass media information is structured, with well though composition, which makes it more memorizable. Information is imprinted in readers memory, creating so called "anchor", which is commonly used in neuro-linguistic programming practices (Levchenko, 2001).

Nowadays, especially considering information warfare, widely conducted across the globe, discussions about effectiveness/necessity of control over information flows become extremely heated. In this paper, we analyze 
existing solutions, implemented in various countries and communities, e.g., creation of community media oversight boards, content validation during licensing process, expert reviews of broadcasts, etc. Most communities approach fighting pathogenic text through creation of additional legal barriers for publisher/broadcaster. Unfortunately, none of currently used approaches are feasible, since after deeper analysis, performed by the author, all of them are either insufficiently objective or independent, or have technical flaws, which make them unfit for Ukrainian environment.

We see resolution for the pathogenic text influence on human consciousness in person herself, in her selfawareness and ability to independently assess situation and make decisions. One of approaches to protecting society from pathogenic text without censorship, could be marking of pathogenic level of each specific article or publication, in the way similar to one adopted in Germany (Volkov \& Sarytchev, 2000), but marking all information products, including printed. We also suggest not to limit markings to "pathogenic" or "nonpathogenic" labeling, but show percentage of text pathogenicity. By informing consumer of level of negative impact by particular text, we give him/her opportunity to decide about necessity or desire to read this text.

Suggested system is similar to nutrition labeling for food products. Nobody should dictate a person what to eat, but we can explain, how excessive consumption of, e.g. fats and cholesterol, impacts health as well, as provide markings how much each product contains these ingredients. Decision about necessity to consume particular product is made by person independently, based on health status and, finally, appetite.

Conclusion: Approach described in this paper would allow each individual to control consumption of pathogenic texts, based on individual preferences, psychological well-being and need for adrenaline stimulation. Paper also demonstrates that for practical implementation of pathogenic text detection, there is need for an objective method of text classification and describes method developed by the author after series of psychological and sociological researches, which allows to apply criteria for detecting pathogenic text without human intervention. We propose automatic classification method based on Bayesian filters (Himmelblau, 1970), (Yerazunis, 2003).

Keywords: mental health, informational warfare, mass media, information, consciousness, influence, protection, text classification.

\section{References.}

1. Maksymenko, S. D. (2008). Generic psychology. (изд. 3rd). Kyiv: Center of educational literature.

2. Bila, I. M. (2014). Psychology of child creativity. Kyiv: Phoenix.

3. Levchenko, L. (2001). Psychological pecularities of mass media operations. Human and Politics, 2, 103-109.

4. Volkov, E. N., \& Sarytchev, V. V. (2000). Means of mass illusionistics, part 2. School psychologist, 46.

5. Himmelblau, D. M. (1970). Process Analysis by Statistical Methods. John Wiley \& Sons Inc.

6. Yerazunis, W. S. (2003). Sparse Binary Polynomial Hashing and the CRM114 Discriminator, MIT Spam Conference,2003. Retrieved from SourceForge: http://crm114.sourceforge.net/CRM114_paper.doc 


\title{
Bulling as a Model of Systemic Deficit. Healing Strategies
}

(Angela Borshchevska, Nataliya Ryshkovska)

\author{
Lviv National Medical University named Danila Galitsky, Lviv, Ukraine
}

\begin{abstract}
Introduction. The change in the social situation of the development of modern children and adolescents is characterized by the destruction of the natural institutions of socialization - the family and the children's community, the orientation of upbringing to the individualist model, the tendency to restriction of communication between children and peers. All this negatively affects the process of socialization of children, leads to the growth of various forms of social deprivation, including bulling, an increase in the number of children and adolescents of the disadvantaged, isolated in the children's community. In the last 10-15 years, the problem of child abuse in schools is becoming more and more relevant. In particular, cross-cultural studies in 40 European countries have shown a large spread of frequencies: from $9 \%$ of schoolchildren (in Norway) to $45 \%$ (in Lithuania) are faced with bullying situations two or more times a month (Rose C.A., Espelage D.L., 2012). According to the US Centers for Disease Control and Prevention (CDC), from 70 to $80 \%$ of adolescents aged 14-15 years, in one form or another, become victims or participants in the bullng. According to the director of the department of the Ministry of Education of L. Samsonova, 109,000 appeals from children and their parents about harassment at school were recorded in 2017 (Kotlyar, 2018).

The urgency of the research of the bulling is due to the fact that the experience of contact with harassment affects the behavior and attitude of all participants, forming their habit of relations of domination / subordination and stable patterns of behavior. The children who practice harassment are used to impunity and more often than their peers demonstrate deviant forms of behavior (fights, theft, vandalism, weapon storage, school absenteeism, the use of psychoactive substances). Among the immediate effects of the bulling are alertness, insomnia, complexity with concentration of attention. Children undergoing a booling, more often than their peers, dropped out of school, were prone to depression and suicidal behavior. Among the remote effects of harassment are loss of confidence, difficulty in communicating and intimate relationships with the opposite sex, low career outcome, difficulties with trust, formation of social anxiety (fear to speak with certain groups of people, for example, with those who shows aggression, fear to speak in public) and generalized anxiety (Siobhan Hugh - Jones, Peter K. Smith, 1999).
\end{abstract}

Purpose. To investigate the structure of the bulling`s system factors in the Ukrainian context and to generalize strategies of harassment prevention.

Methodology. In the process of work used methods: scientific observation, analysis and synthesis, sociological research.

Bulling is a systemic, multidimensional problem. Its participants are: the family, the school teacher, class, society. Point picking someone or something will not help one. If harassment has already begun in a particular environment, then this means that the environment is viral. So he needs to be cleaned and healed. Numerous videos on the Internet, messages in the media - is an open, explicit form of bulling. It's horrible and endlessly scary. But much more dangerous are not physical, visible, but hidden forms of persecution. Because there are no complaints about this. It is not put forward as a public inquiry, and, worst of all, it is perceived as an ordinary phenomenon (Alla Kotlyar, 2018).

The problem of detection and diagnostics of bulling in Ukraine at the present stage concerns the following: it is accidental (episodic) character; missing: research programs. relevant questionnaires; no portrait of a victim of persecution has been created; the victim's experience is not relevant to adults; In children's homes, boarding schools, special institutions for minors there is an extremely high risk of violence; frequent denial of bulling in educational institutions; lack of competence for a victim survey; Limited experience of applying to specialists (Kihichak, Borshchevska, 2018).

The main subsystems for which the change strategy should be directed.

Family level. The psychotype of the child, with which she then "will sound" in school life, is formed up to seven years. Therefore, competent in matters of healthy principles of communication, parents can accordingly carry out the process of education.

The family should create a pillow of safety and support for the child. Parents should teach the child the ability to "give off". After all, it is a model of communication, which means that when an invasion of the private territory occurs, signals are received in a timely manner about how dangerous it is. And if the communication of the child in the family from the beginning was dangerous, then child gets used to the fact that at any moment the emotional state of the parents can change. And this will be followed by unpredictable punishment. This means that the system that supports child safety is in a state of permanent excitement. And then such a child or adolescent will be in readiness to constantly resist, regardless of quality and intensity of exposure. Or there will be a depletion of protective potential due to the nervous system's overexcitation. 
The following subsystem is a school. School is a hierarchical structure. If the school is dangerous, aggression will necessarily be formed and accumulated. Fear and aggression are always near. Security is also a multilayered concept.

In school, this is the built safety of the physical body of the child. When both parents and children know that the teacher has no right to touch the body of the child aggressively; that any fights will be stopped immediately.

The family and school are two important subsystems responsible for the child, separated from each other. And it is very important to develop the openness of communications in the middle of these structures and between them. Being in an emotional proximity to an authoritative adult for her, the child learns to feel, including their needs, to sympathize with, protect their limits.

Subsystem is a society.

Bulling is an aggression in its most detectable, malignant form. Previous generations received a message in the process of education: taboo on any manifestation of aggression, including and healthy. Now in our society there are many aggressions. We are infected with the virus of aggression. But aggression is a very significant unpleasant emotion that is part of the structure of emotional and social intelligence. In addition, anger is energy. In order to adapt to the new territory, to critically understand new knowledge, to tell the teacher that you think otherwise, a healthy aggression is necessary.

Conclusions. The situation of the boiling is terrible for all participants. And if you stay only at the level of conflict, the charge that can be directed toward healing will be spent on unnecessary confrontation. This applies to any relationship.

Consequently, society must form the basis of responsibility, mutual respect in relations. It is important to carry and develop a culture of non-violent communication, including, in particular, broad programs of early psychoeducation of parents, training of communicative competences of teachers.

Keywords: bulling, communication, family, system, prevention, disease.

\section{References.}

1. Anzhela Kihichak - Borshchevska (2018). Bulling in schools as a factor in mental ill health. Information and Methodological Journal "School" V6 (150), P 8-16.

2. Alla Kotlyar (2018, August 18-23) Bulling. With wide eyes closed. Mirror of the week, Retrieved from https://dt.ua/SOCIUM/buling-z-shiroko-zakritimi-ochima-285910_.html

3. Rose C.A., Espelage D.L. (2012) Risk and protective factors associated with the bulling involvement of students with emotional and behavioral disorders. Journal "Behavioral Disorders" V 37 (3),P.133-148

4. Siobhan Hugh - Jones, Peter K. Smith (1999) Self-reports of short-and long-term effects of bulling on children who stammer Goldsmiths? University of London, Londinium, England, United Kingdom. British Journal of Educational Psychology. V 69 (2), P 141-158. 


\title{
Explorative Study of Psychosocial Stress Factors that Cause Professional Burnout Among Teachers, Who Leave Near the Front-Line Zone in the East of Ukraine
}

(Andriy Girnyk ${ }^{1}$, Yulia Donets ${ }^{2}$, Sergiy Bogdanov ${ }^{2}$, Victoriya Solovyova ${ }^{2}$, Lyudmyla Romanenko ${ }^{3}$ )

${ }^{1}$ Department of Psychology and Pedagogy, National University of "Kyiv Mohyla Academy", Kyiv. Ukraine

${ }^{2}$ Center for Mental Health and Psychosocial Support, National University of "Kyiv Mohyla Academy”, Kyiv. Ukraine

${ }^{3}$ Center for Social Rehabilitation of Children with Disabilities "Leleka", Popasna, Ukraine

\begin{abstract}
Introduction. The purpose of the research was to determine the degree of the pedagogists' burnout and to develop recommendations for a training program on burnout prevention among teachers working near the contact line $(0$ to $15 \mathrm{~km})$ between the Ukrainian army and the groups of separatists. The research was conducted in the framework of the United Nations Children's Fund project "Strengthening resilience of educational professionals and building capacity of community members in provision of psycho-social services in conflictaffected eastern areas of Ukraine". The National University of "Kyiv-Mohyla Academy" has previously carried out a series of quantitative and qualitative studies of psychosocial stress and its impact on children in Lugansk and Donetsk oblasts (Bogdanov, 2017a). In particular, the level of psychosocial stress among schoolchildren was studied and stress factors that affect children living near the front-line were investigated (Bogdanov et al, 2016). However, prior to this a systematic study of the Ukrainian teacher's resiliency and mental health has not been carried out despite convincing observations and burnout complaints, which were repeatedly proclaimed by teachers and school psychologists. The current study is the first step in exploring the causes of psychosocial stress and assessing the level of emotional and professional burnout among teachers in the East of Ukraine. The results of the study will inform the development of a training program on burnout prevention and stress management for teachers working in the $15-\mathrm{km}$ zone from the front-line.
\end{abstract}

Related Work.

There is common agreement among researchers on the main factors that describe the phenomenon of burnout. These include: emotional exhaustion, cynicism or depersonalization and reduced professional performance (Bianchi, Shonefeld \& Laurent, 2015, Maslach, Jackson \& Leiter, 1997). Emotional exhaustion is characterized by a feeling of emotional emptiness and physical overload; a person lacks energy, their mood is low. Cynicism is characterized by a distant attitude to their work; individual demotivation and rejection of their work. Finally, the lack of professional effectiveness involves a sense of inadequacy and incompetence associated with a loss of self-confidence (Maslach, Shaufeli \& Leiter 2001).

Concepts of burnout share the general view that burnout could be seen as a result of a long, unresolved stress at work or that burnout is caused by a long-term mismatch between the requirements related to the work and the available resources of employee (Maslach, 2001). Thus, burnout is the result of the chronic failure of adaptive mechanisms and should not be confused with period of acute stress at work.

The influence of psychosocial factors on teacher burnout has been considered in previous studies (Vodopianova, Starchenko \& Nasledov, 2013, Kuprianova, Dashieva \& Karaush, 2013, Pavlova, 2014), yet none of these studies have explored the influence of war and prolonged stay near the zone of military action on teacher's professional burnout.

\section{Results and Discussion.}

This study has a mixed quantitative and qualitative design. The level of burnout was measured using the questionnaire "Professional burnout" (version for teachers and university professors), developed by N.Vodopianova $(2001,2013)$ based on the model described by K. Maslach and S. Jackson (Maslach, 1997). The questionnaire consists of three scales: emotional exhaustion, depersonalization / cynicism and professional success. The answers are assessed based on scale of frequency varying from "never" (0 points) to "always" (6 points). The causes of psychosocial stress among teachers, the effects of the military conflict on teachers, and the teacher's need in psychological support were studied within individual and focus group interviews. Group discussions were more focused on identifying the main causes of stress, and individual interviews on description of stress influence on physical, emotional, and behavioural levels. The readiness of teachers to participate in burnout prevention activities and their interest to attend such training was studied both in group and in individual interviews.

Field research was conducted on August both in the Luhansk and Donetsk region. All respondents (41 people from the Luhansk region and 40 people from the Donetsk region from the age of 21 to 56 years old) fulfill the questionnaire "Professional stress". 
The 53 respondents of the focus groups were teachers from different educational institutions such as schools, professional colleges, school psychological services. Participants have had possibility to choose, if they want to speak with Interviewers Russian or Ukrainian languages. In total, 5 focus groups were held (3 in Lugansk and 2 in Donetsk oblast). There were also 8 individual interviews with pedagogical staff working near the front-line zone in Luhanska Oblast and 20 individual interviews in Donetska Oblast. All interviews were audio recorded, and written transcripts were content-analysed.

The research identified five key factors that are correlated with psychosocial stress among teachers.

1. Influence of war and leaving close to the front-line zone

2. Excessive workload and poorly organized work environment

3. Uncertainty about the future, sense of insecurity, and inability to plan their own lives

4. Working with difficult students

5. Ideological differences with students and their parents.

The factor "Influence of war" is one of the most frequently mentioned factors among teachers who are living close to the contact line and it consists of five sub-categories.

- Stress due to the risks of living in the armed conflict area as well as feeling responsibility for the student's life in the conflict area.

One teacher says: "I go to work and I think: what if it shoots, where will I immediately fall down? Where will I be. where will I lie? Where am I going to hide? And I have already told my husband: if there is a hatch - I will jump into the hatchway and hide. And one is even more scared for children."

- Sense of loss of control over the situation, insecurity and unwillingness to act under extreme conditions:

"Since the onset of the war I have somehow developed the perception of my helplessness and limited opportunities"

- Feeling of danger, tension, anxious reaction to sounds, rustling, explosions:

"Any knock somewhere, and the first thought is about that shelling starts again. Even if it is some event, fireworks, immediately the first thought is about that it begins."

- Losses, injuries of loved ones, death of neighbours, acquaintances:

" A shell in Balka exploded right in front of me.I thought that was it, that's how the house was shaken. And my husband was outside, he was barring the windows. his had a shell-shock, was thrown into the snow. It's very hard for me to talk about it now."

- Loss of housing, property and the threat of loss of work by family members:

" Three shells hit in her [my colleagues] hous, the house was destroyed. Antonina only had the things left that she was wearing."

The factors presented above are relevant only for the group of pedagogists from Luhanska Oblast, because responders from Donetska oblasts are living relatively far away from the fighting area. Therefore both groups have fulfilled self-assessment questionnaire and it seemed interesting to compare the degree of burnout in groups within $15 \mathrm{~km}$ from the contact line with the degree of burnout in the group located at a relatively safe distance. The findings are presented in Table 1 .

Table 1. The degree of self- assessed professional burnout of pedagogists in Donetska and Luhanska oblasts

\begin{tabular}{|c|c|c|c|}
\hline & Degree of burnout & $\begin{array}{c}\text { Donet-ska Oblast, } \\
\%\end{array}$ & $\begin{array}{c}\text { Luhan-ska Oblast, } \\
\%\end{array}$ \\
\hline \multirow{4}{*}{$\begin{array}{l}\text { The total degree of } \\
\text { professional burnout }\end{array}$} & Low & 2.5 & 0 \\
\hline & Medium & 15 & 19.5 \\
\hline & High & 45 & 41.1 \\
\hline & Extremely high & 37.5 & 39.4 \\
\hline \multirow{4}{*}{ Emotional burnout } & Low & 2.5 & 2.4 \\
\hline & Medium & 25 & 22 \\
\hline & High & 37.5 & 39 \\
\hline & Extremely high & 35 & 36.6 \\
\hline \multirow{4}{*}{$\begin{array}{c}\text { Depersonalization/ } \\
\text { cynicism }\end{array}$} & Low & 0 & 0 \\
\hline & Medium & 20 & 31.7 \\
\hline & High & 10 & 4.9 \\
\hline & Extremely high & 70 & 63.4 \\
\hline Professional success & Low & 85 & 68.3 \\
\hline
\end{tabular}




$\begin{array}{lcc}\text { Medium } & 15 & 24.4 \\ \text { High } & 0 & 7.3 \\ \text { Extremely high } & 0 & 0\end{array}$

The Cronbach's alpha is high in the both groups studied -.769 in Donetska Oblast and -.754 in Luhanska Oblast. Reliability by scale:

- Depersonalization/cynicism scale: in Donetska Oblast.837, in Luhanska -.788

- Emotional exhaustion scale: in Donetsk Oblast.847, in Lugansk -.770.

- Professional success scale: in Donetsk Oblast.177, in Luhanska Oblast.379.

The results show that both groups of teachers experience an equally high degree of professional burnout. Of the teachers within $15 \mathrm{~km}$ of the contact line $41.1 \%$ had a high degree of burn out and $39.4 \%$ had extremely high degree of burnout, while the prevalence of high and extreme levels of burnout were $45 \%$ and $37.5 \%$ for the teachers $40-60 \mathrm{~km}$ from the contact line. This indicate no noticeable effect of proximity to the contact line on the degree of the pedagogists' professional burnout based on their self-assessment. This can be explained by the fact that the experience of their four-year stay in an area where there are high risks for their life and health has helped them to develop protective mechanisms against the threat of death, loss of housing and property, and uncertainty about their future.

On the other hand, some of the stress factors that arose as a result of the war situation, have an effect on representatives of both groups. These factors include overload due to an increase in the number of reports and the amount of extra-curricular work. So one teacher reported: "Teachers are so loaded with work that when lessons are over he thinks: God, there are still the notes, notebooks, prepare this, do that! That is, your working day is over at $1 \mathrm{pm}$, roughly speaking, but you leave school at $4 \mathrm{pm} . "$

Other factor is an impact of the uncertainty about the future and the inability to plan their lives. One teacher says: "Before the war, we used to develop some plans for the future, while now we just really live today. One lives through a day and says "Thanks God." Because nobody can predict what will happen tomorrow, because we have already been there".

Similarly, the both groups are characterized by increased stress due encountering a greater number of complicated cases at work (teaching to IDP children, teaching to children with special educational needs). "We are confronted with the fact that children are very vulnerable. It has happened that we were under shelling, we had to observe fear in the eyes of children, and we had to do something to avoid that. There was a child who just started weeping. Shelling starts - and he gets hysterical." Such difficulties could be effectively resolved through implementing in-service training programs for teachers that will concentrate on obtaining knowledges about psychological trauma and its impact as well as on development communicative skills needed for establishment supportive relationships with affected children.

The last group of stress factors that causes burnout in both groups of teachers is ideological contradictions with parents and students regarding their perception of the causes of the armed conflict in the eastern part of Ukraine. "Some are for Ukraine, some - for the militia. And when you come and start speaking. And when you start speaking, say, about the "Heavenly Hundred" and so on, while completely opposite things have been told to the children. And how could all of that be combined? Well, for me, for example, it is very hard."

As mentioned above high and ultra-high rates of emotional exhaustion, both at the physiological level and at emotional level, have found numerous reflections in teacher's expressions. Such symptoms of mental health problems as avoidance, hyperarousal, intrusions, lack of energy, sleeping problems, unexpected fears where identified in teacher's statements. Considering the predominance of high and super-high levels of burnout, one can predict the high level of spread of mental health disorders among educators in the East of Ukraine, primarily among those living on the front-line. At the moment, no other existing data is available that could specify mental health problems among teachers. However, other researchers point to a limitation of the concept of burnout, noting that it is not something different from the already known depression or its other varieties, such as neurasthenia. (Bianchi, 2015) The proponents of the burnout concept argue that depression is more general, and burnout is conditioned by the specific situations at work (Maslach, 2001). As Bianchi et al. (2015) mentioned in his last review the current state of research knowledge does not allow unanimously to resolve this controversial issue, but there is a significant number of studies that indicate the interconnectedness of these phenomena and the causal link between them. It should also be noted that today there is a lack of research that would study the clinical manifestations of depression and clinical manifestations of burnout. Similarly, there are no statistics on the health status of teachers in the East of Ukraine, in particular the spread of cardiovascular diseases, which in some other studies correlate with high levels of burnout (Melamed et al., 2006). This finding is also confirmed by numerical references provided by teachers in this study.

\section{Limitations of the study}


Its limitation was use of a small number of respondents that increase possibility for a non-representative sample of the teachers in each area.

\title{
Strength of the study:
}

The strength of this study was its relevance, given the length of the armed conflict in the East of Ukraine and its negative impact on teacher's psychosocial wellbeing, especially for those, who are living close to the front-line zone.

Conclusions (and Future Work)

Considering high rates of professional burnout, it is important to carry out a prevalence study of symptoms of depression and post-traumatic disorders among teachers working on the front-line and the organization of specialized programs of psychological and psychotherapeutic care.

Dealing with psychological trauma requires additional training of teachers and changes in the attitude towards the child that emphasizes showing understand, empathy, and support in the teacher child relationship. The relevant teacher training program has been developed and implemented by National University of "Kyiv-Mohyla Academy" and United Nations Children's Fund office in Ukraine earlier and can be used further in improving the skills of teachers (Bogdanov, 2017b). Based on this already piloted training program and on the presented in this article research findings new modules for teachers on preventing burnout are expected to be developed. A system of supervisory support for teaching staff need to be included as an important component of the prevention of professional burnout.

Acknowledgments. The authors are grateful to United Nations Children's Fund in Ukraine and NGO "Volunteer" for excellent technical and organizational support of this study. The authors are also grateful to Iryna Ivanyuk for her assistance in organizing the research.

\section{Authors contributions.}

Andriy Girnyk - development of individual and group interview guides, moderating 2 focus group discussions and 20 interviews, testing 40 respondents, analysis of findings of the qualitative research and writing the text of the article

Yulia Donets - moderating 3 focus group discussions and 8 interviews, testing 41 respondents, analyzing test results and writing the text of the article

Sergiy Bogdanov - development of research methodology, analysis of research results, writing the text of the article.

Victoriya Solovyova - recruiting respondents and logistics support of the research in Donetsk Oblast

Liudmyla Romanenko - recruiting respondents and providing logistics support for the research in Lugansk region.

Conflict of interest. The authors whose names are listed above certify that they have no affiliations with or involvement in any organization or entity with any financial interest, or non-financial interest in the subject matter or materials discussed in this manuscript.

\begin{abstract}
The subject of the research was the correlation between life circumstances and the degree of emotional and professional burnout of pedagogical staff working near ( 0 to $15 \mathrm{~km})$ the contact line between the Ukrainian troops and the separatist groups in Donbas. The purpose was to develop recommendations to design a training curriculum on stress prevention and management for pedagogical staff. The sample consisted of 81 teachers who were divided into two groups: teachers, who work in the area $0-15 \mathrm{~km}$ from the front-line (41 persons) and the second group, who work in the area $40-60 \mathrm{~km}$ from the front-line (40 people). The mixed method approach utilized both quantitative self-assessment and qualitative group and individual interviews. The results show that both groups of teachers experience an equally high degree of professional burnout. Of the teachers within $15 \mathrm{~km}$ of the contact line $41.1 \%$ had a high degree of burn out and $39.4 \%$ had extremely high degree of burnout, while the prevalence of high and extreme levels of burnout were $45 \%$ and $37.5 \%$ for the teachers 40-60km from the contact line. Among stress factors that are correlated with teacher's burnout we found: war, excessive and poorly organized work, uncertainty about the future, working with difficult students, ideological differences with students and their parents. Based on these results, recommendations for the design a training agenda on professional burnout prevention pedagogical staff have been developed.
\end{abstract}

Keywords: mental health, mental stress, disease prevention, in-service training, war.

\section{References.}

1. Bogdanov, S., Girnyk, A., Lazorenko, B., Savinov, V., \& Solovyova, V. (2016) Social-psychological factors that negatively impact resiliency of children, who leave in the front-line zone in the East of Ukraine. In Naidionova, L., Chorna, I., Batrachenko, I. (Ed) Problems of political psychology: collection of scientific works. (40-51) Kyiv, K: Millenium. 
2. Bogdanov, S. (2017a) Methodological book: teacher's training on strengthening resilience among school children. Kyiv, K: Pulsary.

3. Bogdanov, S. (2017b) Research summary: UNICEF psychosocial support programs for school children in Donetska and Luhanska oblasts. Retrieved from electronic archive of National University of "Kyiv-Mohyla Academy":

4. http://ekmair.ukma.edu.ua/handle/123456789/11861

5. Bianchi, R., Schonfeld, IS., \& Laurent, E. (2015) Burnout-depression overlap: a review. Clin Psychol Review, 36, 28-41

6. Maslach, C., \& Jackson, S. E. (1981). The measurement of experienced burnout. Journal of Occupational Behavior, 2, 99-113.

7. Maslach C., Jackson S. E., \& Leiter M. (1997) The Maslach Burnout Inventory Manual. Third Edition. In Zalaquett, C. P., \& Wood, R. J. Evaluating Stress: A Book of Resources. (191 - 218). The Scarecrow Press Editors.

8. Maslach, C., Schaufeli, W.B., \& Leiter, M.P. (2001). Job burnout. Annual Review of Psychology, 52(1), 397-422.

9. Melamed, S., Shirom, A., Toker, S., Berliner, S., \& Shapira, I. (2006) Burnout and risk of cardiovascular disease: evidence, possible causal paths, and promising research directions. Psychological Bulletin, 132 (3), 327 353

10. Vodopyanova N.Ye., Starchenkova Ye.S., \& Nasledov A.D. (2013). "Professional Burnout" Standardized Questionnaire for Specialists in Socio-Occupational Professions. Bulletin of StPbSU, 4, 17 - 27.

11. Vodopyanova N., \& Starchenkova Ye. (2008). Burnout Syndrome: Diagnostics and Prevention. St. Petersburg, 2008

12. Kupriyanova I. Ye., Dashiyeva B. A., \& Karaush I. S. (2013) Quality of Life and Mental Health of Pedagogists Working in Various Educational Systems (general, corrective, inclusive). TSPU Bulletin, 87 - 93

13. Pavlova O. S. (2014). Factors Influencing Perception of the Quality of Life of Pedagogists at Correctional School. Scientific electronic journal "Koncept", 26, 6-10. doi: 159.9.072.43:330.59 


\title{
Features of Psychosocial Support of Combatants' Wives
}

\author{
(Nataliia Didyk)
}

Institute for Social and Political Psychology of National Academy of Educational Sciences of Ukraine, Kiyv, Ukraine

Introduction. In those NATO countries the troops of which take part in foreign military operations the significant attention is paid to the psychological support of both military personnel and their families at all stages of the combat task (before deployment, during deployment, and after deployment) (Moelker et al., 2006). For example, Canadian troops have been supporting families for over 60 years. This program is governed by the Canadian Military Families' Convention, which recognizes the complexity of intercourse between healthy families and effective warriors, and underlines the moral obligation of the Canadian Armed Forces to those who are close to the militaries. The families of the regular army have the right to use all services and programs designed for families (Military Family Services, 2016).

But the circumstances faced by militaries' families abroad differ from the situation in today's Ukraine. First of all, it should be noted that military events occur in the territory of their own state, where families live, and caused by the need to protect their own land. The military aggression of Russia caused the beginning of the antiterrorist operation in the East of Ukraine (here and after - ATO) in the spring of 2014 and caused the mass mobilization of the military-waged population, some of whom signed a contract after demobilization and remained in service. Since April 2018, after obtaining the status of an international armed conflict, the legal status of the ATO has been changed to the Joint Forces Operation (here and after - JFO) (Zakon Ukrainy, 2018). Secondly, military events on the territory of Ukraine have been going on for the fourth year in a row, and families of militaries who served on a contractual basis have been in a state of war for the fourth time already and have been experiencing constant emotional stress. Thirdly, constant unregulated media and social networks information about the events in hostilities area, about the loss of units, about the actions of the enemy contribute to an additional emotional stress.

All these factors suggest the need for psychosocial support for the families of present militaries. The programs for working with families of military personnel in military formations are only at the initial stage of development in today's Ukraine. Civic organizations and volunteers are those who have accumulated experience in providing such assistance.

As usually, support activities take place in a group format or individual counseling. Psychosocial support before, during, and after deployment includes three types of work: informational, social and psychological (Calvert et al., 2006). We suggest to take a look on the arrangements for psychosocial work with family members that occur after deployment in the form of study case.

Purpose. The study is aimed at highlighting the approbation of the of psychosocial support of militaries' families' method, which take place jointly with the military formations of Ukraine.

Methodology. The study was conducted within the framework of cooperation between the NGO "Public Movement for Empowering Women in Ukraine", the National Guard of Ukraine, and the Armed Forces of Ukraine.

The case consisted of 29 group meetings involving 280 women. Each meeting began from the acquaintance of the participants, the arrangement of the event purpose and structure. Each meeting consisted of three parts:

1. Informational. The representatives of the military unit answered socially concerned questions on women's worries, and also brought the information, currently relevant and useful to the family of a military officer. During this part, women also shared their experience on social issues solving.

2. Psychological. This part was aimed at the psycho-emotional discharge of participants, so psychological work was carried out by means of the body-oriented technique. The principle of organization of group body-oriented therapy was used (Malkina-Pykh, 2007). Only women and psychologists (who were women as well) stayed to complete this part, while all men who were present in the first part have left the group.

3. Individual consultations (conducted by request).

Between the parts of the meeting participants had a possibility to communicate freely while savoring tea and sweets. This opportunity facilitated the exchange of contacts among participants and the identification of active women, who might be involved in the further thematic events.

The psychological part of the psychosocial support was conducted in a group therapy form. This form was taken into account because of the analysis of experience with military families in other countries (Calvert et al., 2006), and because of understanding the value of group work. In a group the participant gets an opportunity not only to successfully interact with others, but also to achieve an internal comfort to use his/her potential to the full (Ormont, 1998). 
Such principles of group therapy were taken: the coordination of rules, the explanation and discussion of the results for each technique, the level of trust in the group, and the participants' socio-demographic characteristics consideration (Malkina-Pykh, 2007).

To complete the psychoemotional discharge task the body-oriented techniques were used, as emotionally significant experiences "grow into the memory of the body" and tend to stay in it. In body-oriented therapy it is believed that accumulated traumas and disappointments cause a disorder between feelings, mind, and body. A person begins to feel non-holistic, loses contact with the self, or becomes unsatisfied with the quality of this contact. Psychologically, the loss of contact with the self is the same as the loss of contact with the body, and by means of the body-oriented therapy technique a person develops the ability to restore own sensual nature. Body therapy forms "the bridge" between thoughts, actions, and emotions, and thus makes it possible to understand and change them. This, in turn, allows to find internal resources for the necessary changes (Malkina-Pykh, 2007).

Taking into account the features of the group, the techniques were applied in the following sequence (duration 11.5 hours):

- The method of controlled psychophysiological self-regulation, synchromic gymnastics "The Key" by Khasay Aliyev. This technique represents the way of human motor activity synchronizing with her/his actual psychoemotional state (Kisarchuk et al., 2015). The body therapy part began precisely with the exercise "Carousel" or "Whirlwind" (turning rhythmically to the right-left, around the vertical axis at the lumbar level, both hands "fly" freely in one direction, then in another);

- Techniques by A. Lowen. According to Lowen, a sensitive attitude to the needs of their own bodies brings people closer to their "original essence" and reduces the alienation from themselves and others. The cause of neuroses, depression and psychosomatic disorders is the suppression of feelings, which manifests itself in the form of chronic muscular tensions that block the free flow of energy in the body. Patients with neuroses, according to Lowen (2000), spend most of their energy to keep up the work of psychological defensive mechanisms through muscular tension to protect personality from the impact of both real internal feelings and external influences, and mental fears.

If this is the first meeting of the group, it is recommended to use only a few techniques: the technique "Lowen Arch" (Malkina-Pykh, 2007) and the modified technique "Scream" (the modified version is conducted by the leader to let each participant scream individually, without sound and with eyes closed).

- Progressive muscle relaxation (by Jacobson). The method was proposed in 1922 by Chicago physiologist and psychiatrist Edmund Jacobson. He proceeded from the well-known fact that emotional stress is accompanied by the strain of transversely striped muscles, and calming down - by their relaxation. It was natural to assume that muscles relaxation should be accompanied by a decrease in neuromuscular tension. By relaxation Jacobson understood not only the muscles relaxation, but also the state opposite to mental activity (Lazurenko, 2011).

The complex of techniques had been changing depending on the group features, but all the techniques were simple, so participants could carry them out by their own. All of the above techniques have warnings related to health, which should be taken into account while using certain techniques with a particular group.

Results. The visible results after the psychological part of psychosocial support of the group are manifested as: elevated mood; increased level of trust to one another and to psychologists; readiness to share own experiences with other participants, and ask psychologist for an individual consultation; readiness to hear useful additional information from a psychologist; desire to attend the next meeting.

After meetings in this format the $100 \%$ of participants gave positive feedback (they mentioned it in the final discussion and in the feedback questionnaires).

Limitations and strengths of the study. The techniques provided in the process of group work are designed to get the immediate results during the meeting and for self-usage at home. The survey of participants after 30-days methods usage has shown that their psycho-emotional state has improved, and communication with her husband and children has become better. However, a quantitative analysis of the systematic individual usage of the technique was not carried out.

Since the specifics of military actions don't have a clear distinction between the deployment stages, women who were at different stages of the combat task (before deployment, during deployment, before coming back home and 1-3 months after deployment) were involved in the meeting, so each meeting needed modification of the format depending on the group.

Social value. The organization of psychosocial support for members of the families of military personnel is an important factor to the whole military system, since military's presence at home during the restoration period will affect his psychological state before returning to the military service.

Originality. The case presented in this paper is a description of the first time tested in Ukraine methodology for working with military families on the basis of military units.

Conclusions. Wives, just like their husbands, are in stressful conditions for a long time, so first of all it is necessary to help them to relieve emotional tension. And only after this it is advisable to explain the possible 
psycho-emotional states of the serviceman who are about to return home. Methods of body-oriented therapy are those psychotherapeutic tools which in this particular case confirmed their effectiveness by providing emotional discharge in both group work and exercises at home. The system of support for militaries' wives needs further improvement and specialization.

Keywords: mental health, social integration, armed forces, military family, women's military service, violence, trauma, relationship, case study.

\section{References.}

1. Calvert, C., \& Switzer, G. (2006). Deployment Support - Strength through Partnership. In Human Dimensions in Military Operations - Military Leaders' Strategies for Addressing Stress and Psychological Support (pp. 20A-1 - 20A-10). Meeting Proceedings RTO-MP-HFM-134, Paper 20A. Neuilly-sur-Seine, France: RTO. Retrieved from:: http://www.rto.nato.int/abstracts.asp.

2. Lazurenko, S.I. (2011). Mozhlyvosti autohennoho vidnovlennya psyxofiziolohichnoho stanu lyudyny. Problemy suchasnoyi psyxolohiyi [Opportunities of autogenous restoration of psychophysiological state of a person]. Zbirnyk naukovyx prac' K-PNU imeni Ivana Ohiyenka, Instytutu psyxolohiyi im. H.S.Kostyuka NAPN Ukrayiny [Problems of Contemporary Psychology: Collection of scientific works of Kamianets Podolsk National University named after Ivan Ogienko, Institute of Psychology named after. G Kostyuk NAUP of Ukraine], 12, 560. (ukr).

3. Zakon Ukrayiny "Pro osoblyvosti derzhavnoyi polityky iz zabezpechennya derzhavnoho suverenitetu Ukrayiny na tymchasovo okupovanyx terytoriyax u Donec'kij ta Luhans'kij oblastyax” № 2268-19 (2018). [Law of Ukraine "On the peculiarities of state policy on ensuring the state sovereignty of Ukraine in temporarily occupied territories in the Donetsk and Luhansk oblasts" № 2268-19]. Retrieved from: http://zakon5.rada.gov.ua/laws/show/2268-19 (ukr).

4. Lowen, A. (2000). Biogenergetics. Therapy that works with the body. Saint-Petersburg: Rech. (rus).

5. Malkina-Pykh, I. (2007). Telesnaya terapiya [Body Therapy]. Moskow: Litres. Retrieved from: https://play.google.com/books/reader?id=YUqgAAAAQBAJ\&hl=uk\&lr=\&printsec=frontcover\&pg=GBS.PT1 (rus).

6. Military Family Services (2016). A Family Guide To The Military Experience. Retrieved from: https://www.cafconnection.ca/getmedia/5d8caf66-d97f-4f59-b444-e0aa98404501/A-Family-Guide-E.aspx

7. Moelker, R.; Andres, M.; Poot, G.J.A. (2006). Supporting Military Families - A Comparative Study in Social Support Arrangements for Military Families (Theoretical Dimensions \& Empirical Comparison between Countries). In Human Dimensions in Military Operations -Military Leaders' Strategies for Addressing Stress and Psychological Support (pp. 18-1 - 18-14). Meeting Proceedings RTO-MP-HFM-134, Paper 18. Neuilly-surSeine, France: RTO. Retrieved from:: http://www.rto.nato.int/abstracts.asp.

8. Kisarchuk, Z.G.,. Omelchenko, Ya.M,. Lazos, G.P, Litvinenko, L.I., \& Tsarenko, L.G. (2015). Psyxolohichna dopomoha postrazhdalym vnaslidok kryzovyx travmatychnyx podij: metodychnyj posibnyk [Psychological help to the victims as a result of crisis traumatic events]. Kyiv: LLC "Publishing House" Logos". 9. Ormont L.G. (1998). Hruppovaya psyxoterapyya: ot teoryy k praktyke [Group psychotherapy: from theory to practice]. Saint-Petersburg: RUN. (rus). 


\section{The Mental Health between Epigenetics and Individual Beliefs}

(Marin Drămnescu, Vladimir Enăchescu, Monica Păduraru)

The Bucharest Academy of Economic Studies

Introduction. Mental health is an integrative concept that is not limited to dysfunctions or accentuations of psychic processes or mechanisms of thought. The research effort focused on the idea that mental health is a functional optimum found at the intersection of cellular behavior, the physical environment, the external environment, with all its subtypes, the environment in which the individual manifests itself and the subjective, psychological environment, dominated mainly by unconscious behavioral routines, beliefs, values, and ultimately individual perspective on life.

Mental health represents and manifests itself as an emerging process resulting from the correlated functioning of the biological, physiological, and in particular cellular mechanisms, the various, random and / or permanent influences and stimuli of the physical, social and professional environment and the superior motivational structures of the type of beliefs and individual perspective on life.

Approach. The perspective of conceptual and functional understanding of mental health is based on a psychological and epigenetic approach with openness to the role of higher-level motivational structures, individual beliefs and weltanschauung, in the acquisition, maintenance and strengthening of mental health. In the scientific argumentation of the research it is considered that the superior motivational structures are and behave like an independent environment, similar to the outside of the individual. This environment in its manifestation can stimulate, generating and configuring cellular responses and behaviors, as forms of cellular response to stimulation, affecting the functioning of the body in general. The cellular behavior resulting from stimulation through individual beliefs and from an individual perspective on life translates into cellular learning acts that will be genetically coded and passed on to descendants but may also form dysfunctions with somatic or psychological manifestations.

Results. The results of the research synthesize the way of cellular response to series of stimuli from the physical environment and from the subjective environment of the individual, namely the superior motivation structures and the impact of these reactions on the mental health. The results of the research lead to highlighting the possible correlation between cellular behavior and general mental health as well as their interdependencies. The possible change in the cellular environment as a result of some stimulation of beliefs or beliefs considered by the individual to be positive or negative may influence cellular behavior on a beach from their normal activity to shutdown, disturbed operation or out of optimal parameters.

Strengths of the study. The strengths of research are marked by the epigenetic and psychological approach demonstrating the importance of cognitive and affective processes in achieving and maintaining the mental health balance with a decisive role in adapting the individual to any type of environment. Understanding the interdependencies between mental health as a fundamental element of the individual in becoming personality and multidimensional adaptation and cellular behavior opens up new horizons for research in other fields such as education, personal development, philosophy or medicine.

Conclusions. The findings of the research open up the possibility of the integrated approach of mental health by combining environmental stimuli and influences, externally or subjectively, with biological and psychological processes, highlighting the functional interdependencies between them. It is emphasized the idea that not only human personality is a bio-psycho-social construct, but mental health is also a functional optimum of the triad of heredity and normal biological functioning, environment as an experiential factor and education in terms of models, values, beliefs and beliefs individual.

Keywords: mental health, cell behavior, epigenetic approach, beliefs, subjective environment. 


\title{
Role Models' Peculiarities of Women with Crisis Pregnancies
}

(Natalie Heisonyuk, Yaroslava Andrieieva)

\author{
Yuriy Fedkovych Chernivtsi National University, Chernivtsi, Ukraine
}

\begin{abstract}
Introduction. The phenomenon of role models is essential for the personal formation and like most of the essential aspects they are clearly seen in crisis or critical situations. The more common the situation where a person faces one's crisis experiences is, the more important it is to find the proper way to study it so that mental health professionals might be able to help their clients. That's why we suppose that pregnancy being not only one of the most common experiences but a period when a woman faces the necessity to review her role models, self-presentation, personal traits and scripts of interacting with partner and child, should be a subject for scientific and counseling discourse. Considering the changes and challenges of modern society, such as changes in gender scripts, prevalence of social media and social-psychological outcomes of generation gap, not to mention the specter of applied studies in the field we have to state that the concept of crisis pregnancy has to be reviewed and as a form of deviant maternity should be discussed as a phenomenon based on socialpsychological grounds. We assume that a major part of crisis pregnancies can be explained by malformed role models or conflict which arose between role models taken from one's close social environment and those taken from media.
\end{abstract}

Purpose. The main purpose of the paper is to introduce the discussion of the role models' peculiarities of the women with crisis pregnancies and their importance for modern mental health discourse. Our more particular purposes were to define crisis pregnancy as one of the types of deviant maternity and to define the part of role models in crisis pregnancy formation.

Methodology. We considered a theoretical review of the crisis pregnancy phenomenon and its' role models on the basis of psychoanalytical, humanistic, social-psychological and cross-cultural studies as an objective for the given paper. We took the concepts of deviant maternity and self-presentation (Goffman, 1959) as the first step for this study.

We assume the analysis of the data taken from crisis pregnancy centers' clients as the next step of our empirical research. We suppose to interview the clients about the impact social media has on their maternity, and use following techniques: WIPPF questionnaire, Leary interpersonal communication skills test, Rosenberg's SelfEsteem Scale to obtain data for statistical analysis.

Results. It is common for our scientific discourse to define crisis pregnancy as "a pregnancy which is neither planned nor desired by the woman concerned, and which represents a personal crisis for her". Usually, only situational agents are viewed as those which made a pregnancy to be a crisis one (Brown, 2016). But considering crisis pregnancy apart from its' psychological and social-psychological (or in other terms dispositional and situational) background deprives mental health professionals of the comprehensive vision of the given phenomenon. Thus our purpose is to perform a profound analysis of dispositional agents of a crisis pregnancy and its' background motherhood role models.

On the basis of the profound review of psychological studies in the field made by G. Filippova we can assume that pregnancy is not only initial but one of the most important stages of maternity, "crisis stage of women's life with its' peculiar experience of sexual identity and a special situation of adaptation" also. Most of the researchers agree that pregnancy should be viewed as a stage accompanied by a whole range of crisis experiences. Researchers agree that different psychological problems arise at different terms of pregnancy (V. Brutman, A. Varga, M. Radionova, G. Filippova, and others).

According to Filippova distorted role models of the pregnant women which lead to crisis pregnancy are based on the sensitivity and aggravation of psychological problems and personal conflicts, from her past, relations with her own mother and her maternity models, unresolved childhood psychological problems, peculiarities of one's adaptation to marital relations.

Thus reassessment of problems with woman's mother and husband or partner are characterizing the first trimester and vanish by the end of the trimester. While the second trimester is characterized by growing changes in woman's appearance, schedule, and reassessment her role repertoire, thus influencing her self-presentation. And the fears of the delivery process and one's own incompetence after the child is born are more peculiar for the third trimester. According to the stated above, we can assume that almost every case of pregnancy can be seen as a crisis one on the dispositional basis. And as it goes with any crisis case it can have quite opposite outcomes: either reaching personal maturity and integrating one's experiences and reconstruction of one's relationship with society or different personal disturbances or disorders (Brown, 2016).

Let's consider the concept of role models as the one underlying crisis pregnancy. The concept of role models is construed as a form of personal experience, which was internalized on the stage of primary socialization or taken for granted from referential sources at later stages of personal becoming, and thus used as means for the personal 
structuring of social interactions and for the definition of personal borders. Considering that role models are one of the basic elements of self-presentation, their understanding will enable a person to form a more effective selfpresentation and make oneself ready to accept and integrate those parts of one's self and role models which are new or maybe even contrary to existing self-schema (Goffman, 1959).

Researchers agree that following characteristics of the woman with crisis pregnancy role models: deprivation of a proper image of a mother-role which comes either from an absent mother or an existing conflict between her and her mother; disintegrated parts of a motherhood image or their being secluded from one's self-presentation, usually formed under the pressure of media and an image of "what ideal mother should be like"; decision to have a child just to be accepted or affiliated to their social environment; and disintegration of woman's role repertoire are among those which mostly lead to crisis pregnancy.

Limitations and strengths of the study. Sample's homogeneity (i.e., that usually women, who address crisis pregnancy centers, don't have advantageous psychological environment and background) and lack of empirical data in modern studies to compare our data with are basic limitations of the given study. The opportunity to assess personality traits, role models and self-presentational peculiarities of the crisis pregnancy centers' clients are the strengths.

Practical and social value. Our study is aimed to provide better awareness for the mental health professionals in the assessment of pregnant women self-presentations and role models and assisting their integration of the new experience and new roles. Considering the changes in the social-psychological environment: the role of social media in defining one's self-efficacy, growing tendency for staying body-positive, social request for personal self-realization and self-fulfillment, need for psychological assistance in critical and crisis situations, is growing in its' importance thus contributing to social well-being.

Conclusions. Basic concepts for the study of role models and their distortions presented by clients of crisis pregnancies centers are given. We have reviewed the grounds for defining pregnancy as a critical stage in female personal self-realization in this paper. Besides we came to a conclusion that the concept of crisis pregnancy has to be reviewed from mere obstetrical or situational one and be studied as a dispositional phenomenon also.

Keywords: motherhood, personal identity, social role, mental health, social media.

\section{References.}

1. Brown, A. (2016). Social media is putting pregnant women under pressure to look perfect. Retrieved August 1, 2018, from https://theconversation.com/social-media-is-putting-pregnant-women-under-pressure-to-lookperfect-61881

2. Goffman, E. (1959). The presentation of self in everyday life. New York: Anchor Books.

3. MaçolaI, L., ValeII, I., Do, \& Carmonall, E. V. (2010). Assessment of self-esteem in pregnant women using Rosenberg's Self-Esteem Scale. Retrieved July, 2018, from http://www.scielo.br/scielo.php?pid=S0080$62342010000300004 \&$ script=sci_arttext\&tlng=en 


\title{
Psychological Sense of Ownership: from Disorders to Norm
}

\author{
(Iryna Hubeladze)
}

Institute for Social and Political Psychology of National Academy of Educational Sciences of Ukraine, Kyiv, Ukraine

Introduction. Psychological sense of ownership is feeling that something is yours. It is a basic of individual and collective self-determination. Ownership is considered as a social and psychological phenomenon, which is based on the basic instinctive need of property, whose satisfaction is closely related to the formation of the individual and the functioning of the group consciousness; psychological attribute of personality, which distinguishes it from among others; the basis for categorization and differentiation, which is possible only in social interaction (Karnyshev, 2006; Pipes, 2007; Khazratova, 2009). Person spread his/her Self to everything that at least to some extent belongs to his/her, what he/she can entitle as "mine".

A lot of scholars argue that feeling of ownership is one of the most important factor of individual attitudes, motivation, and behavior (Pierce, Kostova \& Driks, 2001; Friedman, 2010; Smirnova \& Sukhanova, 2014). Psychological ownership determines self-identity, self-adjustment, and well-being (Khazratova, 2009) as well as ownership of tangible (e.g., home, things) and intangible (e.g., ideas) objects (Pierce, Kostova \& Driks, 2001).

Purpose. The purpose of this paper is to provide the information on normal manifestation and disorders in psychological property. We suggest that some of these types of behavior depend on peculiarities of certain people understanding and feeling of ownership.

The feeling of property implies the need to give away, not only material resources, but also their time, care, emotions. Caring for the objects of his property (about a house, his own business, a pet or a houseplant) and developing them in a certain way, the person assumes responsibility for their condition, protection and further fate. A sense of responsibility, in turn, prompts a person to determine the priorities of his activity, to a better self-organization and a rational distribution of his forces and time. It contributes to the formation of a more developed value system, which, in addition to meeting their own needs and desires, is also focused on helping others, caring for them. At the same time, the sense of responsibility gives the feeling of its own significance and the necessity of other people, which increases self-esteem and belief in oneself and encourages further development, to new achievements. Life becomes more conscious and purposeful.

In norms psychological ownership is a basic for personal identity forming. It includes relations between person and thing, person and other person on this thing, person's attitudes towards himself. But more than $75 \%$ people identified property as a main source of their stress.

In abnormal form it may be realize as an aggressiveness and conflict about possession of the thing, worries about their status and belongingness. It can manifest in many ways, including chronic resentment, embitterment, hostility, hatred, temper tantrums, rage attacks, and frequently, verbal and physical abuse.

According to Karnyshev A., there are some types of owners but two of them are disordered. Both hoarding and squander are in opposite sides from normal ownership behavior (Karnyshev, 2006). As a psychological disorder they have an ongoing dysfunctional pattern of thought, emotion, and behavior that causes significant distress, and that is considered deviant in that person's culture or society (Butcher, Mineka, \& Hooley, 2007). Like medical problems, they have both biological as well as environmental nature.

Unusual behavior based on ownership characterized certain mental health conditions such as compulsive hoarding (Steketee \& Frost, 2003; Preston, Muroff, \& Wengrovitz, 2009) and kleptomania. It is also true for criminal activities, such as shoplifting, robbery, and vandalism. The ritual of shopping provides a temporary escape from worry and anxiety.

Hoarding disorder is a behavioral pattern characterized by excessive acquisition of and an inability or unwillingness to discard large quantities of objects that cover the living areas of the home and cause significant distress or impairment. Compulsive hoarding behavior may has risks for health, impaired functioning, economic burden, and adverse effects on friends and family members. Compulsive hoarders may be aware of their irrational behavior, but the emotional attachment to the hoarded objects far exceeds the motive to discard the items. Hoarding is more common in people with psychological disorders such as depression, anxiety and attention deficit hyperactivity disorder. This disorder can make significant distress or impairment in social, occupational, or other important spheres including maintaining a safe environment for self and others.

The most useful and successful method for overcoming compulsive hoarding is cognitive-behavioral therapy. It should be discovered why person is compelled to hoard. Learning to organize possessions in order to decide what to discard and develop decision-making skills are very useful. Also person should gain and perform relaxation skills. Attending family and/or group therapy is desirable.

Squandering is common for people who need to satisfy everything their needs and desires, not limiting themselves. As usual they are people who became the owners at the result receiving inheritance or "lucky ones". 
Self-esteem of these people depends on awareness their opportunities advertise and show their consistency. Psychological source of such behavior is low self-esteem and need to be appreciated, noticed, and approved.

Practical/Social value. Understanding the reasons of psychological ownership formation their normal manifestation and disorders will have influence on social practices of people, possibilities to foresee and correct their behavioral patterns.

Conclusions. Psychological ownership can make normal and abnormal manifestation in social practice of people. It depends on both biological and social sources. Psychological feeling of ownership determines personal peculiarities and behavioral patterns which can express in different social practices.

Keywords: sense of ownership, psychology of ownership, disorders, norms, compulsive hoarding, squandering

\section{References.}

1. Karnyshev, A.D., Burmenko, T.D., Ivanova, E.A. (2006). Man and Property. Irkutsk. 349 pp. (In Russian). Карнышев А. Д. Человек и собственность: учебное пособие / А. Д. Карнышев, Т. Д. Бурменко, Е. А. Иванова. - Иркутск. : «Издательство», 2006. - 349 с.

2. Pipes, R. (2007) Property and Freedom. Knopf Doubleday Publishing Group. 352 pp.

3. Khazratova, N. (2009) Psychological Nature of Feeling of Property. Social Psychology. 5. 103-110. (In Ukrainian) Хазратова Н. Психологічна природа почуття власності / Н. Хазратова // «Соціальна психологія». - 2009. - №5. - С. 103-110.

4. Pierce, J.L., Kostova, T.\& Driks, K.T. (2001) Towards a theory of psychological ownership in organizations. Academy of Management Review, 26 (2), 298-310. doi: 10.2307/259124

5. Friedman, O. (2010) Necessary for possession: How people reason about the acquisition of ownership. Personality and Social Psychology Bulletin, 36, 1161-1169. doi:10.1177/0146167210378513

6. Smirnova, E.O., Sukhanova, M.D. (2014) An attitude to property as a subject of psychological research. Modern foreign psychology. Issue 3, \#4, 18-32 (In Russian). Суханова Е.О. Отношение к собственности как предмет психологического исследовании я / Е.О. Смирнова, М.Д. Суханова // Современная зарубежная психология. - Выпуск 3. - №4ю - С.18-32.

7. Butcher, J., Mineka, S., \& Hooley, J. (2007). Abnormal psychology and modern life (13th ed.). Boston, MA: Allyn \& Bacon.

8. Steketee, G. \& Frost, R.O. (2003) Compulsive hoarding: Current status of the research. Clinical Psychology Review, 23, 905-927. doi:10.1016/j.cpr.2003.08.002

9. Preston, S.D., Muroff, J.R. \& Wengrovitz, S.M. (2009) Investigating the mechanisms of hoarding from an experimental perspective. Depression and Anxiety, 26, 425-437. doi:10.1002/da.20417

10. Mental Disorders in the Social Environment: Critical Perspectives. Edited by Stuart A. Kirk. New York: Columbia University Press, 2004. Pp.464. 


\section{Nuclear Power Plant Disaster: Impact on Mental Health and Lifestyle of Liquidators}

(Olha Humeniuk)

Institute for Social and Political Psychology, National Academy of Educational Science of Ukraine, Kyiv, Ukraine

Introduction. The example of liquidators was studied as a long-term consequence of the traumatic accident affecting mental health and lifestyle, as well as its changes. To this end, the study was conducted where 305 respondents participated (176 - a group of liquidators, 129 - a control group). The examination of approaches to the study of lifestyle has resulted in distinguishing following four psychological components: value, quality of life, subjective assessment, and level of subjective control (locus control). Given the empirical data of the research, such lifestyle patterns of liquidators as "victim"; "constructive and optimistic"; "passive and narcissistic", "active and responsible" have been identified, including a description of specific features thereof of each.

The Chornobyl accident (ChNPP) is a significant event in the life of liquidators causing changes in all psychological components of their lifestyle, which has been proved empirically - by quantitative and qualitative studies. The author has finds out that the Chornobyl disaster is considered by liquidators to have been a momentous experience in their lifes (Kuzmenko, 2002; Khodorivska, 2005). The paper describes remote social and psychological consequences of the ChNPP accident for the liquidators, including negative dynamics of perception of an accident, low assessment of their own health and low estimation of quality of life, change in value structure and lack of life perspectives (Yakovliev, Volovich, Popovich, 1997).

Design. 305 employees of the Ministry of Interior of Ukraine (MIU) participated in the study. The test group included 176 responders from the MIU who served in the area of liquidation of the consequences of the Chornobyl accident in 1986-1990, the control group consisted of 129 employees of the MIU who did not take part in the liquidation of the consequences of the Chornobyl accident. Respondents from both groups of males aged from 47 to 65 were university graduates and had served at the MIU for more than two decades. Approximately $85 \%$ of respondents are retired from the MIU.

Methodology. Rokeach value survey (RVS); Schwartz outcome scale-10; Morphological test of vital values, V.F. Sopov, L.V. Karpushin; WHO Quality of life assessment instrument (WHOQOL-100); questionnaire "Level of subjective control" E.F. Bazhina, E.A. Golinkina, L.M. Etkind; the technique of self-relation research, V.V. Stolin, S.R. Panteleyev, a questionnaire developed by the author.

Results \& Conclusions. A comparative analysis of the data obtained made it possible to distinguish specific features of the liquidators' lifestyle that was changed as a result of work in the ground zero epicenter of the accident. Given the comparative analysis, significant transformations in all structural components of lifestyle of participants of the accident at the ChNPP have been distinguished: value, quality of life, subjective assessment and level of subjective control (locus control).

According to the data and interviews with the liquidators, the following four sub-groups of respondents were formed, subject to their subjective assessment of the Chornobyl disaster impact on the transformation of their lifestyle and life as a whole: 1) the accident has affected their lifes and completely changed their lifestyle; 2) the accident has changed their lifestyle; 3 ) the accident has partially contributed to the change of their lifestyle; 4) after the accident their lifestyle has hardly changed.

Based on the general characteristics of the changes, the types of lifestyle ("victim"; "constructive and optimistic"; "passive and narcissistic", "active and responsible") of responders have been developed and the structural and content specifics of the distinguished types have been outlined. The "victim" type is characterized by a very strong negative impact of the accident on the change in lifestyle of liquidators (according to the subjective values of respondents), low motivation and low significance of social values, low level of satisfaction with life, dependence between self-esteem and attitude of society, externality and tendency to accuse blame other people and the state of their problems.

The "constructive and optimistic" type is characterized by lack of the impact of the accident on the change in their lifestyle, and the impact is subjectively assessed as a positive rather than negative. Among the representatives of this type, the prevailing attitudes are the average motivational orientation, the significance of social values, the high level of satisfaction with life as a whole, and the high assessment of the lack of coherence and the subject of social relations. Respondents of this type consider others responsible for their problems, but they are sure that they themselves are responsible for their health.

Strong, predominantly negative influence of the accident on the change in lifestyle is experienced by the "passive and narcissistic" type. This type experiences low importance of individual and high value of social and common values, low level of satisfaction with the quality of life, high assessment of the agent of social relations 
and personality, as well as high expectations of positive attitude of others in the expressed outward internal stability, externality in regulating the process of living in society.

The "active and responsible" type is distinguished by such specific socio-psychological Specific sociopsychological features as subjective assessment of the impact of an accident on the change in their lifestyle moderate (equally positive and negative), high appreciation of individual values as well as of professional and social relations. They consider themselves responsible for the state of their health and for failures in their lives.

Keywords: man-made disaster, quality of life, lifestyle, social psychology, way of life, mental stress, social life, personality

\section{References.}

1. Kuz'menko, T. M. (2002). The influence of extreme situations on human life orientation (on the example of the Chornobyl catastrophe). Kyiv: IMMB.

2. Khodorivs'ka, N. (2005). Chornobyl and the human: social adaptation. Kyiv: NAN Ukrayiny; In-t sotsiolohiyi [NAS of Ukraine; Institute of sociology].

3. Yakovlyev, B. S. (1997). Participants in the liquidation of the consequences of the Chernobyl accident as a social group. Kyiv: Chornobyl'interinform.

4. WHOQOL Group. Field Trial WHOQOL-100. February 1995: facet definitions and questions. Geneva: WHO (MNH/PSF/95.1.B), 1995 


\title{
The Adaptability Factor of Young People with the Status of a Disabled Child in the Context of Medical and Social Expertise
}

(Victoria Khramtsova, Yulia Honchar)

State Institution «Ukrainian State Institute of Medical and Social Problems of Disability Ministry of Public Health of Ukraine», Dnipro, Ukraine

\begin{abstract}
Introduction. Socially stressful situations refer to the sphere of macro social problems and require significant personality resources from the individual. They also may contribute to chronic psychological traumatism, which is manifested by distress states and increase of pre nosological forms of violations in mental adaptation. Being an important factor in the structure of mental health, the dynamics of psychological adaptation depends not only on the conditions of the social environment and social attitudes, but also on functional states, personal resources, life experience (Dubinina, 2013). For adaptation to proceed successfully, sufficient development of such a factor as adaptability (the capacity and the desire to adapt to changes, the developed ability to appropriately adopt the norms and values of the society in which the individual lives) is necessary. Strong adaptability makes it easier to transfer changes in life, to adequately navigate in a difficult situation, increases emotional stability and the ability to change. On the contrary, emotional failures, difficulties of interaction indicate that the individual's attitudes strongly disagree with the cultural, social and communicative environment and, accordingly, are of low resource (Nalchadzhan, 2010). Procedure for establishing a disability group can be referred to a socially stressful situation, since one of its components is the acquisition of a socio-economic resource.
\end{abstract}

Purpose. The purpose of the study was to investigate the adaptability factor as a marker of social stress situation in the context of medical and social expertise.

Methodology. The randomized study was performed on the basis of the research institute, and included patients, obtaining the disability group. The inclusion criteria were: the status of disabled child, the age of 18-29 years, the absence of concomitant mental disorders. The study was conducted in 3 stages: 1- study of medical documentation; 2- psychological testing procedure (after signing the informed consent); 3- examination of the materials of expert commission decision. The following methods were applied: clinical-psychological method, psychological diagnostics, statistical method. Social biographical features, medical history, psychological features were studied by the means of the Adaptivity test (such issues as behavioral regulation, communicative qualities, moral normativity, personal adaptive potential, disadaptive states) (Raigorodskii, 2006). All patients were divided into 3 groups: those, which were getting the disability group for the first time, those, which went for appeal and those, which went for the reassessment. To study the reliability of differences between groups, the paired Student t-test was used.

The methodological basis was the concept of psychic adaptation of Berezin F. B., where adaptation reactions and personality decompensations could be considered within the framework of one adaptation model (Berezin, 1988).

Research was based on a systematic approach to psychological aspect of mental adaptation study. Adaptation was viewed as holistic process of interaction in the "person-environment" system, where the goal, connected with the leading need, was the system-forming factor (Berezin, 1988).

Results. 85 young people with the status of disabled child were examined, they all were in the situation of medical and social expertise for obtaining disability group. In the course of the conversation and medical documents study it was revealed that the disability group was regarded by young people as an important social factor of material support and the possibility of obtaining an education, also the need for a disability status was actively supported by parents. Young people, getting the disability group for the first time, didn't have any experience of solving problematic and crisis situations connected with expertise, and young people, which disagreed with the earlier decision of the expert commission and tried to appeal it, had the negative experience. So the most significant prevalence of behavioral regulation decrease was revealed in those two groups $(91.7 \%$ and $75.6 \%$ ), as well as the increased proneness to conflict, avoidance of contact and mutual understanding with others $(66.7 \%$ and $48.9 \%)$, adaptation disorder and disadaptive states $(83.3 \%$ and $75.5 \%)(p=0.017)$. Patients in the appeal group in 53.3\% had the decrease of adaptation with possible neuropsychic breakdowns with the involvement of functional states. Patients, which had minor abnormalities of anatomical structures, physiological functions, and got disability status by social factor for the period of education and profession obtaining, in $94.8 \%$ had the reduction of adaptation and disadaptive states $(\mathrm{p}=0.015)$. Young people, which already had disability status and came for the reassessment, compared with patients, getting the disability group for the first time $(\mathrm{p}=$ $0.043)$ and on appeal $(\mathrm{p}=0.0006),-$ had less difficulties with adaptation $(61.5 \%)$.

Limitations and strengths of the study. Adaptability in the situation of expertise can be considered as a factor of personal reaction to significant changes in the life of patients with chronic physical illnesses and as a personal 
resource for psychological assistance and appropriate correction. The restriction is the adjustive behavior of patients.

Practical / social value Using the method of adaptivity disorders identification in medical and social expertise, especially involving functional systems, makes it possible to define the psychological component in the structure of the disease more accurately and develop psychological preventive measures aimed at personal, interpersonal and situational components. The social aspect consists of psychological preventive and correction measures, aimed at successful integration of young people with special needs into society.

Conclusions. The most stressful the situation of expertise was for patients, which had minor violations of anatomical and physiological structures, as well as for those which were getting the disability group for the first time.

The discrepancy between the desired result, the impossibility of obtaining it and the lack of the necessary resource contributes to the development of disadaptive states.

The social microenvironment contributes to the formation of the individual's attitude towards obtaining state financial compensations, thereby strengthening the stressfulness of the expertise context for them.

The state of disadaptation of young people which did not receive the disability group - was a factor that could increase their isolation and stigmatization.

Keywords: mental health, adaptability, disadaptive states, adaptation, social stress situations, medical and social expertise, young people with special needs, incapacity for work, social inequality, young person.

\section{References.}

1. Dubinina, E. A. (2013). Mental adaptation in cardiovascular diseases: phenomenology, dynamics, prognosis [Psihicheskaya adaptatsiia pri serdechno-sosudistyh zabolevaniyah: fenomenologiia, dinamika, prognoz]. RGPU in honour of A. I. Gertsen. Spb.: OOO «Copy-R group».

2. Nalchadzhan, A. A. (2010). Psychological adaptation: mechanisms and strategies [Psihologicheskaiia adaptaciia: mexanizmy i strategii]. Moscow: Eksmo.

3. Berezin, F. B. (1988). Psychic and psychophysiological adaptation of Man [Psihicheskaia i psixofiziologicheskaya adaptaciya cheloveka]. Lviv.

4. Raigorodskii, D. Y. (2006). Multi-level personal questionnaire "Adaptability" (MLO-AM) A.G. Maklakov and S.V. Chermyanin [Mnogourovnevyi lichnostnyi oprosnik «Adaptivnost» (MLO-AM) A. G. Maklakova i S. V. Chermyanina] // Samara: «BAHRAH-M». 


\section{Changing Approaches to Dementia Management: How Relevant Is It for Ukraine? \\ (Oleksandra Khudoba)}

Lviv Regional Institute for Public Administration of the National Academy for Public Administration under the President of Ukraine, Lviv, Ukraine

Introduction. According to various estimates, from 58\% (Alzheimer's Disease International, 2015), 60\% (World Health Organization, 2015) to 66\% (Skladzien, E., Bowditch, K., \& Rees, G., 2011), (Brodaty, H., \& Donkin, M., 2009) of people with dementia live in low and middle-income countries, and this percentage is expected to increase over the next few years. It can further increase the inequality in access to medical and social services both between countries and among different age groups within countries.

Despite the scale of the spread and economic impact of dementia on the family, on caregivers and on the community as a whole, the disease is either not discussed at all or is not a priority in low-economic countries (World Health Organization, 2012).

Over time, countries, which could face the need for the effective policy and plan to implement dementia measures, will encounter a number of specific obstacles that they have to overcome. Therefore, today, the important step is to study the experience of countries that have embarked on their path to counter dementia and are determined to succeed in combating this disease.

Purpose: to attract attention of policy and decision makers to dementia problems in Ukraine to facilitate developing system of health care and social care for people living with dementia and their caregivers.

Methodology. A systematic search of the literature was conducted and inclusion/exclusion criteria applied to the retrieved papers. Searchers in electronic statistical databases helped us to identify the countries for making the following comparative analysis (World Life Expectancy, 2018), (Ministry of Health of Ukraine 2017).

Results. Since Ukraine is not yet on this list and the problem of dementia is not relevant to it, we tried to make the short comparative analysis of Ukraine with countries for which dementia is one of the national priorities (France, the Netherlands, the USA, the UK, Norway and Australia).

In the world ranking of countries, Ukraine occupies the 176th position in terms of death rate from Alzheimer's disease/ dementia, that at first glance does not cause anxiety and looks favorably enough. In the overall structure of mortality of the Ukrainian population, the same indicator is only $0.38 \%$. In the developed countries, the trend towards the same indicators is completely opposite: all six of our chosen countries in the world ranking on death rate from Alzheimer's / dementia fall into the first 30 top positions, and in the national ranking of mortality, this indicator ranges from $9.91 \%$ (Norway) to $15.37 \%$ (Great Britain).

Taking into account the morbidity indicators among the population of the older age groups psychic disorders occupy the penultimate place in the overall morbidity structure, leaving behind only blood diseases. The fact that the incidence of circulatory system occupies up to $19 \%$ of the total morbidity structure, and the mortality rate almost 54\% leads us to believe that dementia can be "hidden" in this indicator. The reason for this may be a low level of addressing of population for help in medical institutions and, accordingly, a low level of diagnosis of dementia.

Limitation and strengths of the study. Since dementia has been considered by Ukrainian scientists only from the medical point of view, and the issues on how to manage dementia or how to develop a dementia strategy in Ukraine haven't been analyzed yet, our research is mainly based on the foreign scientists' studies. The key advantage of the proposed study is that it is one of the first attempts to look at the problem of dementia in Ukraine from the public administration point of view in different aspects and directions. It is an attempt to initiate a professional discussion with policy and decision makers on issues of developing and implementing a strategy for people living with dementia and their families.

Social value. Alzheimer's disease and other dementia is a global health problem, and is of an exceptional size, affecting the increase in costs and social changes in society. The personal, social and economic consequences of dementia are enormous, which leads to the increase in the costs of long-term care to governments, communities, families and individuals and the loss of productivity for economies. It is expected that this issue may be most "painful" for developing countries: according to experts, the number of elderly people aged 65 and older will have been increased by $140 \%$ by 2030 , while in developed countries this figure will have reached $51 \%$ (Dobriansky, P. J., Suzman, R. M., \& Hodes, R. J., 2007).

Conclusions. The problem of counteracting dementia in Ukraine is not yet a national priority, but conducting cross-sectoral studies can fundamentally change the situation. The comparative analysis of countries on several indicators available to us within the framework of this study gives grounds to believe that Ukraine will face the need for a detailed analysis of the problem of dementia. 
Achievement of success in the complex situation of counteracting dementia can be reached through the establishment of intersectoral cooperation at the primary level, where the provision of medical and social services is the closest to the patient and his cares. Coordinated collaboration on prevention, early diagnosis, effective treatment and care will increase access to services for those who need it.

Keywords: mental health, health policy, disease prevention, organization of health care, health statistics.

\section{References.}

1. Alzheimer's Disease International. (2015). Dementia statistics.

2. World Health Organization. (2015). Call for action by the participants of the first WHO ministerial conference on global action against dementia. Geneva, 2015: 2.

3. Skladzien, E., Bowditch, K., \& Rees, G. (2011). National Strategies to Address Dementia: A Report by Alzheimer's Australia. Alzheimer's Australia, Australia.

4. Brodaty, H., \& Donkin, M. (2009). Family caregivers of people with dementia. Dialogues in Clinical Neuroscience, 11(2), 217-228.

5. World Health Organization. (2012). Dementia: a public health priority. World Health Organization.

6. World Life Expectancy. (2018). World Health Rankings. Retrieved from : http://www.worldlifeexpectancy.com/cause-of-death/alzheimers-dementia/by-country/female.

7. Ministry of Health of Ukraine (2017). Schorichna dopovid' pro stan zdorovia naselennia, sanitarnoepidemichnu sytuaciiu ta resultaty diialnosti systemy ochorony zdorovia. 2016 [Annual report on the health status of the population, the sanitary and epidemiological situation and the results of the Ukrainian healthcare system's activities. 2016]. Retrieved from : www.uiph.kiev.ua/d.

8. Dobriansky, P. J., Suzman, R. M., \& Hodes, R. J. (2007). Why population aging matters: A global perspective. National Institute on Aging, National Institutes of Health, US Department of Health and Human Services, US Department of State. 


\title{
Parental Competence with Autism's Children: Current and Perspective Research
}

\author{
(Hanna Khvorova)
}

Institute for Social and Political Psychology National Academy of Educational Sciences of Ukraine, Kyiv, Ukraine

Introduction. This research presents and tests the theoretical model of parental competence with autism's children. Autism is a special type of functioning of the nervous system that results in a deficit of social functions (which is not primarily connects with a decrease in intelligence), has a varied effect on many systems of the organism (cognitive, communicative-speech, sensory, basal systems (food, sleep, etc.) and requires significant and highly specialized care services in all spheres of life. Parents raising children with disabilities are faced with additional problems, compared with parents of normotypic children. They include stigma, lack of acceptance by the larger society as well as additional daily hassles specific to the child's mental or physical condition (Burlaka, Shevtsov, \& Lundquist, 2007). Parents caring for a child with ASD tend to experience additional stress that affects their ability to parent (Baker-Ericzen, Brookman-Frazee, \& Stahmer, 2006). In addition, parents of children with ASD have to avoid intrusiveness that may hinder children's development of independent living (Wood, 2006) and communication skills (Siller \& Sigman, 2002).

We have determined that under the condition of transformation of parental functions (child's autism, for example), the competence of parents has five levels (from very low to the highest - according to the ability to formulate problems and find resources for its solution) and consists of three components - the ability to interact with the child, the ability to interact with the social environment (at the micro and macro levels of social communication), the ability to provide a level of quality of their own lives.

Purpose. The main question of the study: what kind of parent's behavior and parental social and psychological characteristics provide a positive direction for the development of a child with autism, and how the social environment at the micro level (family, teachers of special education, friends, acquaintances) and at the macro level (civil society organizations, state organizations and services, public authorities) of social communication affect this ability.

Design / Methodology / Approach. In the framework of the study, 21 parents of children with autism aged 4-16 years completed the Alabama Parenting Questionnaire (APQ) questionnaire, which is widely used to study parenting practices.

Results. There was a tendency of growth of parental involvement (a positive characteristic that reflects the degree of parental involvement in the child's life) as the child grows up, whereas in the case of parenting with normal-type children this trend is reversed (the involvement of parents falls as the child grows, which is favorable for a timely upbringing of a child (Burlaka, V., Graham-Bermann, S. A., \& Delva, J., 2017). The use of positive educational practices and the low level of physical punishment have been noted.

Limitations and strengths of the study. The described survey was pilot, but there were a few limitations: a small number of respondents, a discrepancy in a number of APQ questionnaires questioning the situation of paternity with a child with autism, the use of only one diagnostic tool.

Practical / Social value. With the results of this stage of the study, it is planned to conduct parental training for 12 weeks (functional stages of emotional development of the child and means of promoting the development of child-parenting interaction, communication, speech (guided by the approach DIR-Floortime), training in the method of unfinished situations, parent supervision from using parent video materials) with the diagnosis of children's development on the Vineland-3 scale and characteristics of child-parenting and parenting practices of parents of children with autism (for a modification of questionnaire for parental attitude (A. Vargas, V. Stolin) for a family that cares for a particular child, PARI (parental attitude research instrument), modified for the case of paternity with children with autism by the APQ questionnaire and the authoring questionnaire "Measures of care" to determine the level of parental intrusiveness). Measurements will take place at the beginning and after the completion of parenting education.

Originality /Conclusions. Extensive research on parental practices with children with autism and child's and parental characteristics will help improve parenting education, improve the level of interaction between parents and teachers of special education, facilitate the removal of parental education programs into the level of public health programs and promote the introduction of parenting programs in general protocols of intervention, care and autism support.

Keywords: ASD, community-based services, parental intrusiveness, parent education, parent training, parentmediated interventions. 


\section{References.}

1. Baker-Ericzen M., Brookman-Frazee L., Stahmer A. Stress levels and adaptability in parents of toddlers with and without autism spectrum disorders. Research \& Practice for Persons with Severe Disabilities. 2006;30(4):194-204.

2. Burlaka, V., Graham-Bermann, S. A., \& Delva, J. (2017). Family factors and parenting in Ukraine. Child Abuse \& Neglect, 72, 154-162. https://doi.org/10.1016/j.chiabu.2017.08.007

3. Burlaka, V., Shevtsov, A., \& Lundquist, L. (Eds.). (2007). Introduction to habilitation and rehabilitation of children with disabilities. Kyiv: Herb.

4. Chuprikov A., Hvorova A., Autism Spectrum Disorders. Medical, Psychological and Pedagogical Support. LAP LAMBERT Academic Publishing, 2013.

5. Gotlib, A. (2017, April 2). Autism diagnosis as a test of humanity [Parents Association]. Retrieved October 13, 2017, from http://mini-rivne.com/maty_diagnoz-autuzm/

6. Khvorova, H. (2014). Formation of parental competence in correctional education of children with polysystem disorders of development (Vol. 28). Kyiv: Scientific Journal of the National Pedagogical Dragomanov University.

7. Khvorova, H. (2015). Content and level of parenting competence in the correctional-pedagogical aspect (Collection of scientific works). Kamyanets-Podilsky: Kamyanets-Podilsky National University named after Ivan Ogienko.

8. Mikheeva, N. The Method of Unfinished Situations (MUS) for the diagnosis of parental competence // Practical Psychology and Social Work: Scientific-Practical and Educational-Methodical Journal. - 09/2010. N9 - P. 49-56.

9. Siller, M., \& Sigman, M. (2002). The behaviors of parents of children with autism predict the subsequent development of their children's communication. Journal of Autism and Developmental Disorders, 32(2), 77-89. DOI: $10.1023 / A: 1014884404276$.

10. Stadnick, N. A., Stahmer, A., \& Brookman-Frazee, L. (2015). Preliminary Effectiveness of Project ImPACT: A Parent-Mediated Intervention for Children with Autism Spectrum Disorder Delivered in a Community Program. Journal of Autism and Developmental Disorders, 45(7), 2092-2104. http://doi.org/10.1007/s10803015-2376-y

11. Wood, J. J. Parental intrusiveness and children's separation anxiety in a clinical sample. Child Psychiatry Hum Dev. 2006 Fall;37(1):73-87. 


\title{
The Research of the "Courage to Continue" Using Narrative and Ideographic Approaches
}

\author{
(Zoia Kireeva, Olena Odnostalko)
}

Odessa I. I. Mechnikov National University, Odessa, Ukraine

\begin{abstract}
Introduction. Human life is not a straight rising up line. It represents a curved line that resembles a cardiogram, which reflects recessions and upsurge, normative (age, family, professional, social) and abnormal crisises, in the form of complex / difficult / extreme situations. What kind of strength / strengths, individual personality traits, mental states, social environment make a person adapt / not adapt, stand / fall, resist / break, find / lose themselves in difficult situations and save / lose their mental health?
\end{abstract}

Purpose is: to study the experience of living-through a hard life situation from the position of the inner world of the personality.

Methodology /Approach. In modern psychological science, studies in which an individual who is experiencing a difficult situation from the position of his own inner world is analyzed, appear. According to this tendency and the idea of research, we used ideographic and narrative approaches. The examinee who is going through a serious non-normative life situation made up a personal story in the form of a metaphorical narrative description. According to M.L. Crossley, while analyzing narratives we focused on: identifying important concepts, tone of narrative, images, key event, future scenarios and personal ideology, as the most comprehensive characteristics of personal narrative in adulthood (Crossley,2009).

Results. As a result of the empirical study, we refused to use the known definitions of a difficult life situation, but offered the author's term "Crash stage". By which we mean the objective non-normative stage in the life path in which a person loses relative stability, realizes the destruction of life in the present, irrevocability to the past and uncertainty of the future. "Crash-stage" is not just a stressful / difficult situation, it is a kind of traumatic stress that does not overload the adaptive possibilities, but concentrates and strains them. There are pre-stage, "crash-point", post-stage and result-stage in the "crash-stage". Each stage has its own dynamics and features of living. The result-stage involves several options for functioning: 1) preserving / maintaining self-identity or "the courage to continue" (Sir W. Churchill); 2) false support with a negative result (for example, the emotional stages proposed by E. Kubler-Ross (negation, anger, bargaining, depression, acceptance); 3) destructive (use of tranquilizers, alcohol, drugs, suicidal behavior). Person as a self-organizing system in the "crash-stage" undergoes changes with the result according to which his further personal life history develops. To the "crash stage" we refer the following situations: severe illness, disability, the collapse of a career and/or business, reputation and status, disruption of life goals and loss of meaning, disruption of work capacity and social relations.

Analysis of the personal history of the "crash-stage" living-through made it possible to single out the following stages of the living-through: pre-stage - "Fortress", "crash-point" - "Sudden attack"; post-stage "Siege", "Siege continues with enemy raids", "Reconstruction under siege" and incomplete result-stage, as well as important concepts in accordance with the above criteria adopted for narratives. Thus, the proposed history allows us to conclude that the tone of personal narrative is generally optimistic. This is transmitted in the content of history and through the form ("The sun is always above the fortress", "The sky becomes blue and the sun begins to shine"). The images used by the examinee indicate that he reflects his / her personality traits / personal features ("able-bodied, energetic, confident in the future, positive, friendly, hospitable", "established work and order", "answers to the enemy", "not to fall in the spirit"). According to our observations, the examinee is energetic, competent, self-confident, persistent, with high activity in the performance, sociable, benevolent, he/she has a conviction in his own high level of "human strength", incontinence, straightforwardness, inner freedom, social courage, stress-resistance, high level of vitality, optimism and motivation for success, the type of temperament mixed - choleric-sanguine. The key event for the examinee was "Crash-point", an event, which the examinee calls "Sudden attack", that changed the life of the examinee, his temporal perspective and the surrounding people. However, even in this situation, the examinee presents himself (self-presentation) in the course of the narrative, as a resilient, aware of his actions, a confident person, waiting for help from outside ("Dirty from the fires of the face and body of the defenders, clear movements, that the fortress sustains such a siege for the first time. There is no panic. The fortress did not fall, but it was badly damaged"). The subject describes the perceived behavior of others and the violation of social contacts ("The environment is shocked by what is happening and do not know whether it is possible to visit the fortress. choose a wait-and-see strategy of behavior"). At the post-stages of the "crash-stage", the examinee transmits his experiences, which testify to the expressed dissociation of the components of viability: an acute sense of himself outside of life, a weak influence on the results of stressful changes, insignificant activity (control), non-acceptance of risk, with medium openness environment and society (challenge). He significantly reduced self-esteem and level of optimism, there is a 
deterioration in the emotional state ("The mood of residents varies from optimistic to pessimistic and vice versa: their resources are depleted, but they are active as much as possible"). The examinee is aware of the minimality of emotional social support, given its high value. There is a belief in support from outside. There is a motivation to "stand up" under the influence of a psychological abuse, reflecting the personal ideology of the examinee: "do not give up under any circumstances." The scenario of the examinee's future is aimed at restoration, without a clear attach to the future time perspective. According to the story of the examinee, the "crash stage" has not ended, but there is a possibility that the result-stage will end with the self-identity preserving / maintaining ("The Fortress starts reconstruction on its own.") Develops a new strategy and tactics".

Limitations and strengths of the study. We refer to the use of ideographic and narrative approaches as to the strengths of the research that allow to study the specific experiences of a person in a hard life situation from the perspective of his/her inner world.

Practical / Social value is: establishment of the components of the functioning of the human system in the experience of living-through a hard life situation with the goal of creating a rehabilitation program. The program is aimed at maintaining and restoring the resources of an individual experiencing the hard life situation.

Originality/Conclusions. Thus, we believe that the process of living the "crash-stage" with the self-identity preserving / maintaining is influenced not only by the level of development of the individual psychological and personality characteristics of the individual and its activity. Rather, it is about synergy of functioning components of the human system "wounded, but not defeated" in the direction of obtaining a useful result. The examinee's system includes individual and typological and personality traits (temperament type, vitality, optimism), motivation, intellect, will, resources, reflection, self-esteem, experience, life scenario, social environment (family), self-regulation, the concept of human strength as the ability to withstand whatever adversity, resilience, etc. In further studies, it is planned to study changes in the time horizon and the features of social support during the "crash-stage" living-through.

Keywords: mental health self-regulation psychology.

\section{References.}

Michele L. Crossley. (2009). Introducing narrative psychology. Philadelphia: Open University Press. 


\title{
On Solving the Problem of Mental Health Care with the Social Work Input
}

\author{
(Liliya Klos, Larysa Klymanska, Nina Hayduk, Halyna Herasym)
} Lviv Polytechnic National University, Lviv, Ukraine

Background: According to statistics, the number of the mentally disabled among the population is $4-5 \%$ (World Health Organization, 2018). Complex social circumstances faced by a person with mental illness are incompatible with the values of a humane and tolerant attitude toward people with "otherness", which corresponds to the social problem definition (Rubington \& Weinberg, 1995, p. 4.). There is a need for social change.

Purpose: The study aims to identify possibilities and ways of bringing in social work in solving the problem of mental health care in Ukraine.

Methods: Theoretical research methods were used to determine the current state of constructing the mental health care problem to find out opinions of experts (psychiatrists, psychologists, persons with mental illness, and those from their surroundings) on the challenges and needs of the mentally disabled in Ukraine. Qualitative content analysis of the materials of narrative interviews with clients of the social organization and expert interviews was done to identify opportunities for involving social workers in solving the problem of mental health care by the example of Lviv.

Results: Researchers are unanimous in the conclusion that "life with mental illness is also a life with those serious social losses that accompany this illness" (Polskaya, 2004, p. 157). As of January 1, 2017, 1673328 residents of Ukraine were registered due to mental and behavioral disorders (Cabinet of Ministers of Ukraine, 2017). The hope for resolving acute problems in mental health care in Ukraine is associated with social work, focusing on the bio-psycho-socio-spiritual human nature.

Modern concepts of mental disability can be divided into two types: medical and social. The medical model attributes to individuals the status of "sick" and "deviant", who should be "corrected" or isolated from society. The social type of explanation recognizes mental disability due to the historical development and unjust society arrangement (Romanov \& Yarskaya-Smirnova, 2006). Hence, the change in the social status of people suffering from mental disability is possible only under the condition of change in the dominant perceptions of the "disease of the soul". Summarizing numerous works devoted to the study of the concepts of mental illness, we note that the content of these concepts has a significant degree of negative valence. By the definition of R. Farr (Farr \& Markova, (Ed.), 1995), the form of a social

conception with a negative valence is a stigma.

In the process of problematization of social circumstances associated with people with mental illness, professionals-experts (psychiatrists and psychologists) play an ambiguous role creating medical stigma (Sas, 2007, pp. 373-375). Hospitalization largely contributes to reducing the variety of social roles of an individual to a single role - that of a patient, and forming a distorted, negative self-concept (Goffman, 1961).

It is important to return the "voice of a patient" to studies to understand the actual needs of the mentally disabled (Porter, 2008, p. 57). In 2017, a study of the thoughts of people with mental illness about the challenges experienced by them in their environment was conducted. The method of an in-depth, narrative interview was chosen, and clients of the daytime programme of the Center for rehabilitation and social adaptation (8 persons, three of whom are men, five - women; their age: 25-42 years) were interviewed. A comparative analysis of the texts, their structural description, and the statements coding were done as a major procedure of the representation analysis. Our informants attributed the understanding and support of family, relatives, friends and neighbors to the main factors in confronting the illness. At the same time, the immediate environment demonstrates a stigmatized, biased attitude to people with mental illness, with their self-stigma being also present there.

An expert survey of social service providers dealing with health care issues of the mentally disabled in Lviv was also conducted. The sample comprised 10 experts, with a snowball sampling technique used. All the experts, representatives of 6 non-governmental organizations and 4 state institutions, stressed the need for counteracting stigmatization in the individual's environment, particularly by means of social rehabilitation.

Consequently, there is a need for involving social work as an instrument to overcome stigmatization / selfstigmatization in social inclusion of people with mental disability. Thus, there is also a need for training social workers for professional activity in mental health care.

To address the above need, the Department of Sociology and Social Work is introducing an MSW programme (specialization) in mental health care, with its main principles based on the Concept of the development of mental health care in Ukraine for the period up to 2030. This policy document emphasizes, in particular, the social workers' role strengthening and the development of professional competences in mental health care (Cabinet of Ministers of Ukraine, 2017). We rely on the advanced experiences in mental health care worldwide, with clinical social workers playing an important role in various institutions applying the client-centered 
approach (NASW, 2011). A social worker in mental health care is competent in different professional activity aspects, in particular, s/he applies the ethical principles of social work, engages, assesses, intervenes and evaluates interventions with individuals, families, groups, organizations, and communities (CalSWEC, 2011). The new educational programme is based on the value-oriented, client-centered, competence-based approach, and evidence-based social work practice. The Clinic of Community Health is also being established based on Lviv Polytechnic.

Conclusion: The findings show the need for the social work input in solving the problem of mental health care in Ukraine. Accordingly, the social work education is addressing the need.

Keywords: mentally disabled, social problem, social change, social work, destigmatization, social work education, social inclusion

\section{References.}

1. Cabinet of Ministers of Ukraine (2017). Order No.1018 as of 27.12.2017 on the approval of The Concept of the development of mental health care in Ukraine for the period up to 2030. URL: https: //www.kmu.gov.ua/ua/npas/pro-shvalennya-koncepciyi-rozvit

2. Pol'skaya, N.A. (2004). The mentally ill in modern society: The problem of stigma. Sociological Journal, 12, 157.

3. Porter, R. (2008). The patient's view. The history of medicine "from below". V.Y. Shliumboma et al. (Eds.), Illness and health: New approaches to the history of medicine (pp. 41-72). SPb.: European University at St. Petersburg: Aleteya.

4. Romanov, P., \& Yarskaya-Smirnova, E. (2006). Disability policy: The social citizenship of the disabled in modern Russia. Saratov: Scietific Book.

5. Sas, T. (2007). Madness factory. Ekaterinburg: Ultra: Culture.

6. CalSWEC. (2011). Integrated Foundation \& Advanced Competencies for Public Mental Health in California. URL: http://calswec.berkeley. edu/files/uploads/ docx/ Mental\% 2520Health/02_mh_comps_formatted_final.pdf.

7. Goffman, E. (1961). Asylums. Essays on the social situation of mental patients and other inmates. N.Y.: Anchor Books.

8. Farr, R., \& Markova, I. (Ed.). (1995). Representations of health, illness and handicap in the mass media of communication: A theoretical overview. Chur, Switzerland: Harwoord Academic Publishers.

9. NASW. (2011). Center for Workforce Studies \& Social Work Practice. Social Workers in Mental Health Clinics \& Outpatient Facilities - occupational profile. Washington, DC: National Association of Social Workers. URL: https: //www.socialworkers.org

10. Rubington, E., Weinberg M. (1995). The study of social problems. Seven perspectives. NewYork; Oxford: Oxford University Press.

11. World Health Organization (2018). Mental health atlas 2017. Geneva. URL: https://creativecommons.org/licenses/by-nc-sa/3.0/igo 


\title{
The Narcissistic Ways to the Existential Self-Fulfillment
}

\author{
(Maria Klymenko)
}

\author{
Ivan Franko National University of Lviv, Lviv, Ukraine
}

Introduction. Social processes are increasingly heading to the points of culture of individuality and personal efficiency in the last decade. Personal achievements, being initiative and competitive, aspiration of the wellbeing, happiness, self-values, self-senses and life orientations, self-realization and development of own competences are becoming more actual and publicly approved. So that the self-care, adequate and stable high self-esteem, assertiveness, feeling that one can fulfill personal ambitions, can compete in modern, some kind, hedonized XXI century society, are more perceived as normal, even desirable, forms of traits in the personality structure.

Purpose. Therefore, we stand in front of the question: how healthy narcissism influences on the sense-forming human activity and on the feeling and awareness of existential inclusion into the life essence in particular.

Methodology. Nineteen undergraduate students of Lviv high schools participated in the present study (46 female and 44 male students). Each of them was given an anonymous questionnaire package, which included tests: the narcissism evaluation test "Self" (F. Deneck and B. Hilzhenstock), "The Scale of Existence" (A. Lengle), "Satisfaction with the Life Scale" (E. Diner).

The narcissism evaluation tests "Self" (F. Deneck and B. Hilzhenstock) is directed to study various aspects of the narcissistic regulation system as the phenomenon that can be introspected. It includes 163 items and the scale from 1 to 5 for expressing the opinion. "The Scale of Existence" (A. Langle) is an approach to assess the ability to find personal meaning in life and to reach existential fulfillment. It consists of 46 items and the scale from 1 to 5 for answers. "Satisfaction with the Life Scale" (E. Diner) is a 5-item scale designed to measure cognitive judgments of one's life and every item has the scale from 1 to 7 that allows people to agree or disagree with statements more variatedly.

The next step was to process the data using methods of multivariate statistics: cluster, comparative, correlation, regressive analysis. And for the qualitative data analysis was also used Excel. The consolidated data analysis is briefly presented in this paper.

Results. Normal narcissistic self-regulation functions on the maintaining the emotional balance, feelings of internal stability, self-worth, self-confidence, personal well-being, sense of life. In general it makes person's Self congruent and able to adapt to changing conditions of the reality, it protects, fulfills and preserves structural integrity of Self. Positive perception of one's presonality, actually the self-worth, is supported by psychodynamic processes that base their work on the system of self-coordinated self-dynamism.

The study of the healthy narcissism refers to the psychoanalytic paradigm: theory of object relations, existentialpsychoanalytic theory, Ego-psychology in particular. This work is based on theories of Z. Freud, H. Kogut, O. Kernberg, J. Miller, K. Morf, D. Foster and K. Kambell, R. Raskin, A. Lengle [5].

Healthy narcissism is seen as normal personal trait that is inherent for all people in some average intensity manifestation and its deficit actually produces pathological conditions, which are revealed in exact narcissistic pathology.

Specifying: narcissistic self-regulation is a specific system of self-regulation, aimed at protecting, filling and preserving structural integrity, temporal stability and positive perception of oneself [1].

Another focus of this study pays our attention to self-fulfillment. Self-fulfillment is a multi-faceted construct, the definition of which exists in modern psychology in different manifestation of self-realization, sense of life, life orientations, and experience of happiness or life satisfaction. Literally it is an act of fulfilling one's ambitions, desires, personal senses, life ideas or even it can be defined as a state that one can feel at the moment of life [8]. A. Gewirth uses this concept for the fundamental "testing of the good and welfare of human life" [2].

In this work self-fulfillment is considered in the ideas of existential-analytical paradigm, which says that selffulfillment is:

- A deep understanding of one's Self and the world around;

- An understanding of personal values and the life senses;

- An understanding of all the overcoming contradictions in human existence [7].

So, healthy narcissism gives you the ability to accept the admiration of others and ability to admire others; gives a solid sense of self-worth, adequate self-esteem, a healthy sense of pride and the capacity to feel self-love as idea of self-protection [3]. Healthy narcissism is something that opens up to us our authentic Self, makes it possible to connect to other people authentic personalities [6]. This Self dynamism is responsible for feeling the confidence and acting according to life sense, which can only be found through the prism of personal self-worth. is a source of "self-realization", manifestation of "healthy" traits: ambitions, inspiration, ideals [4]. People with healthy narcissism have their hopes, dreams and ambitions, they are coping with the anxiety that life produces, 
they are able to accept failures and deal with fears and uncertainty, and they can approve themselves and withstand the disapproval of others.

Self-value plays role of the indicator for person's regulatory processes, it shows exactly how those processes work. A high and adequate self-value, which needs to be crystallized internally and established externally - is the source of integrated and coherent self-experience [7].

In the context of above described theory, an introductory study was conducted. That had given such empirical conclusions:

1. Healthy narcissism, or effective narcissistic self-regulation, stays in positive connections with almost all indicators of self-fulfillment: personality (as the ability to stay more open to the own personality and the world); self-transcendence (as the ability to be emotionally connected with values and meanings of life), experience of freedom (as the ability to see different branches of life and make among them personal choices), responsibility (as a feeling that every personal choice has it values in the existence), existentiality (as personally willed the inclusion in existence) and the general comprehension of oneself as a person who is fulfilled.

2. The factors of self-fulfillment in the context of narcissistic self-regulation are: the meaningful sense Self, the self-sufficiency, the feeling of Self-power, a less tendency to devaluate objects, and the desire to have an interiorized or exterior object that inspires.

Limitations and strengths of the study. The strengths of the research are its novelty and relevance. Meaningfulness of life usually has an impact on its quality, sense of well-being and mental health. Our personal senses are usually formed through perception the world as full of values and we feel our value in it as well. Limitations are about the size of sample (test sample included 90 investigated persons) and the need for more indepth study of individual value orientations.

Practical value. The results can be used for trainings or consulting work in order to improve the quality of life of people who have problems with self-value.

Conclusions. So, adequate, or in other words, "healthy" narcissism is associated with higher rates of existential self-fulfillment. Such individuals are more inclined to stay in dialogical exchange with the world and to get closer to evocation of their essential personal life sense. It was empirically confirmed that narcissistic selfregulation, which was investigated as the general manifestation of Self's power, stays in statistically significant relations to subscales of personal self-fulfillment and life satisfaction indicators. That says: the more adequate narcissistic self-regulation is - the more effective is disclosure of human's personality, ability to transcend and experience freedom; such people are more able to take responsibility on their "being" and "living", life feels as more meaningful and filled with individual vital senses and values.

Narcissistic self-regulation may have an impact on the authentic perception of one's Self, may assist in opening up the opportunity to see and feel values in life and integrating them into personal experience.

Keywords: narcissism, narcissistic self-regulation, psychoanalysis, self-fulfillment, self-system, self-value, existentiality, personal life senses.

\section{References.}

1. Deneke, F.-W. (1994) Die Regulation des Selbsterlebens bei Gesunden, psychosomatischen, psychoneurotischen und alkoholkranken Patientenein taxonomischer Forschungsansatz. Psychotherapie, Psychosomatik und medizinische Psychologie, 44, 260-280.

2. Gewirth A. (1998) Self-Fulfillment. Princeton University Press, 10-20.

3. Kernberg, O. (1984) Severe personality disorders: Psychotherapeutic strategies. New Haven, CT: Yale University Press, 70-105.

4. Kohut H. (1971) The Analysis of the Self: A Systematic Approach to the Psychoanalytic Treatment of Narcissistic Personality Disorders, New York, International Universities Press, 123-134, 223-260.

5. Klymenko M. (2017) Self-regulatory features of the «healthy» narcissism. Problemy suchasnoi psykholohii. Zbirnyk naukovykh prats Kamianets-Podilskoho natsionalnoho universytetu imeni Ohiienka; Instytutu psykholohii imeni H.S. Kostiuka NAPN Ukrainy - Kamianets-Podilskyi National Ivan Ohiienko University, G. S. Kostiuk Institute of Psychology at the National Academy of Pedagogical Science of Ukraine, 37, 142-155 (In Ukrainian).

6. Längle A (2004) Objectives of Existential Psychology and Existential Psychotherapy. International Journal of Existential Psychology and Psychotherapy, 1, 99-102.

7. Längle A. (2011). The existential fundamental motivations structuring the motivational process. Leontiev DA

(Ed) Motivation, Consciousness and Self-Regulation. Hauppauge, New York: Nova, 27-42.

8. Schneider K, Längle A (2012). The renewal of humanism in psychotherapy: Summary and conclusion. Psychotherapy, 49 (4), 480-481. 


\section{Multidisciplinary Approach to Research of the Adherence to Treatment Phenomenon in Patients with Diabetes Mellitus}

(Anna Kogut ${ }^{1}$, M. Bobryk ${ }^{1}$, O. Potapov ${ }^{2}$, I. Frankova ${ }^{1}$, J. Komisarenko ${ }^{1}$, O. Khaustova ${ }^{1}$, O. Chaban ${ }^{1}$ )

${ }^{1}$ Bogomolets National Medical University, Kyiv, Ukraine

${ }^{2}$ Center for Innovative Medical Technologies of the National Academy of Sciences of Ukraine, Kyiv, Ukraine

Background: Diabetes Mellitus (DM) - is one of the most common chronic diseases, and its control are affected by the patients' psychological attributes (Esmaeilinasab et al., 2016). The number of patients with this disease is expected to increase in a future. Given the increasing prevalence of DM, there is an urgent need for the treatment of DM and associated complications. Glycemic control largely depends on compliance with medication therapy. In fact, the most common problem in patients with DM - is a lack of medication compliance (Shamsi, Khodaifar, Arzaghi, Sarvghadi, Ghazi, 2014). For example, laboratory data of single components of the metabolic syndrome, according to International Diabetes Federation Consensus were dependent measures in multivariable regression models with self-reported alexithymia severity (TAS-20) and socio-demographic data. Alexithymia is a clinical trait, consisting of the diminished introspective and interoceptive capacities that has been shown to implicate elevated autonomic outflow and to bias for hypertension (Lemche, Chaban, Lemche, 2014). One of the challenges in promoting adherence is having an accurate understanding of adherence rates and the factors that contribute to non-adherence (Lehmann et al., 2014). It's essential to consider the clinical assessment of psychological aspects in patients with DM, in order to prevent potentially adverse self-management care behaviors leading to diabetes-related complications, including declining levels of Life Quality (Conti et al., 2017). Patient`s quality of life is one of the principal component in clinical decision-making (Chaban, Khaustova, Bezsheiko, n.d.).

Purpose: Improving the effectiveness of DM patients' therapy and demonstrating the consequence of psychosocial factors on their adherence to treatment.

Method: This study was conducted during the period from July to August 2017 on the basis of the Kyiv Endocrinology Center and the Department of Endocrinology in a partnership with the Department of Medical Psychology, Psychosomatic Medicine and Psychotherapy of the Bogomolets National Medical University. Study population $(n=60)$ consists of two comparative groups $(C G)$ of the patients with DM type $1(D M 1)(n=16)$ and type 2 (DM2) ( $\mathrm{n}=33$ ), other patients had newly diagnosed DM of both DM1 and DM2. Study data consists of: hospital chart data (including: age, demographic data, body mass index, level of systolic and diastolic arterial pressure, blood glucose and glycated hemoglobin (HbAlc); psychometric validated scales (including: Medication Compliance Scale (MCS), Holmes and Rahe Stress Scale (HRSS), Dysfunctional attitudes Scale (DAS), Toronto Alexithymia Scale (TAS-20), the Depression, Anxiety and Stress Scale (DASS-21) and Chaban Quality of Life Scale (CQLS). Glycemic control was assessed by HbA1c results.

The statistics analysis was performed by using descriptive statistics and Pearson's correlation with MS Excel and SPSS Statistics 22.0.

Results: Statistically significant difference was found between groups of patients with high (HC), middle (MC) and low level of compliance (LC) according to MCS. Patients with LC had statistically higher level of HbA1c results according to MCS (LC (M=13), SD:1 vs. MC (M=9.83), SD:1.4 vs. HC (M=9), SD:1.4). Average values by MCS results for CG - DM1 $(M=19)$ and DM2 $(M=18)$ present MC; by HbA1c results - DM1 $(M=10)$ and DM2 $(M=10)$ at the same level. So, there was no significant statistically difference found between scores by the results in CG.

A significant bilateral indirect correlation was found between the results by MCS (LC) with high level of the DAS, TAS-20, DASS-21, HRSS scores on level $\mathrm{p}<0,001$ and direct by CQLS $(r=0,37)$ results on $\mathrm{p}<0,01(\mathrm{HC})$. The relationship was also found between the scores by: 1) DAS (direct) - with the indicators of age, blood glucose level and depression, on level $\mathrm{p}<0,05$, alexithymia, stress and anxiety (DASS-21) on p<0,01;2) CQLS (indirect) - with the DAS $(\mathrm{r}=-0,28)$ and TAS-20 ( $\mathrm{r}=-0,29)$ results - on $\mathrm{p}<0,05$, stress $(\mathrm{r}=-0,36)$ on $\mathrm{p}<0,01$ and depression (DASS-21) $(\mathrm{r}=-0,48)$ on $\mathrm{p}<0,001 ; 3)$ TAS-20 (direct) - with the DASS-21 subscales results on $\mathrm{p}<0,01$.

There was found the strong relationship between LC in DM patients with high level by the scores of psychometric scales and laboratory indicators of HbA1c, as evidenced, that patients with LC most often had mental disorders and low rates of treatment effectiveness.

Conclusions: Adherence to treatment was not depended on the type of diabetes and diagnosis. LC and quality of life addicted, in consequence to non-adherence and respectively - inefficiency of DM patients' treatment. So, a multidisciplinary approach - involving psychologists for the improving adherence to therapy together with endocrinology specialists, can potentially improve treatment effectiveness. 
Originality: The compare of DM patients' indicators by the psychosocial status, demographic data and level of compliance, depending on the type of diabetes and diagnosis.

Limitations of the study: The low sample of patients which is planned to correct in further studies.

Strenghs of the study: The concept of "adherence to treatment" is so much spacious unlike the concept of "compliance", which is signifying only a strict adherence to the prescription of a doctor. Adherence to treatment - is a complex of the external and intrinsic factors by the patients' environment and their characteristics as personalities, in a medication aspect. It is an extensive scope for studying and researching both in the fields by the clinical and social sciences directions. Multidisciplinary research would be perspective for a future, because different specialists in distinctive spheres may be unite with the general idea to solving the problem of comorbid.

Keywords: diabetes, health, health care, medical, medical research, medical science, medicine, mental health, mental illness, mental stress, psychology, quality of life, research, scientific research, social well-being.

\section{References.}

1. Chaban, O., Khaustova, O., Bezsheiko, V. (n.d.). Reliability and validity of Chaban Quality of Life Scale. Retrieved from https://www.ecnp.eu/presentationpdfs/70/P.2.h.301.pdf

2. Conti, C., Di Francesco, G., Fontanella, L., Carrozzino, D., Patierno, C., Vitacolonna, E., Fulcheri, M. (2017). Negative Affectivity Predicts Lower Quality of Life and Metabolic Control in Type 2 Diabetes Patients: A Structural Equation Modeling Approach. Front Psychol. 24;8:831. doi: 10.3389/fpsyg.2017.00831

3. Esmaeilinasab, M., Ebrahimi, M., Mokarrar, MH., Rahmati, L., Mahjouri, MY., Arzaghi, SM. (2016). Type II diabetes and personality; a study to explore other psychosomatic aspects of diabetes. J Diabetes Metab Disord. 3;15:54. doi: 10.1186/s40200-016-0281-3

4. Lehmann, A., Aslani, P., Ahmed, R., Celio J., Guchet A., Bedouch P., Bugnon O., Allenet B., Schneider MP. (2014). Assessing medication adherence: options to consider. Int J Clin Pharm. 36(1):55-69. doi: 10.1007/s11096-013-9865-x

5. Lemche, A., Chaban, O., Lemche, E. (2014). Alexithymia as a risk factor for type 2 diabetes mellitus in the metabolic syndrome: a cross-sectional study. Psychiatry Res. 215(2):438-43. doi: 10.1016/j.psychres.2013.12.004

6. Shamsi, F., Khodaifar, F., Arzaghi, SM., Sarvghadi, F., Ghazi, A. (2014). Is there any relationship between medication compliance and affective temperaments in patients with type 2 diabetes? (2014). J Diabetes Metab Disord. 27;13(1):96. doi: 10.1186/s40200-014-0096-z 


\title{
The Influence of the Emotional Intelligence Features on the Intensity of the Loneliness Experience in Adolescence
}

\author{
(Lyudmyla Kolisnyk) \\ Sumy State University, Sumy, Ukraine
}

\begin{abstract}
Introduction. At the present stage of our society development under the conditions of social, economic, political, cultural transformations, industrialization and urbanization, intensive technology development, oversaturation of information and, as a consequence, human inclusion into more and more number of superficial social contacts, the problem of loneliness is becoming especially sharp. It represents an emotional state of the personality, connected with the absence of close, positive emotional ties with others or the fear of their loss and is affected a psychological wellbeing and the life quality in general.
\end{abstract}

The problem of loneliness appears in the human life at every age stage. However, it is particularly acute in adolescence, as it prevents solving age-related problems associated with the development of personal reflection and self-awareness, with the acute need for communication and deep emotional-rich interpersonal relationships, with further professional development.

It should be noted that the phenomenon of loneliness as an experience has both a positive and a negative modality. Winnicott (1960) describes the ability to be alone as one of the most important signs of the maturity of human emotional development. Brennan (1982) and also Sadler (1989) distinguish spiritual and space loneliness, which are related to the search for their identity and meaning of life. Also Peplau (1989) noted: ". solitude is not necessarily connected with loneliness; people can be happy being alone" (p. 171).

However, despite the fact that loneliness can be a positive experience, there is a negative side of this phenomenon. This is evidenced, for example, by the list of negative experiences that overwhelm the lonely person: anxiety, despair, sadness, anguish, impatience, helplessness, fear, boredom, isolation, pity and disgust to oneself, irritation, anger on others, melancholy, alienation, suspicion etc. (Shagivaleeva, 2007). The negative nature of loneliness (loneliness as a problem) manifests itself as follows: loneliness has the ability to subordinate to itself other psychic processes and conditions; violates the internal integrity of the individual; can act as a mechanism of psychological defense; leads to the formation of suppositions and revaluation of the contribution of another person in their own development. According to Kon (1989), loneliness - is "anguish, a subjective state of isolation, incomprehensibility, a sense of dissatisfied with the need for communication, human intimacy" (p. 180).

Thus, loneliness poses a threat to the positive development of personality. Therefore, in our opinion, this phenomenon requires research and intervention, first of all, in the context of its negative manifestation. We consider loneliness as a negative subjective experience of the individual, which arises either in a state of isolation, or even with the objective involvement of person in various spheres of social life and communication, and accompanied by feelings of abandonment, alienation, uselessness (Lashuk, 2010).

Related Work. An overview of the causes of the negative experience of loneliness in adolescence indicates that one of the most relevant factors in overcoming loneliness is the development of flexible social skills for implementing oneself in a social context for the manifestation of their own singularity as an opportunity. A phenomenon that combines a number of such skills is described in the scientific literature as emotional intelligence. Authors of the term "emotional intelligence" (Mayer, Salovey, \& Caruso, 2000) define it as the ability to perceive and express emotions, to understand and use them, to manage emotions in such a way as to promote their personal growth.

Conducted studies revealed the existence of a correlation between the level of emotional intelligence development and psychological well-being and the personal success of youngsters, which affects their experience of loneliness (Mayer, \& Salovey, 1997; Vahrusheva, 2011; Derev'janko, 2009; Myloslavs'ka, 2011). Meyer and Selovey (1997) also describe a study in which students with a higher emotional intelligence have had greater success in their relationships (in interaction with the opposite sex). Miloslavskaya (2011) describes the revealed correlation between the components of communicative and social competence, components of social intelligence, communicative skills and the emotional intelligence level of students. According to her studies there is a correlation between the level of such emotional intelligence component as recognition of emotions of other people and the separate elements of communicative and social competence and social intelligence. The obtained results confirm the existence of the correlation between the components of emotional intelligence and the components of social and communicative competence, components of social intelligence and communicative skills (Miloslavskaya, 2011).

Vakhrusheva (2011), studying the expressiveness of structural and qualitative characteristics of emotional intelligence in adolescence and early adulthood, found that high rates of emotional intelligence are related to the 
vector of benevolence in communication, such characteristics as humility, conformance, tendency to compromise, congruency and responsibility in contacts with others.

Thus, an overview of the above described works allows us to make an assumption about the existence of the correlation between the features of emotional intelligence and the intensity of the loneliness experience in adolescence.

Purpose. The purpose of the paper is to highlight the results of the empirical study on the correlation between the emotional intelligence features and the intensity of the loneliness experience in adolescence.

Methodology. 255 students from the Ukrainian higher educational establishments volunteered to participate in the presented study. There were 93 male and 162 female participants from 16 to 25 years old. The characteristic of the sample is due to the determinated chronological limits of the adolescence.

To solve the research tasks, we used the following psychodiagnostic tools: 1) the UCLA Loneliness Scale (D. Russell, M. Ferguson); 2) Social and Emotional Loneliness Scale for Adults / SELSA (E. Di Tomaso); 3) Meyer-Selovey-Caruso Emotional Intelligence Test / MSCEIT (J. Meyer, P. Selovey, D. Caruso); 4) Emotional Intelligence Questionnaire / EMIN (D.V. Lyucyn). All questionnaires and test were printed and disseminated among students. Participants were asked to respond to a series of questions of the above mentioned questionnaires and to solve the tasks from the Meyer-Selovey-Caruso Emotional Intelligence Test. They also had to give some demographic information about themselves: age and sex. Then the data were collected, processed and analyzed. The correlational analysis of the obtained data was done with a help of Spearman's Rank Correlation in SPSS Statistics.

Results. It was found that $88.24 \%$ of respondent's experience loneliness from time to time, in certain life situations. They are only partially or selectively satisfied with their social contacts and emotional ties. A large proportion of young people, above all, experienced significant deficits of emotional attachment in the field of romantic relationships. A high level of romantic loneliness was demonstrated by $1.57 \%$ of respondents, and the average one is observed in $81.18 \%$ of the interviewed youth. Social links also often did not satisfy the desires of boys and girls - both their quantity and quality. Thus, the average level of social loneliness is peculiar to $79.61 \%$ of boys and girls.

The research of the emotional intelligence of the youngsters found that a large number of students $-37 \%-$ had an average level of the emotional intelligence development. A significant proportion of young people were characterized by low (17\%) and very low (20\%) levels of emotional intelligence. Such data were the result of the use of questionnaires in the form of self-report (EMIN, Lyusyn). An expert assessment of the skills of boys and girls to understand and manage emotions (MSCEIT) showed that the average level of the integral index of emotional intelligence had $64.5 \%$ of the respondents, the lowest $-34.5 \%$, and the high one - only $1 \%$.

As for the link between the depth of the loneliness experience and the level of the emotional intelligence development, the obtained results of correlation analysis have been presented in the table No. 1.

The analysis of this correlation table showed that a negative correlation was found at a high level of statistical significance $(\mathrm{p} \leq 0,01)$ between the general scale of loneliness and the general index of emotional intelligence. It concerns both Meyer - Selovey - Caruso emotional intelligence test $(r=-, 220)$, and Lyucyn questionnaire $(r=-$ , 294). A similar tendency was observed in relation to the link of separate scales of emotional intelligence with the general index of loneliness. Thus, at a high level of statistical significance $(p \leq 0,01)$, a negative correlation was found between the general loneliness index and such Meyer-Selovey-Caruso scales, as "emotional understanding" ( $\mathrm{r}=-, 210)$ and "emotional control" ( $\mathrm{r}=-, 271)$; as well as the following Lyucyn questionnaire scales: "interpersonal intelligence" $(\mathrm{r}=-, 254)$ and "intrapersonal intelligence" $(\mathrm{r}=-, 265)$, "interpersonal emotional management" ( $\mathrm{r}=-, 310)$ and "intrapersonal emotional management" $(\mathrm{r}=-, 335)$, "emotional understanding" $(\mathrm{r}=-, 204)$ and "emotional control" $(\mathrm{r}=-, 321)$, "interpersonal understanding of emotions" ( $\mathrm{r}=$ , 187). 
Table 1. Correlation between the loneliness scales of E. DiTomasso and Russell-Ferguson questionnaires and emotional intelligence scales of Lyucyn questionnaire (EMIN) and MSCET (Spearman rank correlation) $\mathrm{N}=$ 255

\begin{tabular}{|c|c|c|c|c|c|c|c|c|}
\hline \multirow{3}{*}{ 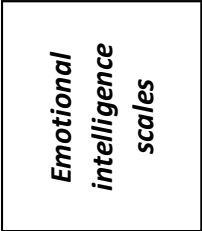 } & \multicolumn{6}{|c|}{ Social and Emotional Loneliness Scale for Adults (E. Di Tomaso) } & \multirow{2}{*}{\multicolumn{2}{|c|}{\begin{tabular}{|c|}
$\begin{array}{c}\text { UCLA (D. Russell, M. } \\
\text { Ferguson) }\end{array}$ \\
general loneliness
\end{tabular}}} \\
\hline & \multicolumn{2}{|c|}{ romantic loneliness } & \multicolumn{2}{|c|}{ family loneliness } & \multicolumn{2}{|c|}{ social loneliness } & & \\
\hline & Correlation & Significance & Correlation & Significance & Correlation & Significance & Correlation & Significance \\
\hline \multicolumn{9}{|l|}{ EMIN Lyusyn } \\
\hline Interp.underst. &,$- 140^{\circ}$ & $p \leq 0,05$ &,- 111 & $\mathrm{~ns}$ &,- 096 & $\mathrm{~ns}$ &,$- 155^{*}$ & $\mathrm{p} \leq 0,05$ \\
\hline Interp.control &,$- 150^{\circ}$ & $p \leq 0,05$ &,$- 147^{\circ}$ & $p \leq 0,05$ &,$- 219^{* \star}$ & $p \leq 0,01$ &,$- 310^{* * 1}$ & $p \leq 0,01$ \\
\hline Intrap.underst. &,- 196 & $p \leq 0,01$ &,$- 123^{*}$ & $\mathrm{p} \leq 0,05$ &,- 105 & $\mathrm{~ns}$ &,$- 187^{*+1}$ & $p \leq 0,01$ \\
\hline Intrap.control &,$- 149^{\circ}$ & $\mathrm{p} \leq 0,05$ &,- 110 & $\mathrm{~ns}$ &,$- 166^{* *}$ & $\mathrm{p} \leq 0,01$ &,$- 335^{* *}$ & $\mathrm{p} \leq 0,01$ \\
\hline Expr. Control &,- 040 & $\mathrm{~ns}$ &, 013 & $\mathrm{~ns}$ &, 044 & $\mathrm{~ns}$ &,- 029 & $\mathrm{~ns}$ \\
\hline Interp.EI &,- 162 & $p \leq 0,01$ &,$- 144^{\circ}$ & $\mathrm{p} \leq 0,05$ &,$- 170^{\star \star}$ & $\mathrm{p} \leq 0,01$ &,$- 254^{* t+}$ & $p \leq 0,01$ \\
\hline Intrap.EI &,$- 180^{\circ}$ & $p \leq 0,01$ &,$- 129^{\circ}$ & $p \leq 0,05$ &,$- 136^{*}$ & $p \leq 0,05$ &,$- 265^{* *}$ & $p \leq 0,01$ \\
\hline $\begin{array}{c}\text { Underst. of } \\
\text { emotions }\end{array}$ &,$- 209^{* *}$ & $p \leq 0,01$ &,$- 130^{\circ}$ & $p \leq 0,05$ &,- 114 & ns &,$- 204^{* *}$ & $p \leq 0,01$ \\
\hline $\begin{array}{c}\text { Emotional } \\
\text { control }\end{array}$ &,$- 155^{*}$ & $p \leq 0,05$ &,- 124 & $p \leq 0,05$ &,$- 181^{\star *}$ & $p \leq 0,01$ &,$- 321^{* *}$ & $p \leq 0,01$ \\
\hline$E I$ &,$- 197^{* \prime}$ & $p \leq 0,01$ &,$- 145^{\circ}$ & $\mathrm{p} \leq 0,05$ &,$- 160^{*}$ & $\mathrm{p} \leq 0,05$ &,$- 294^{*+4}$ & $p \leq 0,01$ \\
\hline \multicolumn{9}{|l|}{ MSCEIT } \\
\hline $\begin{array}{l}\text { Identif. of } \\
\text { emotions }\end{array}$ & ,006 & ns &,$- 205^{* *}$ & $p \leq 0,01$ &,$- 127^{\star}$ & $p \leq 0,05$ &,- 046 & ns \\
\hline $\begin{array}{c}\text { Use of } \\
\text { emotions }\end{array}$ &,- 025 & ns &,$- 182^{* * *}$ & $p \leq 0,01$ &,$- 208^{* *}$ & $p \leq 0,01$ &,$- 154^{*}$ & $p \leq 0,05$ \\
\hline $\begin{array}{l}\text { Underst. of } \\
\text { emotions }\end{array}$ & ,026 & ns &,$- 327^{* *}$ & $p \leq 0,01$ &,$- 290^{\star \star}$ & $p \leq 0,01$ &,$- 210^{* *}$ & $p \leq 0,01$ \\
\hline $\begin{array}{c}\text { Emotions } \\
\text { control }\end{array}$ &,- 025 & ns &,$- 368^{* *}$ & $p \leq 0,01$ &,$- 306^{\star \star}$ & $p \leq 0,01$ &,$- 271^{* *}$ & $p \leq 0,01$ \\
\hline EI &,- 012 & ns &,$- 362^{*+1}$ & $p \leq 0,01$ &,$- 317^{\star \star}$ & $p \leq 0,01$ &,- 220 & $p \leq 0,01$ \\
\hline
\end{tabular}

The statistically significant correlation $(\mathrm{p} \leq 0.05)$ was found between the general indicator of loneliness and the scale of "use of emotions" of the MSCEIT ( $\mathrm{r}=-, 154)$, as well as the "interpersonal understanding" scale of the Lyusin questionnaire ( $\mathrm{r}=-, 155)$.

Regarding separate types of loneliness, a negative correlation at a high level of statistical significance $(p \leq 0,01)$ was observed between romantic loneliness and such Lyucyn questionnaire scales as an "interpersonal intelligence" $(\mathrm{r}=-, 162)$ and "intrapersonal intelligence" $(\mathrm{r}=-, 180)$, "intrapersonal understanding of emotions" $(\mathrm{r}=-, 196)$ and "other people emotions understanding" $(\mathrm{r}=-, 155)$, as well as emotional intelligence in general $(\mathrm{r}=-, 197)$. The statistically reliable connection $(\mathrm{p} \leq 0,05)$ was established between romantic solitude and such Lyucyn questionnaire scales as an "interpersonal understanding" $(\mathrm{r}=-, 140)$ and "interpersonal management" $(\mathrm{r}$ $=-, 150)$, “interpersonal management" $(\mathrm{r}=-, 149)$ and emotional management in general $(\mathrm{r}=-, 155)$.

The data of the mathematical analysis showed a statistically significant correlation $(\mathrm{p} \leq 0,05)$ between family loneliness and such scales of Lyucyn questionnaire as "interpersonal emotional intelligence" $(\mathrm{r}=-, 144)$ and "intrapersonal emotional intelligence" $(\mathrm{r}=-, 129)$, "emotions understanding" $(\mathrm{r}=-, 130)$ and "emotions control" $(\mathrm{r}=-, 124)$, "interpersonal emotions management" ( $\mathrm{r}=-, 147)$ and intrapersonal emotions understanding" $(\mathrm{r}=-$, 123), emotional intelligence in general $(\mathrm{r}=-, 145)$. At the high level of statistical significance $(\mathrm{p} \leq 0,01)$, a correlation was found between family loneliness and all MSCEIT scales: "identification of emotions" $(\mathrm{r}=-$, 205), "use of emotions" ( $\mathrm{r}=-, 182)$, "understanding of emotions" ( $\mathrm{r}=-, 327)$, "emotional control" $(\mathrm{r}=-, 368)$ and emotional intelligence in general $(\mathrm{r}=-, 262)$.

Negative correlation at a high level of statistical significance was also found between social loneliness and such Lyucyn questionnaire scales as "interpersonal emotions control" ( $\mathrm{r}=-, 219)$ and "intrapersonal emotions control" ( $\mathrm{r}=-, 166)$, emotional management in general $(\mathrm{r}=-, 181)$ and "interpersonal intelligence" $(\mathrm{r}=-, 170)$; as well as MSCEIT scales: using emotions ( $\mathrm{r}=-, 208)$, understanding emotions $(\mathrm{r}=-, 290)$, emotions control ( $\mathrm{r}$ $=-, 306)$ and emotional intelligence in general $(\mathrm{r}=-, 317)$. Statistically significant correlation $(\mathrm{p} \leq 0.05)$ was found between social loneliness and such Lyucyn questionnaire scales as "interpersonal emotional intelligence" 
$(\mathrm{r}=-, 160)$ and emotional intelligence in general $(\mathrm{r}=-, 136)$, as well as the MSCEIT scale "identification of emotions" ( $r=-, 127)$.

Limitations and strengths of the study. The obtained results provide a better understanding on the problem of loneliness in adolescence; let to distinguish different types of this loneliness. The study gives the possibility to compare results of the emotional intelligence that has been received with a help of using different approaches $-\mathrm{a}$ questionnaire in the form of self-report, and the one that envisioned an expert assessment. Sometimes results differ from each other that points to the importance of the approach. Nevertheless, there are correlations between different emotional intelligence features and loneliness (separate types and general loneliness) in spite of chosen approach.

The study is limited in a certain way because of lack of the sample variety. Only students of higher educational establishments were the participants of the study. It would be useful to include participants from other social categories.

Social value. So, the results of the empirical study suggest that there is a problem of loneliness in adolescence. This is evidenced by a rather high average indicator of loneliness in general, as well as its separate types: family, social and romantic loneliness.

Young people demonstrate lack of the ability to identify both their own emotions and the emotions of other people; they also have poorly developed ability to express accurately emotions and needs associated with them; they are not smart enough to distinguish accurate and inaccurate, true and false feelings. Young people are mostly not able to use emotions to focus on important information and to trigger emotions that will help them to solve certain problems. The ability to distinguish between emotions, in particular, verbal level, to understand causal relationships, to notice the sudden change of emotions, to understand the complexes of ambivalent feelings need to be improved. The obtained results demonstrate insufficient ability of respondents to be open to emotions, to cause or to get rid of certain emotions consciously, to manage the emotional states of other people.

Conclusions. Thus, the determined data analysis allows to conclude that there is a link between the level of the emotional intelligence development and the depth of loneliness experience in adolescence. The peculiarity of this connection is that with an increase in the level of emotional intelligence development there is a decrease in the depth and intensity of the loneliness experience. The lack of young people's ability to identify, understand, use and manage emotions affects their emotional and social satisfaction and, consequently, the associated experience of loneliness. The worse the abilities of emotional intelligence are developed, the deeper the experience of loneliness.

The link between the separate types of loneliness and the level of emotional intelligence development in general and the prevailing number of its components in particular, is revealed. Complete lack of correlation is observed only between romantic loneliness and emotional intelligence, established by means of an expert assessment of these abilities development.

A further prospect of development of this problem is the identification other factors of the loneliness occurrence, the development and implementation of appropriate psycho-correction programs aimed at loneliness prevention and overcoming.

Keywords: personality, psychology, young person.

\section{References.}

1. Brennan, T. (1982). Loneliness at Adolescence. In: Ed. L.A. Peplau, Perlman. Loneliness. A Sourcebook of Current Theory, Research and Therapy. A Wiley Interscience Publication, 269-290.

2. DiTomaso, E., \& Spinner, B. (1993). The development and initial validation of the social and emotional loneliness scale for adults (SELSA). Personal individual differences, 14/1, 127-134.

3. Hawkley, L.C., \& Cacioppo, J.T. (2010). Loneliness Matters: A Theoretical and Empirical Review of Consequences and Mechanisms. The Society of Behavioral Medicine, 40 (2), 218-227.

4. Jong-Gierveld, J.D., \& Raadschelders, J. (1982). Types of loneliness In: L.A. Peplau, D. Perlman, eds. Loneliness: a sourcebook of current theory, research and therapy. New York: Wiley, 21-39.

5. Killeen C. (1998). Loneliness: an epidemic in modern society. Journal of Advanced Nursing, 28(4), 762770.

6. Mayer, J.D., \& Salovey, P. (1997). What is emotional intelligence. In: P. Salovey, D. Sluyter (Eds.). Emotional development and emotional intelligence: Implications for educators. New York: Basic Books, 3-31.

7. Mayer, J.D., Salovey, P., \& Caruso, D. (2000). Models of emotional intelligence. In: Sternberg. Handbook of Intelligence. Cambridge : Cambridge University Press, 396-420.

8. Winnicott, D.W. (1960). The capacity to be alone. The Maturational Processes and the Facilitating Environment. London: Hogarth Press, 29-36. 
9. Vahrusheva, L.N. (2011). Vyrazhennost' strukturnyh i kachestvennyh harakteristik jemocional'nogo intellekta na jetape junosti i rannej vzroslosti [The features of the structural and qualitative characteristics of emotional intelligence in adolescence and early adulthood]. Candidate's thesis. Moscow [in Russian].

10. Derev'janko, S.P. (2009). Emocijnyj intelekt jak chynnyk social'no-psyhologichnoi' adaptacii' osobystosti do students'kogo seredovyshha [Emotional intelligence as a factor in the individual socio-psychological adaptation to the student environment]. Extended abstract of candidate's thesis. Kyiv [in Ukrainian].

11. Kon, I.S. (1989). Psihologija rannej junosti: Kn. dlja uchitelja [Psychology of early adolescence: Book for the teacher]. Moscow: Prosveshhenie [in Russian].

12. Lashuk,V.G. (2010). Psyhologichni osoblyvosti perezhyvannja samotnosti v junac'komu vici [Psychological peculiarities of the experience of loneliness in adolescence]. Candidate's thesis. Kyiv [in Ukrainian].

13. Myloslavs'ka, O.V. (2011). Emocijnyj intelekt jak skladova komunikatyvnoi' kompetentnosti studentiv [Emotional intelligence as a component of students' communicative competence]. Kharkyv [in Ukrainian].

14. Peplo, L.Je. (1989). Odinochestvo i samoocenka [Loneliness and self-esteem]. Moscow: Progress [in Russian].

15. Sadler, U.A. \& Dzhonson, T.B. (1989). Ot odinochestva $k$ anomii [From loneliness to anomie]. Labirinty odinochestva - Labyrinths of loneliness, (pp. 21-51). Moscow: Progress [in Russian].

16. Shagivaleeva, G.R. (2007). Odinochestvo $i$ osobennosti ego perezhivanija studentami [Loneliness and peculiarities of its experience by students]. Elabuga: Izd-vo OAO «Almedia» [in Russian]. 


\section{Group Support for Vulnerable Groups as a Prerequisite for Mental Health}

(Olha Korobanova)

Institute for Social and Political Psychology, National Academy of Educational Sciences of Ukraine, Kyiv, Ukraine

Introduction. Internally displaced persons have experienced stress and need to improve their attitudes towards difficult life circumstances and rethink the meaning of their own behavior for a positive transformation of these circumstances. Group support which refugees receive in groups of like-minded people and people with a similar life story has a beneficial effect on them.

The purpose of the study: identify the risks and peculiarities of the situation in which the refugees find themselves; to investigate the nature of changes in the group aspect of their life situation, namely, personal contacts, relationships, and role communication; identify strategies and behavior applied by internally displaced persons in order to minimize the impact of the prevailing circumstances, to adapt and reintegrate into new groups.

Theoretical part. Design. The study was conducted in temporary groups formed by chance from those participants who came to the master classes on the announcement. The study involved 189 participants aged from 20 to 63, who were included in 25 groups.

Methodology: the included observation of groups in the course of their work, methods of action, conversation, study of the repertoire of vital roles, as well as art therapy techniques, in particular the "I'm in a group" collage, thematic drawings of contact groups in time context, visualization of established communication circle etc.

Results and discussion. Internally displaced persons lose regular contact with many people with whom they had previously closely communicated. This entails corresponding experiences, as well as a modification of the format of these contacts. Loss of groups and separation from close people leads to modification of role communication. The repertoire of life roles in the direction of detachment, the desire to look at the situation in which a person found himself, from the side, to become an "observer" is significantly reduced. Another positive aspect of the modifications is the provision of assistance and support to others who have similar problems.

The subjects of social behavior are able to self-regulate their own lives, activities, actions, on the basis of previously internalized patterns of behavior, which include desirable development of future events and situations. The person is included in the society and realizes needs, desires and goals by performed in groups` roles. The availability of inclusion causes "interpersonal" (The principles of cognitive communication psychology, 2013) or personality-role interrepresentation as a value-sense and role coherence of the intersubjective field of participants in group interaction. On this basis person create role models of human actions in a particular interaction situation. The process of personality-role modeling is a psychological mechanism for the development of roles as a way of action in a variety of situations (Korobanova, 2017). In our opinion, role-based dimensions of personality are role mobility, variability and differentiation. Uniting into groups of belonging, relying on the feeling of group identity in overcoming the hopelessness as building plans for the future in a group of like-minded people is often peculiar to people in difficult life circumstances.

Group support of participants were associated with acceptance, support, care, ability to solve problems, the emergence of a sense of confidence, relief, communication from the standpoint of equality, based on the principles of justice, goodness, leading to self-realization. As a result their inner world harmonized. Under such conditions, inclusion in the group with a similar history serves as a psychological support function.

It is important to pay attention to the process of setting boundaries during communication. Psychological borders may be marked by the psychological distance, positive or negative emotional manifestations, as well as the definition of similar or different values. Thus, socio-psychological resources to overcome complex life situations and their consequences by vulnerable groups are inclusion in the group, establishment and maintenance of communication links, abilities to identify and support social and psychological boundaries.

Conclusions: the loss of groups and people with whom the refugees maintained communication leads to the loss of communication roles. This phenomenon can be viewed in a positive way, since it releases psychological resources for adaptation and overcoming the prevailing circumstances. There is a comprehension, planning as a condition for refugees to build new models of behavior in the changed circumstances.

Inclusion in groups of internally displaced persons provides them with psychological support and activates resources of overcoming behavior. In general, the group component and, in particular, the availability of group support is important for the mental health and psychological well-being of refugees. Changing the circumstances of living in difficult life situations leads to the loss of groups and psychological roles, as well as the acquisition of new ones; therefore, role-based flexibility, variability and differentiation are important factors in overcoming such situations and their consequences. 
Keywords: stress, aid to refugees, communication practices, communication skills, social role, social protection, mental health, right to health.

\section{References.}

1. The principles of cognitive communication psychology (2013) [Zasady kohnityvnoi psykholohii spilkuvannia] Kazmirenko V. P. [Ed.] Kirovohrad, Imeks-LTD. [in Ukrainian].

2. Korobanova O. L. (2017) Personal-role modeling of active social behavior by youth [Osobystisno-rolove modeliuvannia moloddiu aktyvnoi sotsialnoi povedinky]. Scientific studies on social and political psychology [Naukovi studii z sotsialnoi ta politychnoi psykholohii]. 40 (43). 147-156. Kyiv, Zoloti Vorota. [in Ukrainian]. 


\title{
Public Health Strengthening in the Context of Community Adaptation to the Consequences of a Military Conflict: Salutogenic Approach
}

\author{
(Larysa Korobka)
}

Institute for Social and Political Psychology, the National Academy of Educational Sciences of Ukraine, Kyiv

Introduction. When a problem of strengthening public health in the process of community adaptation to the consequences of a military conflict is being analysed, special attention is paid to finding factors of promotion the well-being and personal growth of a member of a community. In respect to this, we do believe that salutogenic approach (from Latin 'salus' - well-being, happiness) can be the footing for strengthening both individual and public health as well as for constructive behavioural and social changes.

Approach. The study of this problem is based on a salutogenetic concept (A.Antonovsky, 1984; 1996) and its main notion - "sense of coherence" (SOC), which includes three components - "comprehensibility", "manageability", "meaningfulness" - as a health key element and a determining factor for public health improvement and maintenance.

As well as that we are guided by understanding adaptation as a capacity for restorative efforts of both an individual, a family, and a community (F.H.Norris, V.Pfefferbaum, S.Stevens, 2008), where the concept of "resilience" is defined as:

- viability, resistance to trauma, psychological flexibility;

- dynamic process in which positive adaptation takes place in conditions of trouble;

- well-being maintenance despite these difficulties (G.Bonanno, 2007; N.Garmezy, 1986).

Along with that we regard adaptation in difficult life situations as a process of "positive adaptation" or "posttraumatic growth" which is the result of accepting and dealing with the reality accompanied by positive changes at the level of personality, group, and society (R.Tedeschi, L.Calhoun, 2004; S.Joseph, P.Linley, 2006; M.Seligman, 2000; V.Klimchuk, 2016).

As modern psychological research shows, sense of coherence (S.Suominen, H.Blomberg, 2001), resilience (A.Morgan, 2007; F.H.Norris, 2008) and post-traumatic growth (R.Tedeschi, L.Calhoun, 2004) are connected with health, well-being and orientation to healthy lifestyle.

Purpose. This paper is focused on study the connection of SOC with indicators of subjective assessment of the state of health, well-being, quality of life, sense of security, adaptability to the consequences of a military conflict. The purpose of the study is to show the possibility of a salutogenic approach to strengthen both individual and public health.

Design. In the empirical study, 200 people took part - representatives of the professional pedagogical community from three regions of Ukraine - Sumy, Chernihiv and Dnipro (165 women and 35 men aged 25 to 59 years). A questionnaire was used that included questions on identifying a subjective assessment of the quality of life, health, adaptability, safety, attitudes towards the future and other areas of life; Questionnaire "Sense of Coherence" (SOC) by A. Antonovsky and "Questionnaire for Post-Traumatic Growth" R. Tedeschi, L.Calhoun.

Results. According to our research of the community adaptation to the consequences of a military conflict there exist positive correlation $(\mathrm{p} \leq 0,01)$ between the subjective assessment of adaptability and the assessment of health, well-being, quality of life, satisfaction with life-style, a sense of security, an internal control locus, and indicators of posttraumatic growth.

There is a positive correlation between the subjective assessment of adaptability and the assessment of health, well-being, quality of life, satisfaction from the way life is formed, the sense of security, the internal control locus, and by the integral index of posttraumatic growth.

Also, it has been defined that the higher SOC and its components are, the higher level of subjective well-being, satisfaction with one's health $(\mathrm{p} \leq 0,01)$ is as well as adaptability to the consequences of a military conflict $(\mathrm{p} \leq 0,01)$.

Significant differences were found between people with high and low levels of subjective well-being by the indicators "comprehensibility" $(p \leq 0,05)$, "manageability" $(p \leq 0,01)$, "meaningfulness" $(p \leq 0,01)$, and by the integral index of SOC and posttraumatic growth $(\mathrm{p} \leq 0,01)$. This is evidence that persons with a high index of SOCs who believe that the world is understandable, consistent, not chaotic, believe in their ability to help themselves, rely on their own resources or on the support of others. They see the meaning of life, feel happier, are more satisfied with life, and have higher indicators of post-traumatic growth, higher levels of trust and satisfaction with their health.

Practical value. Thus, the theoretical and empirical analysis of the problem gives grounds for constructing a social and psychological model for strengthening public health in the process of community adaptation to the consequences of a military conflict. This model will include: 
- increasing the SOC that would facilitate the transition from "risk factor" to "salutogenic" orientation in which people develop their potential and ability to control their own health and well-being;

- the promotion of psychological resilience as an ability to live a full and productive life despite different constraints;

- increasing the ability to use a stressful situation as an opportunity for further development and achievement of a higher functioning level (post-traumatic growth);

- the facilitation of one or another form of communication aimed at improving awareness on health issues and gaining competence in maintaining it;

- strengthening reflexive processes and increasing readiness for change.

Practical realization of this model will have high social value.

Conclusions. SOC, resiliency and posttraumatic growth are connected with health, well-being and orientation to healthy lifestyle. The more evident they are, the more chances for a person's moving towards better health.

SOC, resiliency and posttraumatic growth are indicators of that social and psychological community resource which ensures the success of its adaptation and strengthening of both individual and public health.

Salutegenesis is a valuable approach to strengthening public health in the context of community adaptation to the consequences of a military conflict.

Keywords: salutogenic approach, resilience approach, post-traumatic growth, strengthening public health, community adaptation to the consequences of a military conflict.

\section{References.}

1. Antonovsky A. (1984): The Sense of Coherence as a Determinant of Health. Advances, Institute for Advancement of Health: 1 (3), 37-50.

2. Antonovsky, A. (1996): The salutogenic model as a theory to guide health promotion. Health Promotion International: $11(1), 11-18$.

3. Bonanno G. A. (2004): Loss, Trauma, and Human Resilience: Have We Underestimated the Human Capacity to Thrive After Aversive Events? American Psychologist: 59 (1), 20-28.

4. Garmezy N. (1986): Stress, competence, and resilience: Common frontiers for therapist and psychopathologist. Behavior Therapy: 17 (5), 500-521.

5. Joseph, S., \& Linley, P. A. (2006): Positive psychology versus the medical model?: Comment: American Psychologist: 61 (4), 332-333

6. Klimchuk V. (2016): Posttraumatic growth and ways of facilitating it in psychotherapy. Science and education: 5 (16), 46-52. [Klymchuk, V. O. (2016). Posttravmatychne zrostannia ta yak mozhna yomu spryiaty u psykhoterapiiю. Nauka i osvita, 5 (16), 46-52 (ukr)]

7. Morgan, A., \& Ziglio, E. (2007): Revitalising the public health evidence base: An asset model. Promotion \& Education: Suppl. 2, 17-22.

8. Norris F. H., Stevens S. P., Pfefferbaum B. [et al.] (2008): Community Resilience as a Metaphor, Theory, Set of Capacities, and Strategy for Disaster Readiness. American Journal of Community Psychology: 41 (1-2), 131134.

9. Seligman, M. E. P., \& Csikszentmihalyi, M. (2000): Positive psychology: An introduction. American Psychologist: 55 (1), 5-14.

10. Suominen S, Helenius H, Blomberg H, Uutela A, Koskenvuo M. (2001): Sense of coherence as a predictor of subjective state of health: results of 4 years of follow-up of adults. Journal Psychosomatic Research: 50 (2), $77-$ 86.

11. Tedeschi, R.G., Calhoun, L.G. (2004): Posttraumatic growth: conceptual foundations and empirical evidence. Psychological Inquiry: 15 (1), 1-18. 


\title{
Personality Features of Pet Owners
}

\author{
(Eduard Krainikov ${ }^{1}$, Eugene Prokopovich ${ }^{1}$, Thais Bezkrovna ${ }^{2}$ ) \\ ${ }^{1}$ Taras Shevchenko National University of Kyiv, Kyiv, Ukraine \\ ${ }^{2}$ Kyiv Institute of Modern Psychology and Psychotherapy
}

Introduction: The diversity of domestic animals which kept by humans can be explained by the realization of a certain need that pets carry out. This raises the question of the complementarity between the owner's personality and the characteristics of the pets.

Purpose: To investigate the personality features of the owners of dogs and cats, depending on their gender.

Methodology: The study was attended by 68 people. 40 persons (20 men, 20 women) aged $25-46$ are the owners of dogs; 28 persons (14 men, 14 women) are the owners of cats. $25 \%$ of women and $20 \%$ of men live in rural areas, $75 \%$ of women and $80 \%$ of men are residents of the city. Among the dog owners, 14 women (70\%) and 16 men $(80 \%)$ have higher education, 6 women $(30 \%)$ and 4 men $(20 \%)$ have secondary education. Among the owners of cats, 21 persons have higher education ( 9 women, 12 men), secondary education -7 persons (3 men, 4 women). The owners of dogs are for the first time 4 women (20\%) and 4 men (20\%); 16 women $(80 \%)$ and 16 men $(80 \%)$ have been owners of dogs before and have some experience in communicating with animals. For the first time, cats have 6 men and 4 women; others had previous animal retention experience.

We used the following research tools: the author's Questionnaire; MMPI; Questionnaire of masculinityfemininity (S. Bem); Scale of social support (D. Zimet); Scale of emotional response (A. Magrobyan, N. Epstein).

Results: Testing using the Questionnaire of masculinity-femininity allowed the following results: 19 women $(95 \%)$ and 18 men $(90 \%)$ showed an IS index of \pm 1 , which indicates almost absolute androgyny of all surveyed dog owners. Among the owners of the cats, the results were distributed differently: 6 women (43\%) and 10 men (71\%) were found to have androgyny. The high level of femininity in women holding cats can be compared with the physiological characteristics of the pets themselves. We can assume that people feel intuitively what the quality of animal will be close to them, and make a choice according to their preferences.

Using MMPI we made an unexpected conclusion: a significant excess of the "impulsiveness" scale was found in $86 \%$ of men and $71 \%$ of women who are cats owners. Also, the overwhelming number of respondents among dog owners (95\% women and $85 \%$ men), as well as $100 \%$ women $86 \%$ of men who are cats owners, showed an excess of indicators on a scale of optimism. We came to the conclusion that the pattern is probably related to the actual social situation in Ukraine. We can assume that, regardless of the pet, people are saturated with stressful events, the monotony of everyday life, and therefore they seek for change. The significant increase in femininity scores we also explain as a response to today's events. Excess was found in $90 \%$ of women - owners of dogs, $86 \%$ of women - owners of cats, and $50 \%$ of men - owners of cats and dogs. Such high rates for women are likely to indicate the acquisition of masculine traits, responsibility and discretion in actions and decision-making. Based on the results of the survey on the Scale of social support, one can see that the indicator of social support in the form of a family is: for owners of dogs $-85 \%$ (women) and $95 \%$ (men), average - $90 \%$; for owners of cats $-86 \%$ (women) and $93 \%$ (men), average $-89 \%$. Such data indicate that in both groups the most significant social support is expected from the immediate environment. Accordingly, they more influence the formation of behavior and satisfaction with social support. In general, social support has proven to be significant for most of the subjects. Respondents mostly rely on their surroundings, count on support and understanding by the most significant figures in their lives, most satisfied with the state of affairs with the immediate surroundings.

According to the Scale of emotional response, high rates of empathy in women were obtained regardless of the animals they hold ( $80 \%$ of the owners of the dogs and $86 \%$ of the owners of the cats). It is known that the ability to emotional responses is in the turn correlation with aggressiveness and predisposition to violence; in high correlation with complacency, willingness to forgive others. The average rate of empathy for men was within the normal range. Interestingly, none of the respondents showed low or very low levels of empathy among pet owners. We explain this data by the fact that keeping and communicating with pets can't leave anyone indifferent.

Practical value: Based on the results of the study, we formulated recommendations for choosing a pet.

Conclusion. The vast majority of analyzed dog owners (95\% of the total) are androgens. Women who hold pets are generally more empathic than men who hold pets.

Keywords: individual differences, personality traits, psychometric test. 


\title{
Subjective dimension of mental health: Ukrainian adaptation of the Orientation to Happiness Scale
}

\author{
(Iryna Kryvenko, Galyna Petryk)
}

Ukrainian Catholic University, Lviv, Ukraine

\begin{abstract}
Introduction. Although the questions of well-being and happiness were raised many centuries before, since Martin Seligman became the APA President in 1998, the focus on positive aspects of mental health started being much clearer. Happiness studies became important not only for philosophers and other humanities, but for specialists in wide areas that are called up for making life better. Together with other social practices and services, psychology is one of a kind. Numerous researches show correlations of happiness indicators with low neuroticism (Gomez et al., 2012), good mental (Kiecolt-Glaser et al., 2004) and physical health (Danner et al., $2001)$ etc. Thus, it is urgent to have good instruments for measuring happiness experience in order to get information for diagnostics and anticipation of heavy stress and negative mental health outcomes.

According to M. Seligman's concept of authentic happiness (2002), people tend to choose one of three different ways to be happy: through pleasure, through engagement, and through meaning. Orientation to Happiness Scale $(\mathrm{OTH})$, created by C. Peterson, N. Park and M. Seligman (2005), is an 18-item questionnaire for measuring the most typical person's approach to happiness. However, considerable cross-cultural differences are proved to appear concerning this concept (e.g., Vella-Brodrick et al., 2009; Kose, 2014; Kenkyu, 2011).
\end{abstract}

Purpose. This research aimed to propose a valid and reliable Ukrainian adaptation of the OTH, and to examine the psychometric properties of the scale.

Design. To reach these aims, firstly, English-Ukrainian double-translation in two variants was made for combining a questionnaire Ukrainian test-version. Later two studies were conducted. Study $1(N=468 ; 122$ males, 346 females; age 16-58, Mean $=22.92, S D=8.9)$ was for checking structural validity and reliability, Study $2(N=123 ; 59$ males, 64 females; age 16-55, Mean $=22.81, S D=8.2)$ was for testing time stability, construct and criterion validity.

Results. In Study 1 on the results of explorative factor analysis a three-factor structure due to a theoretical framework was confirmed. Positions of items inside the subscales were slightly different from the Parent Form, although generally the 18-item scale was replicated. The need of items replacement was proved by better $\alpha$ Cronbach coefficients comparing to the original version item location. The reliability indices for Ukrainian adaptation are.73 for "pleasure",.80 for "meaning",.65 for "engagement". One possible explanation of the differences in the subscales structure is cultural divergence of the orientation to happiness concepts between Ukrainian and American respondents.

Study 2 revealed a satisfactory test-retest stability for each subscale in 4-week period (Spearman rank correlation coefficients between.73 and.81, p<.001). The construct validity of the Ukrainian version of OTH Scale was examined by the analysis of correlations between the questionnaire subscales with SWLS (Deiner et al., 1985), ABS (Bradburn, 1969) and PWBS (Ryff, Keyes, 1995). Positive relations were found at the level of $p<.05$, which generally corresponds to the results of other researchers and to the theoretical concept. During criterionvalidity analysis statistically significant differences $(\mathrm{p}<.05)$ in orientations to happiness were shown for religious and non-religious people, reflecting the specificity of connections between happiness, faith and religious behaviour.

Limitations. Certain limitations of the current research should be noted. Firstly, the sex distribution in Study 1 sample is not equal. It was created according to the Parent Scale adaptation sample (Peterson et al., 2005, p. 29), however, the differences between males and females in orientations to happiness were revealed in further researches (e.g. Brdar, 2009). The future study should be focused on links between OTH subscales and sociodemographic variables. Secondly, the some additional statistical procedures (e.g., CFA) can be carried out for testing the three-dimensional model and item locations in the subscales. It is possible to find some other structural solutions (like Anić, Tončić (2013) did, describing only two - hedonic and eudaimonic - orientations, or as Seligman (2011) in his new PERMA model established five dimensions of happiness). Thirdly, in this research we were not controlling personality variables which may possibly moderate the relations between orientations to happiness and different measures of subjective well-being (Vella-Brodricket al., 2009).

Practical value. The received questionnaire may be used by specialists in wide fields of psychological assessment, either for the researches on topics of happiness and subjective well-being, or for evaluation of client's status on different stages of positive psychology interventions or any other spheres of counseling.

Conclusions. The research demonstrated good psychometric properties of the Ukrainian variant of Orientation to Happiness Scale, namely its internal consistency, satisfactory structural, construct and criterion validity.

Keywords: psychometric test, personality, quality of life, cultural difference, religion, psychology. 


\section{References.}

1. Anić, P., Tončić, M. (2013). Orientations to Happiness, Subjective Well-being and Life Goals. Psihologijske teme, 22(1), 135-153.

2. Bradburn, N. M. (1969). The structure of psychological well-being. Oxford: Aldine.

3. Brdar, I. (2011). Approaches to happiness, life goals and well-being. In T. Freire (Ed). Understanding Positive Life: Research and Practice on Positive Psychology. Lisbon: Climepsi Editores, 45-64.

4. Danner, D. D., Snowdon, D. A., \& Friesen, W. V. (2001). Positive emotions in early life and longevity: Findings from the nun study. Journal of Personality and Social Psychology, 80(5), 804-813.

5. Diener, E., Emmons, R. A., Larsen, R. J., \& Griffin, S. (1985). The Satisfaction with Life Scale. Journal of Personality Assessment, 49, 71-75.

6. Gomez, V., Allemand, M., \& Grob, A. (2012). Neuroticism, extraversion, goals, and subjective well-being: Exploring the relations in young, middle-aged, and older adults. Journal of Research in Personality, 46(3), 317325.

7. Kenkyu, S. (2011). Orientations to happiness in Japanese people: Pleasure, meaning and engagement. The Japanese Journal of Psychology, 81(6), 619-624.

8. Kiecolt-Glaser, J.K., McGuire, L., Robles, T.F. \& Glaser, R. (2002). Emotions, morbidity, and mortality: new perspectives from psychoneuroimmunology. Annual Review of Psychology, 53(1), 83-107.

9. Kose, I.A. (2014). Psychometric Properties of the Orientations to Happiness Scale and Measurement Invariance Between Samples of Turkish and Russian University Students. Social Indicators Research, 122(3), 945-959.

10. Peterson, C., Park, N., \& Seligman, M. (2005). Journal of Happiness Studies, 6, 25-41.

11. Ryff C., Keyes C. (1995). The Structure of Psychological Well-Being Revisited. Journal of Personality and Social Psychology, 69(4),719-727.

12. Seligman M. (2011). Flourish. NewYork: FreePress.

13. Seligman, M. (2002). Positive psychology, positive prevention, and positive therapy. In C. Snyder \& S. Lopez (Eds). Handbook of positive psychology. New York: Oxford, 3-9.

14. Vella-Brodrick, D.A., Park, N. \& Peterson, C. (2009). Three Ways to Be Happy: Pleasure, Engagement, and Meaning: Findings from Australian and US Samples. Social Indicators Research, 90(2), 165-179. 


\title{
Readaptation of ATO Veterans and their Wives: Experience of Psychosocial Assistance School
}

\author{
(Borys Lazorenko ${ }^{1}$, Kateryna Kalnytska ${ }^{2}$ ) \\ ${ }^{1}$ Institute for Social and Political Psychology of NAES of Ukraine, Kyiv, Ukraine \\ ${ }^{2}$ National Technological University, Chernihiv, Ukraine
}

\begin{abstract}
Introduction. Veterans may have posttraumatic conditions and disorders of adaptability. Those can provoke secondary psychotrauma for their wives. So both veterans and their wives require adaptations. Such approaches as CBT and EMDR are effective for re-adaptation processes, but in case of a dangerous situation for a veteran the re-trauma may arise.

There is a need for short-term technological interventions aimed at transforming negative states to positive experience. There is a need to teach veterans and their wives how to provide self- and mutual assistance to cope with posttraumatic states and dis-adaptive reactions. We have developed a re-adaptive complex of technologies for the transformation of negative states into life experience.

The purpose is to determine the results of the re-adaptation of veterans and their wives' technology within the framework of their joint training in the skills of self- and mutual assistance.
\end{abstract}

Approach. The study was conducted in conjunction with psycho-correction classes and a training course on self- and mutual assistance for veterans and their wives. The School of Socio-Psychological Assistance created by the Laboratory of the Institute of Nursing and Midwifery of the National Academy of Sciences of Ukraine and the Department of Social and Psychological Aid to the Population of Chernihiv National University of Technology was chosen as the form of training.

The course of the School's activities included the learning of the rehabilitation complex. The complex consisted of the author's technology of transformation of negative states into a positive life experience (Lazorenko, 2017), the techniques of breathing therapy and body-oriented therapy, group mutual assistance and psychosocial support.

The School course was conducted free of charge for 4 months and included 12 sessions, 3 hours each. Sessions included role play and mini trainings of participants to assimilate certain technology. The technique of homework tasks was also performed. During the course a closed online-group "Together we are strong" worked within the Facebook for advising and supervising school participants.

To determine the course effectiveness a complex of questionnaires was used: List of symptoms of PTSD (Bezsheiko, 2016), "Multi-level personality questionnaire "Adaptability"” (Maklakov, \& Chermyanyn. 2006), authored self-assessment questionnaire on changes in the quality of life. Data collection was carried out in the form of a questionnaire survey of the School members at the beginning and after graduation. The total amount of participants in the course was 36 persons. Two families of veterans and their wives were included in the casestudy.

Results. According to The PTSD Checklist in the family " $X$ " a husband showed slight fluctuations of the indicators as a response to the applied re-adaptation technologies. His wife's grades were obtained at the end of the course, as she joined it later. These indicators were used for a general comparison with male indicators after the course ending. Indicators of husband and wife show a certain synchronization of their psycho-emotional states, with the exception of manifestations of excessive reactivity, due, in our opinion, to the fact that in this family the main responsibility of financial support belongs to the woman.

Among the husband's indicators of dis-adaptation the indicator of violations of behavioural regulation became almost three times less after the course. On the other hand, the wife showed still high indicators of violations of behavioural regulation, although they were almost one third less than that in husband's ones.

In the family " $\mathrm{X}$ " there were appeared positive changes in the quality of life. A man has moderately improved his physical and psychological well-being, he has felt the moral help of his wife, has ceased to be locked in himself, has significantly improved his attitude towards his parents, wife, and children. Also, the attitude of parents, wife and children towards him has improved. He has learned to control himself, realized that it was necessary to restore order in himself, began to appreciate the family more. The veteran's wife has significantly improved her physical and psychological well-being, she has decided to take care of her health, has become more self-confident. Her attitude towards her parents, her husband and children has significantly improved. She noticed that husband's attitude towards her has improved moderately, the self-confidence, and faith in her husband have appeared. She has learned to realise her emotions and to cope with them.

In the family "Y", according to The PTSD Checklist, the wife has showed a general decrease in symptoms, with the exception of the increase in the symptom of excessive reactivity more than doubled, which (according to our observation) indicates the search for solutions to family problems. Such search can be testified by the insignificant fluctuations of the husband's indicators. 
According to the questionnaire of adaptability the husband's indicators of violations of behavioural regulation and communicative abnormalities decreased more than twice. At the end of wife's studies the indicator of the breaches of behavioural regulation slightly increased, other indicators of violations decreased almost twice.

Positive changes in relationships were recorded by the self-assessment questionnaire on changes in quality of life. The husband noted his attitude towards his parents, wife and children and, vice versa, their attitude towards him has improved significantly. The wife noted that her physical and psychological well-being have improved significantly. She stopped aggressiveness, became more balanced and confident. Her attitude towards her parents, her husband and children has improved significantly.

Members of the family's "X" and "U" have acquired the skills of psychological self- assistance and the skills of giving it to their partners.

Limitations and strengths of the study. The aim of the progress in the psychotrauma overcoming was achieved through this study. But better results could be achieved by more tough control of the individual sessions attendance as we associate the enhancement of attendance with increasing responsibility and motivation for both men and women.

Practical/Social value. The rehabilitation complex and the School form of its implementation could also be helpful as the way to reduce manifestations of post-traumatic states and dis-adaptation, and to improve the quality of family life for more veterans, internally displaced persons, their families and all those who had psychotraumatic experience.

Originality. Such a comparative study of the dynamics of post-traumatic stats and the adaptability of the veterans' family and also positive changes in quality of life was conducted in Ukraine for the first time.

Conclusions. The effectiveness of rehabilitation technologies for veterans' families is revealed. It has been determined that veterans and their wives have acquired primary self- assistance skills and skills in providing and receiving psychological assistance. The decreases in the rates of post-traumatic disorders and abnormalities of adaptability has been confirmed empirically. According to the spouses' self-esteem, the quality of their family life has improved significantly.

Keywords: re-adaptation, psychological, assistance, learning,

\section{References.}

1. Lazorenko, B.P. (2015). Reabilitatsiynyy kompleks nadannya psykholohichnoyi dopomohy ta sotsial'nopsykholohichnoho suprovodu uchasnykiv ATO, shcho zaznaly psykhotravmy ta PTSR [Rehabilitation complex of providing psychological assistance and socio-psychological support of ATO participants who have suffered from psychotrauma and PTSD]. In V.I. Os'odlo et al. (Ed.) Aktual'ni problemy psykholohichnoyi dopomohy, sotsial'noyi ta medyko-psykholohichnoyi reabilitatsiyi uchasnykiv antyterorystychnoyi operatsiyi [Actual problems of psychological help, social and medical-psychological rehabilitation of participants of antiterrorist operation]. (pp. 190-192). Kyiv: NUOU. (ukr).

2. Bezsheiko, V. (2016). Adaptatsiya Shkaly dlya klinichnoyi diahnostyky PTSR ta opytuval'nyka "Perelik symptomiv PTSR" dlya ukrayins'koyi populyatsiyi [Adaptation of the Scale for clinical diagnostics of PTSD and of the questionnaire "List of symptoms of PTSD" for the Ukrainian population]. Psykhosomatychna medytsyna ta zahal'na praktyka [Psychosomatic medicine and general practice]. 1 Retrieved from URL https://uk.e-medjournal.com/index.php/psp/article/view/8. (ukr).

3. Maklakov, A.H., Chermyanyn, S.V. (2006). Mnohourovnevyy lychnostnyy oprosnyk "Adaptyvnost" [Multilevel personal questionnaire "Adaptability"]. In D.Y. Rayhorodskyy (Ed.) Praktycheskaya psykhodyahnostyka. Metodyky y testy [Practical psychodiagnostics. Techniques and tests]. (pp. 549-672.). Samara: «BAKHRAKHM». (rus). 


\title{
Reasons of Healthy Behaviour Disorders in Adolescence
}

(Maryna Martseniuk)

\author{
Mukachevo State University, Mukachevo, Ukraine
}

\begin{abstract}
Introduction. The urgency of the issue of health preservation is of increasing interest among representatives of various sciences, because health - is a necessary condition for active and normal human activity.

Today, in conditions of the Ukrainian society development, the young people's state of physical and mental health is particularly acute, as the current situation is aggravated by high rates of youth morbidity, deterioration of the ecological, economic, epidemiological situation, as well as moral and spiritual crisis. The rate of the young people's health deterioration is too great.

A significant part of the reasons that negatively affects the state of health is the consequence of a certain person's behaviour, leading to the emergence of diseases, their transition to a chronic condition, premature depletion of the adaptive potential (Tytarenko, 2006).
\end{abstract}

The purpose of the paper is to provide a theoretical analysis and empirical study of the causes of healthy behaviour disorders in adolescent age.

Methodology. Theoretical analysis, systematization of scientific, theoretical and methodological sources, empirical methods (standardized techniques, observations, conversations), as well as methods of processing and interpreting data (quantitative and qualitative, with the use of mathematical statistics) have been used in the work.

Theoretical analysis of the concepts of "health" and "healthy behaviour" in scientific sources, proved a steady interest of the doctors, psychologists, and pedagogues to the issues. H. Apanasenko, B. Bratus, S. Bielicheva, S. Boltivets, O. Bondarenko, O. Hubenko, I. Hoian, V. Klymenko, N. Zavydivska, O.Kokun, H.Lozhkin, S.Maksymenko, N. Maksymova, V. Moliako, K. Miliutina, V.Noskov, T. Tytarenko, T. Khomulenko and others addressed to them.

They claim, that the issue of health is the most acute in the period of personality formation, especially in adolescent age, since this period of personal development has a significant influence on the formation of fundamental psychological structures, subjectivity in the behavioural, individual and social, spontaneous and conscious dimensions of the individual, as well as approaches to classifications of behavioural disorders have been described (Maksymenko, 2007).

An empirical research was conducted on the basis of general secondary schools of Mukachevo town during February-April 2018, where 55 students of 10 and 11 grade took part. The study was conducted using a number of psychodiagnostic techniques, namely:

1. The questionnaire of healthy behaviour disorders (Lutsenko \& Habelkova), created by national psychologists as an instrument for studying the modern person's predispositions to lead a peculiar lifestyle. This questionnaire allows to analyse the factors that influence the causes of healthy behaviour disorders in adolescent age, among which: craving for smoking, malnutrition, disrespectful attitude to own safety, craving for alcohol, the desire to sacrifice health for the sake of a "fashionable image", low self-control will for health, emotional incompetence and self-destructive behaviour (Lutsenko \& Habelkova, 2013).

2. Hardiness survey (Maddi,Leontiev \& Raskazov), which has been chosen and used in our study to determine the extent of the person's ability to withstand a stressful situation, observing the internal balance and not reducing the success of the activity, contains questions of three scales of the questionnaire - commitment, control and challenge (Raihorodskyi, 2009).

3. The "Life-meaning Orientations" test (Leontiev) has been taken in order to investigate the person's psychological and emotional state, to evaluate the so-called life-meaning "source" that can be discovered by the person either in the future (goals), or in the present (process) or in the past (result), or in all mentioned components of life (Raihorodskyi, 2009).

Resullts. The correlation analysis with Pearson'schi-square test for independence has been applied in order to understand better the psychological causes of healthy behaviour disorders in adolescent age.

The conducted correlation analysis showed that the scales "commitment" and "crawling for smoking" ( $\mathrm{r}=$ 0,407), "challenge" and "crawling for alcohol" ( $\mathrm{r}=0,535)$, Locus control of the "Life" and Locus control of the "Self" $(\mathrm{r}=0,423)$, "challenge" and "self-destructive behaviour" ( $\mathrm{r}=0,515)$ are significantly correlated. As we can see, the craving for smoking can be associated with sense of commitment, belongingness in young people. People with high scores according to this scale give rise to the feelings of uselessness, retardation, they feel themselves "out of life". Preferring smoking such people harm themselves and the environment.

A young person who considers life as a way of gaining experience is usually ready to act in the absence of reliable guarantees of success, to take risks, considering that the desire for simple comfort and safety impoverishes the life of the individual. This behaviour is characteristic to individuals with a high level according 
to the scale "Challenge". However, a person who crawls for alcohol and is prone to self-destructive behaviour is not able to manage his / her life reasonably and rationally, and risk for the sake of temporary pleasure, which may lead to various addictions, self-destructive actions (drug addiction behaviour, self-incision, computer addiction, food addiction, rarely - suicidal behaviour), degradation of personality and, as a result - the ruined life.

The high scores for Locus control of the "Life" and Locus control of the "Self" scales reflect the strong person's self-image with sufficient freedom of choice in order to build his / her life according to one's own goals and objectives, and ideas about its meaning, as well as, the ability in everyday life to manage one's own life, make decisions independently.

The generalised data of Pearson correlation analysis are given in Table 1.

Table 1. Pearson correlation coefficient (R)

\begin{tabular}{|l|l|l|}
\hline Scale 1 & Scale 2 & $\begin{array}{c}\text { R-Pearson } \\
\text { correlation } \\
\text { coefficient }\end{array}$ \\
\hline goals & process & $\mathrm{r}=0,287$ \\
\hline goals & commitment & $\mathrm{r}=-0,275$ \\
\hline process & locus control of the "Self" & $\mathrm{r}=-0,313$ \\
\hline process & challenge & $\mathrm{r}=-0,337$ \\
\hline result & malnutrition & $\mathrm{r}=-0,269$ \\
\hline locus control of the "Self" & locus control of the "Life" & $\mathrm{r}=0,423$ \\
\hline locus control of the "Self" & process & $\mathrm{r}=-0,313$ \\
\hline locus control of the "Life" & locus control of the "Self” & $\mathrm{r}=0,423$ \\
\hline commitment & goals & $\mathrm{r}=-0,275$ \\
\hline commitment & crawling for smoking & $\mathrm{r}=0,407$ \\
\hline control & disrespectful attitude to own safety & $\mathrm{r}=-0,669$ \\
\hline challenge & & $\mathrm{r}=-0,582$ \\
\hline challenge & process & $\mathrm{r}=0,515$ \\
\hline challenge & crawling for alcohol & \\
\hline challenge & self-destructive behaviour & \\
\hline
\end{tabular}

It should be noted, that the "challenge" and "pursuit of the fashionable image", $(r=-0,582)$, as well as "control" and " disrespectful attitude to own safety " ( $r=-0,669)$, correlate inversely with each other. Obviously, the higher the young person's level of challenge, the less the person is exposed to the feeling and the desire to follow fashionable trends, the more the person tends to risk, to endanger. And accordingly, the less control over this process, the higher the level of disrespectful attitude to own safety.

Limitations and strengths of the study. Consequently, as a result of theoretical and empirical research, a number of reasons for healthy behavior disorders in adolescent age have been found:

- low level of the youth acquaintance or competence in the field of health, as well as knowledge of the main risk and anti-risk factors, understanding of the role of health in ensuring the life efficiency and longevity;

- lack of a consistent and continuous health education system, healthy lifestyle skills, models and self-preserving behavior techniques, with the further reproduction in his / her own life;

- lack of priority of health as a life priority and motivation for a healthy lifestyle and health culture;

- aggressive social environment, that is, abuse of alcohol by parents, conflicts in the family;

- sanitary and hygienic problems as well as poor nutrition; 
- psychological reasons: insecurity, inadequate self-esteem, low distress tolerance, emotional imbalance and incompetence, influence of peer circle, youthful exuberance, low self-control, self-destructive behavior are the main among them.

Practical/Social value. The obtained results allow to find out if the students adhere to the healthy behavior and to investigate the causes of these violations in adolescence, as well as to identify problem students, to indicate the probable reason of these violations for further corrective work.

Conclusions. Directions for further research we see in the development of programs for the formation and development of a conscious attitude towards health and healthy lifestyles.

Keywords: health, healthy behavior, adolescent age, healthy lifestyle, health culture. 


\title{
Stress Resistance in the Structure of Individual Psychological Characteristics of Students
}

\author{
(Iryna Martyniuk)
}

National University of Life and Environmental Sciences of Ukraine, Kyiv, Ukraine

\begin{abstract}
Introduction. Faced with various stressors in everyday life, a person evaluates their and his/her own coping resources, changes something in external reality or in the representations in his/her own consciousness, regulates his/her behavior. At the same time, the power of expression of behavioral reactions and its vector is largely due to the stress resistance of the individual.

In modern psychological literature, stress is considered as a structural-functional, dynamic, integrative trait of a person as a result of the transactional process of a collision of an individual with a stress-inducing factor that accommodates the process of self-regulation, cognitive representation, an objective characterization of the situation and the requirements for a person (according to V. Korolchuk, 2009). It is also a measure of stress tolerance of a human, the basis of its successful social interaction, which is characterized by emotional stability, low level of anxiety, high level of self-regulation, psychological readiness for stress (according to R. Kupriyanov, Yu Kuzmin, 2012). This is an integrative trait of a person characterized by such interaction of emotional, conative, intellectual and motivational components of human mental activity that ensure the optimal successful achievement of the goal of activity in a complex emotional environment (according to N. Brezhnev, 2012). Stress resistance provides the individual with the ability to withstand significant mental, physical, conative and emotional stress, while maintaining the efficiency of functioning (according to M. Belova, 2007).

Explaining the relationship between stress and individual psychological characteristics of the individual, scientists hold to the idea of the possibility of formation and development of this characteristics.

From the above it follows that the significant step in the development of stress resistance of a person is the student's age as a period of intensive professional development of the individual.
\end{abstract}

Purpose. In order to study the peculiarities of students' stress resistance, we conducted an empirical study. Its tasks included the following: 1) to find out the level of development of stress respondents, 2) compare the level of stress resistance of students of different courses, and 3) to find out the relationship of stress resistance with other individual psychological characteristics of the individual.

Methodology. In order to determine the level of students' stress resistance, the method "Forecast" according to V. Bodrov was chosen, which makes it possible to find out the level of person's neuro-psychological stability (high, good, satisfactory, unsatisfactory) and the risk of its disadaptation in stress (favorable or unfavorable prognosis of behavior in a stressful situation).

To find out the relationship between stress and other important individual and psychological characteristics of students as subjects of educational activity and professional development, a number of techniques were identified: short indicative test, method of revealing communicative and organizational skills, methodology for diagnosing the orientation of educational motivation T. Dubovitskaya, Self-actualization test, A. Karpov's questionnaire of reflexivity, Purpose in life test in Leontyev's modification, author's questionnaires "My selfeducational activity", "Experimental situations" and "I am learning a profession" (for studying the peculiarities of self-education activity and readiness for it).

The study was conducted during 2017-2018 among the students of the I-V courses of the National University of Life and Environmental Sciences of Ukraine, Ternopil Volodymyr Hnatiuk National Pedagogical University, Yuriy Fedkovych Chernivtsi National University.

Results and Discussion. The results of the study, obtained from a sample of 249 students, indicated that the significant number of students under the study were with low levels of stress resistance (25\%) and very few of them with high level $(1 \%)$ and good level $(17 \%)$ of neuropsychiatric resistance (see Table 1.3- 1.5). Most students under the study (57\%) have satisfactory neuromuscular stability, in which they can be effective only in those stressful circumstances that do not become extreme.

Such a pattern is observed among students of all courses: in each course, the percentage of students with a satisfactory neuro-psychological resistance prevails; in each course, a significant proportion of people have unsatisfactory neuro-psychological resistance (34\% in $1 \mathrm{M}, 10 \%$ in $2 \mathrm{M}, 26$ in 3 months) \%, on the 4 th $-27.5 \%$, on 1-2m year of study in the magistracy $-25 \%$ ), which makes an unfavorable forecast of their state of health and behavior in stressful situations. The analysis of average values of indicators of stress resistance of students of different courses allows to conclude that there are no differences in the level of its development, depending on the degree of professional formation and to suggest assumptions about its possible dependence on individual and psychological characteristics of the subject.

To analyze the relationship between stress resistance and individual psychological characteristics of the students under the study, the r-Spirman correlation coefficient was used, which made it possible to detect a very weak 
statistically significant relationship between students' stress and their general mental abilities $(\mathrm{r}=-0.155$, $\mathrm{p} \leq 0.05)$, internal motivation of the study $(\mathrm{r}=-0.154, \mathrm{p} \leq 0.05)$, motivational readiness for self-education $(\mathrm{r}=$ $0.135, \mathrm{p} \leq 0.05)$, as well as a weak statistically significant relationship between students' stress and their communicative $(r=-0.299, p \leq 0,01)$, organizational abilities $(r=-0.219, p \leq 0.01)$, need for cognition $(r=-0.238$, $\mathrm{p} \leq 0.01)$, meaningfulness of life $(\mathrm{r}=-0.472, \mathrm{p} \leq 0.01)$.

Correlation matrix, obtained using the IBM SPSS Statistics 24 program, shows the existence of interrelationships between the individual and psychological characteristics of the subjects. In order to distinguish the typical individual psychological characteristics of stress-resistant students (whose level of neuromuscular stability is high, good or satisfactory), a factor analysis of the primary statistical data was performed (using the IBM SPSS Statistics 24 program), followed by the use of the methods of the main components and the varimaxrotate.

The analysis of individual psychological characteristics of stress-resistant students revealed 5 main components that describe $67.132 \%$ dispersion. According to the matrix of factor analysis data, the most important (with the value $\geq 0.7$ ) individual-psychological characteristics are distinguished by each factor: 1) readiness for selfeducation $(0,810) ; 2)$ communicative $(0,844)$ and organizational skills $(0,706) ; 3)$ internal motivation of studying $(0,737)$; and motivational readiness for self-education $(0,754) ; 4)$ need for knowledge $(0,859) 5)$ reflexivity $(0,856)$.

Limitations and strengths of the study. The received percentages of students according to levels of stress resistance can be different in other samples. Research of stress resistance was carried out only according to one method. Studying the stress resistance of students was not investigated. The revealed correlations of stressresistance and individual-psychological characteristics of students are weak. The typical individualpsychological characteristics of stress-resistant students are found.

Practical/Social value. Purposeful development of students with isolated individual and psychological characteristics will enhance their sustainability in stressful situations.

Originality/Conclusions. Students have various levels of stress resistance. Students of different courses are not distinguished from each other according to their level of stress. Stress resistance of students is related to their individual and psychological characteristics as subjects of educational activity and professional formation. Typical individual and psychological characteristics of stress-resistant students are well-developed readiness for self-education, communicative and organizational skills, internal motivation of learning and motivation for selfeducation, the need for knowledge, reflexivity.

Keywords: mental stress, students, personality traits, resistance, university education. 


\title{
Relationship Between Indicators of a Person's Mental Health and Attitude to Pets
}

(Katerina Milutina)

PhD, Assoc. Prof of Taras Shevchenko National University of Kyiv, Kyiv, Ukraine

\begin{abstract}
Introduction. During the last century, there has been an increase in the number of cats and dogs in urban apartments. They begin to be perceived not utilitarian, but as companions and pets. At the same time, there are a growing number of problems associated with deviant relations between a man and an animal: homeless animals on the streets of the city, injuries in owners and strangers, a request for euthanasia of young, healthy but uncontrollable animals.
\end{abstract}

Related Work. The study of relations between animals and their owners began not long ago. They were stimulated by a change in the attitude of a man to animals that lived next to him. (Hal Herzog, 2009) drew attention to the fact that during the past history of mankind the utilitarian attitude towards domestic animals predominated, whereas in the XX and XXI centuries the attitude changed and the animal became a partner. Based on the theory of family systems, (E.Yu. Fedorovich, A.Ya.Varga, 2010) consider the role of the animal in the human family and come to the conclusion that the concept of transgeneration transmission of ways of supporting the homeostasis of the family system explains why in some families pets are involved in such cases, but not in others. Noteworthy for the explanation is the fact that the number of families, which are breeding pets in recent years is growing rapidly in all industrialized countries. They can "support" the family at all stages of its life cycle, as we wrote in the previous chapter.

A thorough theoretical-methodological and empirical study, conducted by (Nikolskaya,2007), (Nikolskaya,2009) shows that the interspecific groups "man-pet" are formed under certain necessary and sufficient conditions. Relationships in interspecific groups are determined by certain ecopsychological types of interaction, depending on which in such groups mental phenomena of trust, attachment, dominance structure, formation and adoption of norms and rules of behavior of group members in relation to each other, and interspecific communication are formed.

Somewhat different is the concept of (Mychko 2004), which draws attention to the role of the process of socialization of a dog in the formation of relations between a man and an animal.

This study is devoted to identifying the factors that determine the success of human interaction with domestic pets.

We identified the following factors for the success of interaction:

- Individual-typological features of the animal: species, breed, type of higher nervous activity, personal experience of the animal;

- Individual-typological features of the owner: the type of higher nervous activity, motivation, level of tolerance, level of development of emotional intelligence, the leading system of perception;

- The attitude of a person to a domestic animal, which, in turn, is due to the attitude to animals in society, mythological and fantastic ideas about a particular kind of animals, personal experience of communicating with pets;

- Type of upbringing, which is used by the owner while communicating with the animal.

Based on the results of conducted pilot studies on 43 pairs of owners and service dogs (sheep dogs), it was revealed that the greatest success of interaction was observed when a greater strength of higher nervous activity was combined in the owner than in the dog. When combined in the "reverse" direction, the strength of higher nervous activity is greater in sheep-dog than in the owner, deviations occurred in the form of insufficient obedience and controllability of dogs. But the worst combination was the coincidence of the strength of higher nervous activity of the owner and the dog, because in such dyads, status relationships were slowly and unreliably established. The mobility indices of higher nervous activity, on the contrary, in the case of coincidence, contributed to the establishment of relations, and the mismatch of tempo-rhythmic characteristics complicated the process of joint activity. The motivation for keeping the pet also plays a role when combined with the species and breed of the animal: the need for an obedient guard will not be satisfied with the presence of a British cat, and the elderly person who wants to get the animal - companion will have difficulty communicating with the mobile and unpredictable ferret. One of the important components of the optimization of relations is the level of personal tolerance of the owner, his idea of whether the needs and motives of the animal's behavior can not coincide with the human. Insufficient level of tolerance leads to an underestimation of the mental abilities of the animal, or, conversely, anthropomorphism when trying to understand the animal. Emotional intelligence allows you to clearly recognize the emotional state of another person. One can put forward the hypothesis that a developed emotional intellect will contribute to understanding not only human, but also animal emotional manifestations. The predominant type of perception (visual, auditory, kinesthetic) affects the selection of the 
animal. The kind of interaction which the owner likes - watch, touch, stroke, talk and listen to purring, depends on this.

The concept of the effectiveness of human-animal interaction requires a separate study. The signs of this, in our opinion, can be, first of all, the security of this interaction both for man and for the animal, emotional satisfaction from communication, conformity of expectations and the result obtained. With further research, the content of this concept is specified more precisely.

Results and Discussion. An empirical study of this problem is planned. Several groups of subjects took part in it: adults who did not have animals now, but who had them earlier - 50 respondents; owners of cats and dogs 88 respondents; breeders, experts (cynologists and veterinarians) - 20 respondents. With the help of in-depth interviews, we were able to identify the level of safety and satisfaction of the owners by the relationships with their pets, the state of health and the normative behavior of the animals. At this stage of the empirical study, standardization and approbation of author techniques and modifications of standard tests take place.

To study the typology of animals, questionnaires for owners and expert assessments were used. Attitude to the animal was studied using the author's technique "Types of relations" and the types of upbringing were studied by modifying the Eidemiller technique [6]. At a later stage, a comparative study of the effect of the identified factors on relationships with tamed animals (ferrets, rats) will be conducted.

The functions of the family are historical and connected with the socio-economic conditions in society, so over time, both the nature of the functions and their hierarchy change. It is logical to assume that the more someone is involved in performing these functions of the system, the more likely it is part of the system. Let us analyze how cats and dogs fit into the functions of the family.

Reproductive. The satisfaction of the need for offspring can sometimes be transferred to the animal. Some owners call a dog "My little son", "baby", dress it up in clothes, etc. This behavior is more typical for young families who "train" before they have a descendant and for elderly couples who are at the "empty nest" stage. This helps to harmonize relations in the family or to clarify the prospects for the development of a young couple. Educational. In this function, cats and dogs are very active. Socialization of an animal is the responsibility of its owners. Cats and dogs have their own sensitive periods of development, during which they are most sensitive to educational influences. Education takes place both in the family and on the site, under the guidance of trainers and dog handlers. A well-bred dog is safe for owners, other people and animals, a well-bred cat successfully fits into the home's space and relationships with people. In this case, the opposite happens - a dog has a socializing effect on other members of the family. The household function of the family includes caring for the life and health of pets. The responsible owner selects correct feed, makes vaccinations, if necessary takes the animal to the veterinarian, monitors its safety, etc. Care of the animal includes a rather large number of household activities - day-care service or cleaning the tray, feeding, grooming, cleaning, etc. Dogs and cats also take part in household functions (especially in rural houses) - they guard the house and yard, cats catch mice and rats. In many places, dogs help hunters and shepherds, since it was introduced from time immemorial. In an urban home, the animal acts more as an object of care than an assistant in domestic affairs.

Spiritual communication - communication with an animal can positively influence the spiritual development of a person, it causes a sense of responsibility for the life of another one, develops manifestations of empathy and kindness. Participation in the interspecies community evokes a sense of unity with other living beings in the world. For many owners, the experience of harmony and unity with the animal becomes truly a practice of spiritual experience.

Social-status function is aimed at reproducing the social structure; it does not always concerns animals. As a result of our study, we found out that $68 \%$ of persons had animals in the parent family and they have them now. $12 \%$ of persons had animals, and as a result, they decided not to bring animals any more (poorly disciplined animal, cruel treatment, a vivid impression of the animal's death), and $20 \%$ of persons did not have animals in the parent family, but after separation they themselves got cats and dogs. The tendency to reproduce the interspecific group that was in the parent family still prevails.

Economic function is receiving material assets by one family member from others. In this function, animals are both consumers of material goods, and their producers. For many breeders of thoroughbred cats and dogs, selling kittens and puppies is the main source of income.

The sphere of primary social control extends to people and animals; one of the most important tasks is socialization of the animal and the control of its behavior. If the animal is not included in this function, it becomes uncontrollable and dangerous for other animals and humans.

Leisure is the most important function, for which an animal is usually brought. They play with it, walk around, do agility, and so on. The presence of a cat or a dog structures the rest of the owner, makes it healthier and more active.

Emotional (receiving mental protection and support) is exactly what a person gets while being on friendly terms with his pet. Cats and dogs can regret and console a man. They help to relax and laugh. Special relationships connect children and their pets. 
The sexual function of animals in modern urban conditions is either regulated by the masters (in pedigreed animals), or animals are generally deprived of it in the process of sterilization. Normally, animals do not affect the sexual function of the owners.

Thus, it can be concluded that in the modern world (especially in urban conditions) dogs and cats take an active part in the life of the family, they are involved in most of the functions of the family and bring in it many new and interesting things. An additional function is communicative - communication of family members with each other and with surrounding people. People develop receptivity to non-verbal communication of animals, pets learn to understand people, react not only to special commands, but also to the context of interaction between people. An additional result is the formation of groups of "dog owners" who regularly communicate during the walking of dogs. Discussion of tricks, state of health, and behavior of pets is one of the typical topics for communication and rapprochement of people, both in real life and on the Internet.

One of the tasks of our study was to analyze the place of animals in the family system, depending on the stages of development of the family. 148 respondents were examined with the help of the "family atom" technique and the narrative method: the analysis of the story "We and our pet". The respondents were persons with higher education; their age was from 23 to 60 years, there were 130 women and 18 men. The owners were not breeders, they did not breed animals purposefully, most owners described their relationship with animals as good, problem-free, no one turned to specialists to correct the behavior of the animal. They had cats, dogs, parrots and rats. 75 families had cats, 24 of them had two or three cats. In 32 families there lived dogs, 7 families had 2 dogs. 15 respondents had rodents: 10 families had decorative rats (both in one and in pairs), 5 families had hamsters. 6 owners had large parrots, which were perceived as family members. In a rather large number of families, as many as twenty, animals of different types lived: cats and dogs, a cat and a rat, a dog and a parrot, etc. The owners did not consider such combinations problematic; they and all their animals lived together quite happily. The distribution histogram is shown in Fig. 1.

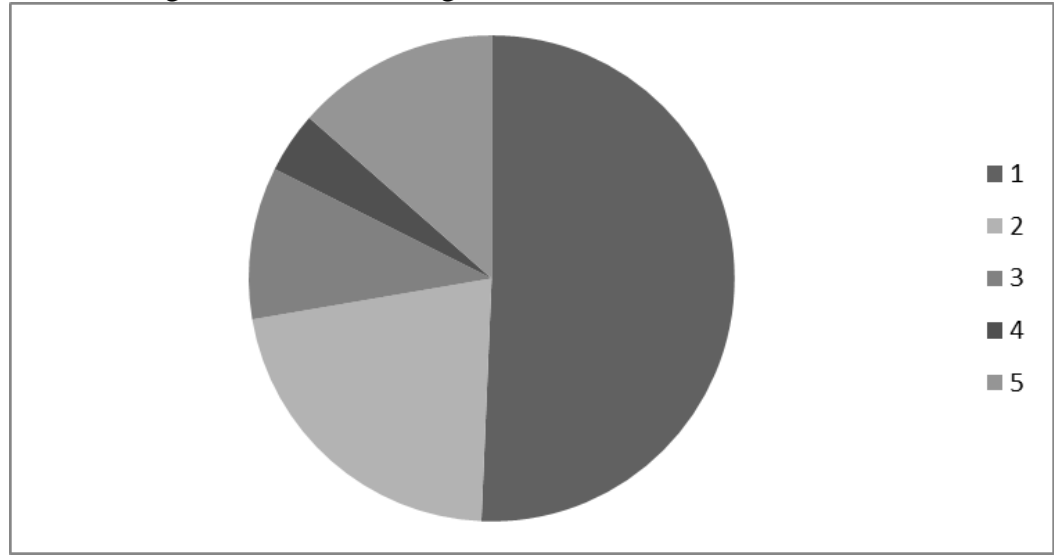

1 - cats, 2 - dogs, 3 - hamsters or rats, 4 - parrots, 5 - two or more different animals.

Fig.1. The histogram of the distribution of the number of pets in respondents

We analyzed the process of interaction between people and their pets, depending on the stages of family development. Subjects assessed their stay at one or another stage.

On the basis of the theoretical research, four groups of factors of the success of the relationship in the system of "owner-household pet" were revealed. It is possible to put forward a hypothesis that relations are influenced by individual and typological features of animals and owners, the attitude of the owner to the animal, the type of education of the pet. Further empirical studies of each of these factors are planned, development and testing of diagnostic tools is underway.

As a result of the analysis of scientific and applied publications and interviewing owners, breeders and veterinarians, another questionnaire was developed. It is not intended to study the level of responsibility of the owner, but to understand the type of attitude towards pets in general, among different respondents, regardless of whether they have a pet or not.

An empirical study of the system of interaction between people and their pets was conducted. 125 respondents belonging to several groups were examined: people do not keep any animals at home (32 subjects), owners of cats $(50$ subjects), owners of dogs (18 subjects), 18 respondents had both cats and dogs, there were also 7 owners, who had parrots. In our study, a tendency was found to display early childhood experiences with animals in adulthood. Those people who had animals in their childhood mostly brought them in adulthood, and preferred animals of the same biological species. Owners of animals were met among those people who did not have children's experience with animals. Only three persons were in deviant relationships with their animals, all of them had no experience of dealing with animal in childhood. Normative relations were distributed in the following way: friendly relations prevailed (67\%), parental-children $(23 \%)$, only $8 \%$ were in "working" 
utilitarian relations and $2 \%$ could not formulate their type of relationship. It was interesting that the owners of both cats and dogs or two or more dogs of different breeds described that they had different types of relationships depending on the species and breed of the animal. The age of the subjects was from 18 to 49 years, women predominated ( $73 \%$ of the subjects). According to the results of the empirical study, the polarization of the attitude towards animals was revealed depending on the age of the subjects: in respondents older than 40 years, a negative attitude toward domestic pets and violation of emotional boundaries is significantly more likely than among the young people.

The pragmatic attitude towards animals was significantly more frequent among the inhabitants of villages and small towns than among the inhabitants of Kiev.

Types of deviant relations were defined on the basis of expert assessments and content analysis of expert texts: veterinarians, cynologists, and felinologists. Criteria for violation of relationships are, first of all, a danger to humans or animals, as well as the high level of discomfort and stress that arises in these relationships. In the frequency analysis of complaints of deviant relations on the part of animal owners, veterinarians, cynologists and felinologists, the following picture of the distribution of deviant relationships was distinguished. In total, 1536 statements were analyzed in social networks of the corresponding direction.

When the criterion $\chi^{2}$ was used, the reliability of the disagreements in the positions of the studied groups to the behavior disorders at the level of 0.05 was revealed. In the group of veterinarians, the greatest activity was observed in reactions to deviant attitudes -484 utterances.

Table 1. Frequency distribution of complaints about violations of relations

\begin{tabular}{|l|l|l|l|l|}
\hline Violations & Veterinarians & Owners & Cynologists & Felinologists \\
\hline Doghunting & 4 & 15 & 3 & 0 \\
\hline Cruel treatment & 45 & 12 & 27 & 7 \\
\hline $\begin{array}{l}\text { Failure to provide } \\
\text { assistance }\end{array}$ & 116 & 64 & 32 & 13 \\
\hline $\begin{array}{l}\text { Failure to consider } \\
\text { needs }\end{array}$ & 214 & 21 & 62 & 123 \\
\hline Irresponsibility & 94 & 43 & 103 & 106 \\
\hline Dangerous behavior & 5 & 22 & 112 & 3 \\
\hline Unpleasant behavior & 6 & 148 & 41 & 95 \\
\hline
\end{tabular}

Professional activity increases attention to untimely appeal for veterinary care and neglect of animal needs feeding inappropriate food, poor conditions of keeping. In the group of owners of animals (both cats and dogs), complaints of unpleasant behavior of animals and search for advice on this matter prevail, the group of rat owners pays more attention to the irresponsibility of the owners and the failure to provide rats with the appropriate veterinary care. The group of cynologists actively discusses current trends in the training of dogs; they are concerned with the combination of irresponsibility of animal owners who do not pay enough attention to the education of pets and aggressive manifestations of deviant behavior of dogs, methods of correction. The opposite picture in the group of felinologists - they are concerned about the neglect of the needs of cats, the irresponsibility of the owners, and accordingly the unpleasant behavior of animals.

Cognitive factors of deviant relations include low awareness of the owners about the psychophysiology of animals, inadequate knowledge of the first signs of diseases, the rules of care, the rules for building adequate relationships.

The wrong motivation for getting a pet belongs to the group of motivational factors: "it was presented as a gift", "it was brought for a child - let it play", "this is a fighting breed - everyone should respect me", "it is fashionable to go to clubs with a dog.". Emotional factors are both the owner's own emotional instability and a low level of recognition of the animal's emotional states. Behavioral disorders are often the result of all the previous factors, but can arise independently of them, when the owner does not consciously fix the inadequate behavior of the animal due to lack of experience and attention.

In accordance with the proposed theoretical model, there is a need to develop a new psychodiagnostic toolkit.

4. Limitations of the study. A separate study requires the concept of the effectiveness of human-animal interaction. The signs of this, in our opinion, can be, first of all, the security of this interaction both for a man and for an animal, emotional satisfaction from communication, conformity of expectations and the result obtained. With further research, the content of this concept was specified more precisely. An empirical study of this problem has been carried out. Several groups of subjects took part in it: adults who do not have animals now, but who had them earlier - 50 respondents; owners of cats and dogs - 88 respondents; breeders, experts (cynologists and veterinarians) - 20 respondents - at the stage of development and standardization of methods. With the help of in-depth interviews, we were able to identify the level of safety and satisfaction of the owners with the relationships with their pets, the state of health and the normative behavior of the animals. At this stage 
of the empirical study, standardization and approbation of author techniques and modifications of standard tests take place.

Significant Mann-Whitney correlation at 0.05 between the "Responsible attitude to the animal" indicators and the quality of emotion recognition and a reliable level of correlation between the indicator of the level of empathy and the recognition of emotions was noted in the respondents. At the same time, there was no reliable relationship between empathy and a responsible attitude towards the animal.

Conclusions (and Future Work) We can conclude that the content of pets is not compensatory (at least among a socially adapted group of respondents). But subjects who had pets had a more positive attitude to themselves and the environment and a lower level of psychoemotional anxiety. Perhaps in the presence of a pet, a more positive attitude to oneself and to others arises, which contributes both to the successful search for social support and to communication with pets. Interaction in the interspecies community is successful and contributes to overcoming the psychological strain provided that the emotional states of animals are adequately perceived.

The prospect of further research is the elucidation of cultural factors and personal characteristics of the owners, influencing the type of relationship to the animal.

Abstract. Dogs and cats living in the town house become part of the family system, and not just of the interspecies community. They take an active part in the functions of the family, sometimes compensating, and sometimes exacerbating the emotional state of family members. Animals fit into the family system in various ways, depending on the stages of family development. In our study it was found that the most diverse animals with which functional and weakly functional families interacted influenced family life positively or neutrally. In dysfunctional families with a high level of anxiety and low differentiation, triangulation and transfer of problem feelings to the animal is triggered. In this case, the animal becomes neurotic, its behavior becomes worth, and the family starts to be even more dysfunctional. There was a need to find out which type of attitude to the animal helped, and which one prevented good interaction with it.

As a result of our research, questionnaires have been developed that study the level of responsible attitude to the animal, the type of relationship, the specificity of the owner's motivation. It has been found that the responsible attitude to the animal is associated with a high level of empathy, social support, and adequate motivation of the owner. The appearance of a pet plays a different role depending on the stages of family development and can serve as an indicator of crisis and conflict relations.

Keywords: mental health, social support, pets, questionnaires, typology, family system.

\section{References.}

1. Varga A.Ya. (2010) Domashniy pitomets v semeynoy sisteme. Voprosyi psihologii 1. - 56-65.

2. Myichko E.N., Sotskaya M.N., Belenkiy V.A., Zhuravlev Yu.V. (2004) Povedenie sobaki. Moskva OOO «AKVARIUM PRINT.

3. Nikolskaya A.B. (2009) Vzaimodeystvie cheloveka i sobaki v urbanizirovannoy srede Voprosyi psihologii, \# $2 \backslash 6,86-94$

4. Nikolskaya A.B.(2007) Diagnostika i korrektsiya otklonyayuschegosya povedeniya u sobak.Moskva Akvarium.

5. Horvitts K. (2004) Rukovodstvo po povedencheskoy meditsine sobak i koshek Moskva, Sofion.

6. Eydemiller E.(2005) Detskaya psihiatriya / E. Eydemiller S-Pb.: Piter.

7. Knight S., Herzog H.(2009) Author New Perspectives on Human-Animal Interactions: Theory, Policy and Research Paperback, Publisher: Wiley-Blackwell 


\title{
East and West about Mental Health: Personal and Social Strategies for the Achievement
}

\author{
(Sergei Naidenov) \\ Scientific-advisory center "Psychorehabilitation", Kyiv, Ukraine
}

\begin{abstract}
Introduction. Any human and society aims for happiness, often understanding it in its own way, but in behavioral aspect - always seek to escape the pain, sufferings, as well as to gain satisfaction. Issues of health started to attract philosophers and researchers of different cultures and epochs in situations when they had lost health themselves or criteria of the phenomenon or knowledge system evaluation changed. Periods of rapid development or crisis of society could motivate to seek ways of achievement and development of mental health both in individual personality and globally. However, without classification of the concept a specialist often performs substitution or cannot choose strategies for qualified help. A purpose is to analyze a category of mental health through the comparison of strategies of its achieving, retaining and developing in different cultural systems.

Earlier the category of mental health (MH) was defined through diminished medical definitions of mental and emotional problems (illness) which were reported in ICD-7-10, further as a system of effective adaptation.

Different systems of knowledge and philosophic concepts defined the category of mental health in different way. Eastern philosophic systems referred to the $\mathrm{MH}$ as the way of achieving happiness and harmony based on holism principles. Scientific and rational approaches of the West are based on principles of social effectiveness, optimal state of health and harmonious mood narrowed down the MH to the adequate or stressful variant of adaptation where adequate adaptation was perceived as the $\mathrm{MH}$ and stressful one as the loss of the $\mathrm{MH}$.
\end{abstract}

Results. Summarizing experience of decades of psychotherapeutic and research scientific practice (Naidenov $1995,1999)$ in the sphere of psychology of stress and health, psychological therapy of affective states and dependencies under the neuropsychiatry and Jungian analysis as well as Eastern medicine and Reiki philosophy, we propose to combine Eastern and Western approaches on the basis of the system theory. Distinguishing aspects of function, structure and coordination we conditionally divide the human personality in the most meaningful subsystems (somatopsychic, emotional, mental, social and coordinating ones) correlating, in our opinion, with coping strategies, subsyndromes of stress and certain stages of personality development that gives possibility to define criteria of the adequate selection of strategies for the $\mathrm{MH}$ achievement. According to four subsystems, we had analyzed methods in different traditional systems of the East (hat ha, layja djnani, raja yoga, Reiki etc.) to define specific problems of the MH and effective personal and social coping strategies (Bayley, 2000; Sandomirsky, 2005).

Conclusions. The strategy for the personality resides in finding those primary groups values of which are the most close to the values of the personality and do not cause the intrapersonal conflict and for his/her subsystems - individual recommendations.

There is a suggested synthetic concept of the MH: if the human of the given level of development lives and interacts under established standards of the reported stage, selecting successful strategies, - he/she is healthy, but if he/she can't solve problems of this level, then he/she is ill or he/she got to the zone of mental disharmony.

Considering strategies, it is necessary to be oriented not exactly at the $\mathrm{MH}$ of the personality, but at the $\mathrm{MH}$ of social group, territory, ethnic group, nation. Such social strategies (Sushkov I.R. 2008) include development of skills and values of the health culture in population of certain social group; formation of valeological culture and skills of the antistress protection in specialists and leaders of the social group; retention in population and leaders of social groups of a confidence and sense of justice towards the leadership elite to avoid situations of social tension and crises of state authorities; raising specialists of social management as mature personalities /or subjects/ with obligatory further incorporating them in systems of local authorities; systems of primary, secondary and tertiary psychoprophylactics under medicine, education and social work on prevention of aftereffects of stresses, mental illnesses and dependency states.

Keywords: mental health, social rehabilitation.

References.

1. Bayley A.A. (2000). Obsession as a common problem; Moscow: Navna.

2. Naidenov S. (1995). Recreation valeology for transformation manconsciouness in program "Antistress"; Athens: Abstracts of 4 European congress of psychology.

3. Naidenov S. (1999). Transformation of manconsciousness in program "Antistress"; Rome: Adsuesces Abstracts. VI European Congress of Psychology.

4. Sandomirsky M.E. (2005). Psychosomatics and body psychotherapy: practical guidelines; Moscow: Class.

5. Sushkov I.R. (2008). Psychological features of social relationship; Moscow: Institute of Psychology RAN. 


\title{
Intersubjectness as a Resource to Maintain Mental Health
}

\author{
(Maria Nakonechna) \\ National Pedagogical Dragomanov University, Kyiv, Ukraine \\ Nizhyn Mykola Gogol State University, Nizhyn, Ukraine
}

\begin{abstract}
Introduction. Intersubjectness is a trait of human interaction that is characterized by the agency evolving. As a result of being related in intersubjectness the participants of the interaction become more reflexive, creative, responsible and active. The integral characteristics that shows growth as a result of intersubjectness is agency. In other words, intersubjectness is an interaction that builds mutual development of the participants. The examples of intersubjectness include, but are not limited to situations when people are inspired by the interaction with the others; when the facilitation process is on; when true, non-manipulative help takes place. Being a strong factor in developing the human potential, intersubjectness helps to maintain and strengthen the mental health.
\end{abstract}

Purpose. The aim is to investigate intersubjectness and its potential for human development and maintaining mental health.

Methodology. The current trends in psychoanalysis suggest a phenomenon known as intersubjectivity (Blackstone, 2006). There is a critical difference between intersubjectness and intersubjectivity. As long as the latter is a form of connection of two unique subjectivities, the intersubjectness is based on agency of a person and his/her ability to put the initialization of activity within oneself. The intersubjectivity is a term used in psychoanalysis, the intersubjectness is now developed within the thesaurus of L.S Vygotsky's cultural-historical psychology and the agency approach. In our research we try to combine qualitative and quantitative methods. The questionnaire of intersubjectness has been created and is now in process of standardization. The experimental situation of the modified game of checkers has been studied.

Results. We searched for the experimental situation that could reveal the basic characteristics of intersubjectness. So we modified the game of checkers - at first the students played the usual game, and afterword they played with the aim to achieve win-win situation: there should be two checkers on the board in the end - one black, one white. This turned the situation form competition to cooperation. We also asked the students about their level of satisfaction after each game. As a rule, the modified variant of checkers gave more satisfaction. Very often students chose to play this modified variant instead of the classical one. Thus in this experimental situation we could model the intersubjectness, as the participants had one goal, it was cooperative, not competitive, and this variant of game gave much joy and satisfaction. So intersubjectness is a complex process of human interaction, and it can be hypothesized that intersubjectness is a resource to maintain mental health. We develop as personalities in the interaction with others, and most complex and facilitating interactions, such as intersubjectness, make a strong contribution to the improving of mental health and psychological wellbeing of a person.

Limitations and strengths of the study. The limitation of the study is the number of participants (12 so far), but the investigation is to be continued on the bigger sample. Another limitation is connected with certain subjectivity in the interpretation of the experimental results. The strength of the study is that it includes real experiment and analyzes real behavior of people in certain situations. Another strong feature of the research is that it is based on L.S. Vygotsky's cultural-historical theory, and the experiment is both diagnostic and developing.

Social value. The value of the research is connected with the possibilities to explore the potential of human development and the higher, more complex forms of interaction. In the beginning of the 21 century we should study not only the diseases and negative aspects, but also the farther frontiers of human nature (A.Maslow).

Conclusions. The intersubjectness can be viewed as a powerful resource to maintain mental health and develop one's personal potential. We should search in the sphere of interpersonal relations for the better possibilities of psychological help for those who need it. Studying intersubjectness shows us that the strategies of cooperation, mutual help and enriching relations have a good impact on the person's wellbeing and can be a starting point of the future psychological growth, which means being closer to mental health, not illness.

So, the concept of intersubjectness can be an important one while reflecting on the psychology of mental health. Some experimental researches have already started, and it tends to be a promising area of understanding the personal development potential.

Keywords: mental health, psychology, personal development, creativity, activity.

References.

Blackstone, J. (2006) Intersubjectivity and nonduality in the psychotherapeutic relationship The Journal of Transpersonal Psychology, 38 (1), 25-40. 


\title{
Political and Legal Informing of Students in Conditions of Military Conflict Between Russia and Ukraine
}

\author{
(Lyudmila Nikonenko)
}

Institute of Social and Political Psychology, National Academy of Educational Sciences of Ukraine, Kyiv, Ukraine

\begin{abstract}
Introduction. Clarification of the role of micro- and macro-environmental factors in formation of person's political and legal consciousness is one of the central problem of political psychology. In conditions of a military conflict, research of them becomes of particular significance, because the main target of powerful information attacks is the citizens' consciousness of the countries that are included in opposition. Youth communities are in the area of special attention, because youth is a sensitive period for the formation of individual's political and legal consciousness.
\end{abstract}

Methodology. The empirical study (2013-2015 years) was conducted to find out the peculiarities of obtaining, cognitive processing of information on the political and legal content of students in conditions of military conflict between Russia and Ukraine. Its aim is finding out the role of various sources of information of political and legal content in informing students.

The study of strategies was carried out through questionnaires and using of factor analysis procedures. On the basis of ten universities of Kyiv, 428 students (2-6 grades) were involved. The processing and analysis of the data was carried out using the SPSS Statistics 20.

Results. According to theoretical analysis of scientific literature, significant sources of information of political and legal content are identified. They are follow:

- Close social environment of the person: members of the family; friends and acquaintances;

- Educational environment of the university: students from the academic group; students of other academic groups, faculties, universities; leaders of student self-government; university lecturers; methodists from the educational work; management of the university.

- public institutions: representatives of civil movements, volunteers; church ministers, activists of religious communities; politicians, activists of political parties; representatives of the authorities;

- media: social networks; thematic internet sites; newspapers; radio; TV; official Internet-resources of the authorities.

Respondents were asked to evaluate the intensity of using different sources for obtaining information of political and legal content according to the 4-points interval scale (options: "never", "sometimes", "often", "permanently"). The 5-points Likert scale has been applied to find out the level of trust to the same sources of information of political and legal content.

Factoring procedures are made separately for the using and trust of various sources of information of political and legal content. The measure of selective adequacy gave the follow results: the Kaiser-Meyer-Olkin criterion $(0.8)$ and the Bartlett spherical criterion is $2589,(\mathrm{p} \leq 0,001)$. The obtained six-factor model of the use of various sources of information of political and legal content describes $66.79 \%$ of the total dispersion. For confidence as a result of the verification, the measure of selective adequacy has been clarified: the Kaiser Meyer-Olkin criterion is 0.842; the Bartlett spherical criterion is 2967,7 ( $\mathrm{p} \leq 0,001)$, which proves the validity of the use of factor analysis. The five-factor model, which describes $66.79 \%$ of the total dispersion, is obtained. The optimal number of factors and their statistical significance were verified according to Cattell's scree test when applying the principal component method (Varimax Normalized).

Students often refer to the sources with a minimum social distance (social networks, thematic Internet sites, friends and acquaintances, family members) for obtaining information of political and legal content. At least they use information from methodologists from educational work, church ministers and activists from religious communities. The six-factor model of using sources is reconstructed. The factors are statistically stable and describe $66.65 \%$ of the total dispersion. Scales are included in the factor (contribution to the total variance is given in brackets): 1) information from the main subjects of political and legal interaction $(14,7 \%)$; 2) receiving information from the mass media $(12,56 \%)$; 3) receiving information from university staff $(11.23 \%)$; 4) receiving information from students $(9,98 \%) ; 5)$ sources with a minimum social distance $(9.56 \%) ; 6)$ receiving information from religious organizations $(8.2 \%)$.

The most students trust in family members, friends and acquaintances; teachers, and representatives of civil society. Anti-trust leaders are politicians, activists of political parties, representatives of the authorities. The fivefactor model $(66.79 \%$ of the total dispersion) includes the follow scales: 1) confidence in educational environment of the university $(18 \%) ; 2)$ trust in the media $(15.53 \%) ; 3)$ trust in close environment $(12,9 \%) ; 4)$ trust in representatives of civil society $(10.3 \%)$; 5) trust in the authorities $(10.1 \%)$. 
Conclusions: There is a qualitative peculiarity of factor structures for the use of various sources of information of political and legal content and trust in them.

The high intensity of using the information receipt channel does not provide automatic trust in it. The rare use of particular source does not always imply a personal emotional rejection of the received information. Formation of a guide to trust or distrust of information takes place in the process of multiple communication of the individual with representatives of the surrounding environment, various public institutions, and the educational environment of universities and the use of various media.

Mostly students turn to sources with simplified access and minimal social distance (media, representatives of a close social environment) with information requests on politico-legal topics. Outsiders of political and legal informing of students are methodologists from educational work and representatives of religious organizations.

Leaders of trust for students are persons from the close environment, teachers and representatives of civil society. Instead, the information received from politicians, representatives of public authorities is the least trusted.

Keywords: personality, students, eating in the media space, information of political and legal content, factor structure of trust information, factor structure of the use of information sources. 


\title{
Psychological Health of a Person: Theoretical Issues
}

(Mykola Papucha)

\author{
Nizhyn Mykola Gogol State University, Nizhyn, Ukraine
}

\begin{abstract}
Introduction. Can we talk about a theory in the context of a person's psychological health? The question is essential. If under "theory" we understand the definition of some concept, then we can see a wide range of psychological health's definitions. But having taken a closer look it turns out that there is a huge theoretical problem.
\end{abstract}

Methodology. If the definition of the concept is not just the naming of some symptoms (which can be different each time), but is a word form of the phenomenon's essence, then we should admit that we don't know this essence. We multiply this "essences", losing the subject. It is strange that we don't know what is "psychologically healthy person", but we know, what is unhealthy. The essence and the phenomenon coincide here (that actually cannot be), and we consider the essence while it is just a symptom, a manifestation. We can help the person to get rid from the symptom, but it is the same as we give the person a big dose of analgetic while he has acute appendicitis. The situation is tragic. This is, as L.S. Vygotsky wrote, "treatment from cough, but not its reasons" (Vygotsky, 2015), and it flourishes now in all psychological practices. And if we add to that the unique singularity of a person's soul, we shall get chaos and confusion. So why do the psychotherapists do help? We shall answer this question a bit later. The theory is needed, and the reason for that is not for helping to reduce the symptoms, but to get rid of the real damages, which induce the symptom. This will be what is called recovery. In order to do this we should start from the real, not fictional understanding the essence of the person's psychological health. Do we know this essence? We do, at least in the methodological continuum of L.S. Vygotsky's cultural-historical theory. L.S. Vygotsky considered that the only really psychological research object is the complex structure that consists from instinctive, affective, motoric and intellectual moments (Vygotsky, 2015). This specific structure is also known as the higher psychological function. Human psychics is an assembly of numerous higher psychological functions, that are flexibly and chronogenetically interconnected and in their continuity consist the interfunctional psychological systems. We can add to this what L.S. Vygotsky couldn't, because he was ahead with his idea (that is empirically proved), and he hasn't lived till the theory of systems (synergetics) appeared. The structure, as it was understood by L.S. Vygotsky, is the currently frozen process in the time and space (in other words, the changes of the structures go on continually, and thus the personality should be understood as a chronotope) (Vygotsky, 2015). The connections within the higher psychological functions and within the interfunctional psychological systems are settled and developed according to the non-linearity laws, and, thus, every person has a nonregistered high number of the levels of freedom to exist and develop, which cannot be predicted by the modern science.

Results. From this standpoint we can present the existence of the psychologically healthy personality as continuously and unpredictably developing and conflict-dramatic, as the connections are established sometimes between very contradictory structures. And this is normal, the professional help is not needed here. The human psychics (interfunctional psychological system) has a need in experiences and, besides, the processes of damage always go along with the processes of self-renewal and creation, that cannot be controlled by person's consciousness. The main for the professional here is the commandment execution of ancient doctors: "First, do no harm".

Sometimes the reconstructive work of interfunctional psychological systems is not enough and then the person adds conscious willed efforts, aimed at the facilitation for the self-organizing psychical activity. These two factors (the unconscious self-organization of interfunctional psychological systems and the person's willed efforts) are actually the higher psychics' work, that is aimed at the organization of human behavior and the harmonization of his/her inner world. This work continues regularly and permanently and this is psychological health. Illness starts when the connections are radically damaged and cannot be adequately reconstructed by the person. The manifestations of it are really diversified. But if the specialist will understand the essence (the damage of interfunctional psychological systems), he will be able to help the person reconstruct that, what is wrong inside, and it means to cure actually and properly.

Conclusions. Now we shall return to the answer to the question. The existing ways of psychological help are not appropriately (with the knowledge of the essence), but accidentally can give a positive effect, because the very nature of higher psychological functions is essentially social, and the attentive, empathic relation from the Other (that is unfortunately so rare in our life) can considerably improve the person's state. In this sense the experience of K. Rogers' humanistic therapy is unique.

Keywords: mental health, psychology, personal development, activity.

References:

Vygotsky L. (2015) Collection of researches. M. V. 1. 


\title{
Employee's Mental Health in the Service Organizations as the Object of Psychological Research
}

\author{
(Igor Proshukalo) \\ University of Educational Management, Kyiv, Ukraine
}

Introduction: preservation the mental health of the citizens in our society is an important task at present time. While science prefers to stay apart from the problems of psychological ensuring mental health the employees either state or private companies because most of its conscious life a person spends at work and it for sure affects it, creating conditions for psychological comfort and well-being, or, on the contrary, triggering the mechanisms of pathological mental changes.

Purpose of study is to analyze the problem of employee's mental health in service organizations as an important part of their professional activity.

Methodology: the complex of general scientific theoretical methods, which are based on the interrelated basis of such approaches as integral, systemic, complex, activity approach and others.

Results: service industry is an intense work, which is associated with the active interpersonal communication, i.e. a worker resides in a situation of communication and interaction with the customers, colleagues, and authorities. This professional activity is always influenced by an individual, so a service sector worker may not be emotionally apart from the matters he/she is engaged in and it is one of the reason psycho-emotional overload. Among another reasons are violation the psychohygienic standards of workflow organization, the nature of the relationship between an employee and manager, the microclimate in the team. An important issue is also the cases of labor maladjustment. The employees in service organizations trying to maintain external efficient style of their professional activities and often take the consequences as the internal disharmony, psychosomatic and psycho-vegetative violations, the development of neurotic disorders. So mental health of employees is connected with their resistance against stress and distress, i.e. their mental stability in respect not only cognitive but also emotional experiences.

Practical value: the first step in addressing mental health of employees any companies is education. Providing managers with information and resources helps them not only to improve the psycho hygienic standards of workflow organization but better recognize signs and symptoms of the psycho - emotional overload which may lead the problems in the mental health of employees: emotional burnout, professional deformation and accentuation of personality traits.

Conclusions: mentally health workers in service organizations are the harmonic, counterbalanced persons, able to implement their vital needs and ability to self-reliance which is associated with such qualities as purposeful activity and adequate self-control and self-perception, developed abilities to concentrate attention, to keep in memory the information, the ability to logical information processing, critical thinking, creativity. Consideration the individual aspects is only initial stage of research the employee's mental health. In the future, it should focus on the study the patterns of mental health, definition of its criteria and psychological conditions for its ensuring.

Keywords: mental health, service industry, worker, manager, customers, work, employee's mental health, mental health of employees in service organizations. 


\title{
The Quality of Social Functioning in Patients with Depression, as a Parameter of State Severity
}

(Lyudmyla Rakhman, Oksana Plevachuk, Iaroslav Shpylovyi)

Danylo Halytsky Lviv National Medical University, Lviv, Ukraine

\begin{abstract}
Introduction. According to specialists' prognosis, significant growth of depressions in the structure of morbidity with mental disorders will be the leading cause of the loss of productivity of the adult population in the near future despite the achievement of psychopharmacology (World Health Organization, 2017). The course of depressions is determined by the clinical polymorphism, the tendency to the atypical variants, prolonged episodes and stressful effects on the patients and their social environment (Maruta, Zhupanova,2016, Maruta, 2013). This leads to significant social maladaptation, which becomes a tangible socio-economic problem (Prib.,2012, Barnett, Gotlib, 1988). Taking into account the specificity of the problem of depressive disorders at the present stage, in addition to understanding the biological and psychological mechanisms of the depression formation, it is necessary to consider social factors that have a significant impact on the development and course of the disease, and the use of the resource of social interaction will play an important role in the treatment efficacy (Asanova, 2008, Fava, et al.,2007, Coyne, et al.,1987).
\end{abstract}

Purpose. Study of social functioning structure in patients with depressive disorders and to identificate the parameters of their social dysfunction.

Design, Methodology and Approaches. 68 patients with depressive disorders during outpatient and inpatient treatment were examined. The following methods were used: clinical and psychopathological, psychometric, pathopsychological, statistical. The clinical and psychopathological method was based on a psychiatric examination in accordance with the criteria of ICD-10, patients' complaints, anamnestic data, symptoms, syndromes (psychopathological interpretation, correlation with classification characteristics of ICD-10) were evaluated. The severity of the depression was evaluated by the Hamilton scale -21 points (HAM-D-21) (Hamilton,1960). Social functioning (SF) was researched according to the WHO Psychiatric Disability Assessment Schedule (WHO/DAS) (Maruta, et.al, 2004); the following factors were evaluated: general behavioural dysfunction, social roles performance, intrahospital functioning and modifying factors.

Results. 26 patients were diagnosed with bipolar affective disorder, depressive episode (F31) - 38.2\%, recurrent depressive disorder (F33) -35 (51.5\%), dysthymia (F34) -6 (8.8\%), depressive episode (F32) -1 patient $(1.5 \%)$. Duration of the disease is $18,4 \pm 6,1$ years. The average age of the manifestation of depressive disorder is $21.3 \pm$ 1.4 years. Duration of depression on average $6.2 \pm 1.6$ months, the number of episodes of depression $-3.3 \pm 0.6$. According to the HAM-D-21, 52 patients (76.5\%) had a severe depression (more than 27 points), and 16 $(23.5 \%)$ were of moderate severity.

In $61.9 \%$, the indicator of general behavioral dysfunction was defined as "severe" and "very severe", reflecting significant systemic disorders of patients social functioning in society with problems in self-service, professional and family activities, activities in the general social sense. The average score of total behavioral dysfunction was 3.2 points. When performing social roles, "severe" (31.6\% of people) and "very severe" (40.4\% of people) dysfunction levels prevailed in all of the evaluated indicators.

The average point of performing social roles dysfunction was 3.7, which indicates low social interactions with loss of social contacts, insufficient performance of professional duties, study and work interest loss, marital and family life, as well as changes on behaviour in non-standard situations.

The analysis of structure of inpatients' dysfunction revealed that the state of "without dysfunction" was observed at $8.5 \%$, the "minimum" dysfunction was $14.4 \%$, "obvious" $-27.1 \%$, "severe" $-30.2 \%$, "very severe" $-19.8 \%$. Obtained data are shown significant problems of depressive patients social functioning in stationary conditions, confirming the need for early psychotherapeutic and rehabilitation interventions. The average score of social dysfunction parameters for a group of inpatients was 3.7. The modifying factors of social dysfunction included patient's positive qualities, special barriers, home atmosphere, support from the outside. The research of actual existing problems, the possibilities to solve them, evaluation of micro-and macro-social environment that can support the patient and be involved in rehabilitation processes was conducted. Violation of functioning with the prevalence of "severe" dysfunction was found in $33.5 \%$ of people.

The study results generalization reflected the average index of social functioning in the "Psychiatric Scale of Restrictions of Life" (WHO / DAS), the total and total average adaptation scores were determined. The most significant violations for depressive patients were observed in social roles performance (average point -3.7 , "very severe dysfunction") and the severity of individual problems that are determinative (modifying) at the decrease of social functioning (the average point 3.4, "severe dysfunction"). However, obvious resource sources are the correction of behavioural dysfunction with early psychotherapeutic intervention, participation of the 
patient in psychosocial rehabilitation measures, conducted in the intrahospital environment (indicators of social dysfunction in these areas are somewhat lower).

Limitations and strengths of the study. Study findings can be generalized to the patients about whom information is obtained.

Practical/ Social value. The obtained results will promote the construction of effective individual rehabilitation programs with mandatory measures aimed at overcoming social dysfunction.

Conclusions. Current research has shown significant structural violations of social functioning in depressive patients. General behavioural dysfunction is manifested by a decrease in activities in the family environment and activities in general social sense. The performance of social roles is substantially affected in the family environment, namely in spheres of marital life, parenthood, social contacts, tangible violations in decisionmaking, solving problems in non-standard life situations. Inpatients' dysfunction is characterized by a lack of interest in the performance of certain work (employment) and the difficulties of external communication. The main modifying factors of social dysfunction in patients are the lack of regular activities aimed at enhancing knowledge, skills in a particular area, and the lack of stable, trust relationships with any person other than close relatives (category "Special Positive Qualities") and factors associated with home atmosphere (in particular, rejection of the patient by a key figure). The total average point of social functioning corresponded to "severe" social dysfunction, leading was role dysfunction. Severe and moderate depressive symptoms form a social dysfunction through the mechanism of emotional interaction violation with the outside world.

Keywords: mental illness, social roles, social behavior.

\section{References.}

1. Asanova, A.E. (2008) Quality of life related to health of patients with depressive disorders. Bulletin of Psychiatry and psychopharmatherapy, 2 (14), 82-85.

2. Barnett, P. A., Gotlib, I. H. (1988). Psychosocial functioning and depression: Distinguishing among antecedents, concomitants, and consequences. Psychological bulletin, 104(1), 97.

3. Coyne, J. C., Kessler, R. C., Tal, M., Turnbull, J., Wortman, C. B., \& Greden, J. F. (1987). Living with a depressed person. Journal of Consulting and Clinical psychology, 55(3), 347.

4. Hamilton, M. (1960). A rating scale for depression. Journal of neurology, neurosurgery, and psychiatry, 23(1), 56.

5. Maruta, N. A. (2013) Recovery of social functioning - the main goal in treatment of depression. Neuronews, 8 (53), 16 - 20.

6. Maruta, N. O., Zhupanova D. O. (2016) Clinical-psychological peculiarities of patients with depression and different levels of medication compliance (diagnosis and correction). Bulletin of Psychiatry and psychopharmatherapy, 24 (1), 5-11.

7. Maruta,N.A., Panko, T.V., Yavdak, I.A. (2004) The criterion of the quality of life in psychiatric practice, H. Reef ARSIS, LTD.

8. Prib, G.A.(2012) Medical-social examination of disability in mentally ill patients (diagnostic, clinic, rehabilitation. Kyiv, IPK DSZU.

9. Fava, G. A., Ruini, C., \& Belaise, C. (2007). The concept of recovery in major depression. Psychological Medicine, 37(3), 307-317.

10. World Health Organization. (2017). Depression and other common mental disorders: global health estimates. 


\title{
Are Extrovert People More Satisfied with Life? Case Study
}

(Lena-Ramona Richițeanu-Năstase, Camelia Stăiculescu)

Bucharest University of Economic Studies, Bucharest, Romania

\begin{abstract}
Striving to achieve happiness is the purpose of any human being. Scientific research have studied happiness in the form of wellbeing including two dimensions: cognitive and affective. While the cognitive dimension reflects judgments about life satisfaction (Diener, 1984), affective dimension refers to the balance between positive and negative emotions. Subjective wellbeing is studied as synonymous with mental health (Diener, Lukas, Oishi, 2002) and reveals the protective role it has against stressor agents and the ability to prevent depression. Psychological and psycho-social research have studied the strong dependence between subjective wellbeing and personality. Research findings have shown that an optimistic, extrovert person has a higher level of life satisfaction. Also, studies show that genetic factors have a great influence in which people evaluate their life (Lykken and Tellegen, 1996). They state that $80 \%$ percent of the variance of subjective wellbeing is explained through genetic factors. Costa and McCrae (1980) stated that extraversion and happiness are correlated. M. Argyle and L. Lu (1990) determined that Eysenck extraversion scale and Oxford Happiness Inventory are correlated. Argyle and L. Lu also affirm that half of the grater happiness of the extraverts can be explain by their greater participation in social activities. In this paper, we shall try to present in introduction the theoretical frame and the results of these studies and then ourselves present the research results of a study made on 150 students enrolled in bachelor and master's degree at Bucharest University of Economic Studies. We have studied if this correlation between extraversion and the level of life satisfaction applies to our sample. In our research we have used two well established and known instruments: Life Satisfaction Inventory (Diener, 2006) and the E-Scale of EPQ (Eysenck Personality Questionnaire). Life Satisfaction Inventory was proposed by Ed Diener in 1985. We used the 2006 form of the instrument. The instrument has 5 items with a 7 Likert scale. The Satisfaction with Life Scale (SWLS) was developed to assess satisfaction with the respondent's life as a whole. Eysenck Personality Questionnaire (EPQ) is a questionnaire that assess the personality traits of a person in terms of extraversion/introversion, neuroticism/stability and sincerity. Our research used only those items that refer to extraversion/introversion. Results show that the correlation is maintained, that E-Scale of EPQ can be used as an instrument to assess the level of satisfaction with life, and that a more extravert person has a higher level of satisfaction with life. Our research also opens some questions regarding the possibility of training this personality trait and proposes in, conclusion of our paper a series of modalities of rising this feature. Also, as a suggestion it is proposed and designed a personal development and coaching program.
\end{abstract}

Keywords: extraversion, satisfaction with life, personal development, wellbeing. 


\section{Pilot Study of Stigmatization of Mental Health Problems in the Ukrainian Educational Environment}

(Olha Savychenko, Natalia Portnytska)

Zhytomyr Ivan Franko State University, Zhytomyr, Ukraine

Introduction. Ukrainian society today faces problems of discrimination, stigmatization of mental disorders. This problem is especially relevant in the educational field where we deal with poor awareness of both students and teachers of the causes, manifestations and resources of the development of children and adolescents with mental disorders. The high level of discrimination of children and adolescents with mental disabilities reduces their capacity for community adjustment. Reduced adjustment ability and cases of bullying interfere with implementation of inclusive educational system.

Purpose. The general purpose of our scientific development is raising the awareness of the population of the problems related to the development of children with mental health disorders, reducing the social stigma and promoting the inclusion of children with mental disorders in the system of inclusive education and other areas of public life. In this abstract we are studying the perception about pupils with mental disorders with the aim of establishing the causes and mechanisms of stigmatization. We expect that this pilot study will distinguish the directions and subjects of educational trainings.

Research Design. We have designed a questionnaire that studies the awareness of the population on the issues mental disorders, emotional filters, barriers as well as knowledge of the personal qualities of people with mental disorders. Modification of the measurement of social distances (E. Bogardus, 1925), semantic differential (C.Osgood, 1964), closed questions and evaluation grids were used to develop the questionnaire. Survey results were subjected to frequency and qualitative analysis and interpretations. The pilot study was attended by 346 people.

Results. We found out that the vast majority of investigated persons $(86.3 \%)$ said that they understood the term "mental health". At the same time, only about $75 \%$ could give some definition. Mental health is associated with a variety of indicators (figure 1).

\begin{tabular}{|r|r|}
\hline internal emotional state of a person, emotional well-being & $20,1 \%$ \\
emotional comfort, cheerfulness, psychological well-being, feeling of happiness & $18,7 \%$ \\
adequate behavioral responses, decision making, interaction with others & $16,4 \%$ \\
Intellectual and mental capacity & $10,4 \%$ \\
effective social interaction, respect for social norms & $9,7 \%$ \\
lack of mental disorders & $7,2 \%$ \\
balance, stress resistance, ability to establish contact, control actions, coping & $5,2 \%$ \\
compliance with age peculiarities & $3,7 \%$ \\
\hline
\end{tabular}

Figure 1. Understanding the concept "mental health" by participants of the educational process

We also studied the awareness of mental health problems. It turned out that the population is quite well oriented in the main mental disorders, they can correlate the names of disorders with their main characteristics. At the same time, there is a better awareness of developmental disorders such as cerebral palsy, Down syndrome. PTSD prevails among other mental disorders due to the situation in the country and the large-scale efforts of numerous colleagues in the direction of overcoming stigmatization of post-traumatic stress effects. We also should notice slightly distorted understanding of autism, anxiety, ADHD.

As for the emotional perception of some disorders, the most common emotions are compassion, sadness, and partly fear - this applies to all disorders. Almost absent are anger, abomination, aggression - these emotions are under taboo in the Ukrainian society, so this result can be explained as socially desirable and should be further explored. The respondents demonstrate some indifference to intellectual disorders, hyperactivity, anxiety and PTSD (which is rather strange, due to the prevalence and social aspects of these problems).

An interesting point for analysis is people's ideas about the ability of people with mental disabilities to participate in various spheres of life (table 1). 
Table 1. The respondents' perceptions of the ability of people with mental disabilities to participate in different spheres of life

\begin{tabular}{|c|c|c|c|c|c|}
\hline & $\begin{array}{l}\text { intellectual } \\
\text { disabilities }\end{array}$ & $\begin{array}{c}\text { cerebral } \\
\text { palsy }\end{array}$ & $\mathrm{ADHD}$ & $\begin{array}{l}\text { autistic } \\
\text { spectrum } \\
\text { disorders }\end{array}$ & anxiety \\
\hline family & 口 & 口 & V & प & 口 \\
\hline bringing benefits & 口 & 口 & 口 & $?$ & 口 \\
\hline household & 口 & $?$ & $?$ & $?$ & 口 \\
\hline learning & $?$ & 口 & 国 & 口 & 口 \\
\hline working & $?$ & & 囻 & 口 & 口 \\
\hline $\begin{array}{l}\text { governing the } \\
\text { state }\end{array}$ & 国 & 国 & $?$ & 困 & 口 \\
\hline teaching others & 囦 & 困 & $?$ & 图 & 口 \\
\hline
\end{tabular}

We also studied the characteristics of the social distance between general population and people with mental disorders. It turned out that they are quite easily accepting such people as neighbors, citizens of the country, users of common services (such as cafes or transport). But it is unacceptable to let these people closer to the family (there are some difficulties in accepting them as friends or classmates of own children, as well as close relatives). The greatest difficulty is acceptance of people with mental disorders in the workplace. The personal qualities of people with mental disorders were evaluated by respondents (table 2).

Table 2. The respondents' perceptions of the personal qualities of people with mental disorders

\begin{tabular}{|c|c|c|}
\hline & Positive qualities & Negative qualities \\
\hline Cerebralnalsy & $\begin{array}{l}\text { Kind, dutiful, clever, } \\
\text { communicable, adequate, } \\
\text { controlled }\end{array}$ & Dependent on others \\
\hline $\begin{array}{l}\text { intellectual } \\
\text { disorders }\end{array}$ & Unmanageable, stupid & Independent \\
\hline ADHD & $\begin{array}{l}\text { communicable, self- } \\
\text { determined }\end{array}$ & Unmanageable \\
\hline $\begin{array}{l}\text { autistic spectrum } \\
\text { disorders }\end{array}$ & & Avoidant \\
\hline Down syndrome & Kind, docile & Dependent on others \\
\hline Anxiety disorders & Independent & $\begin{array}{l}\text { Aggressive, evil, unmanageable, } \\
\text { avoidant, dangerous for others }\end{array}$ \\
\hline
\end{tabular}

Limitations and strengths of the study. Socially desirable answers and missing or insufficient communication experience of respondents with mentally disordered people are limitations of the study. Strengths of the study are that the obtained results allow to explain the main mechanisms of readiness/unpreparedness of the population to implement the ideas of inclusive education.

Practical value. Formation of adequate representations of pupils and teachers about the strengths and weaknesses of pupils with mental health disorders improves mutual adaptation and bullying prevention in the school environment.

Originality. Complex questionnaire for the study of cognitive, behavioral and emotional components of attitude towards children with mental disorders was first created.

Conclusions. Stigmatization of mental disorders in Ukrainian education is related to long-term isolation of mentally disordered people in special schools. This leads to a low level of awareness and the accumulation of negative emotions by all participants of the educational process. Thus, educational trainings for teachers and pupils may be directed to the formation of adequate representations about strengths and weaknesses of mentally disordered children, awareness and tolerance of emotions, finding common ways of their adaptation in pupils' groups. 
Keywords: mental health, mental illness, mentally disabled, discrimination based on disability, child care, child protection.

\section{References.}

1. Bogardus Emory S. (1925). Measuring Social Distances. Journal of Applied Sociology, 9: 299-308.

2. Osgood, C. E. (1964). Semantic differential technique in the comparative study of cultures. American Anthropologist, 66(3): 171-200. 


\title{
Confession as a Psychotherapeutic Tool to Work with Ego Inflation
}

\author{
Psychology and Psychotherapy department in Ukrainian Catholic University, Lviv, Ukraine
}

Introduction. According to modern Jungian psychoanalysis, the problem of Ego inflation is one of the most common causes of mental health problems. Already K.G. Jung (Jung, 1916) began to describe the issue of inflation; he emphasized that Ego, which in its essence, occupies mostly the area of consciousness and exists as a centre of consciousness, can be mistakenly expanded to a much larger area of its formation - the Self, which is understood as totality of the Psyche. Thus, when, Ego assumes the contents of the Self, then this is manifested in the sense of one's grandiosity, godlikeness, omnipotence. In Jungian psychoanalysis, such a symptom is called "inflation". In his work Ego and Archetype, E. Edinger defines inflation as a condition, in which, "something small (Ego) assumes features of something greater (the Self), and as a result increases so much that it goes beyond its size" (E. Edinger, 1992). The result of such inflation may be not only a temporary or lasting changes in the comprehension of the world and oneself, but also behavioural and social changes that can sharply damage the social adaptation of the individual. That is why it is important to know how to work with Ego inflation in psychotherapeutic practice.

The main purposes are: 1 . To pay attention to Ego inflation issue; 2 . To show how cooperation with the religious experience of the person could help to manage Ego inflation; 3. To point out, how to use social and religious experience and modify it into psychotherapeutic tool.

Design/Methodology/Approach of the article. The main methodological background of the article is: first, theoretical analysis of key analytical approaches to the issue of Ego inflation; second, psychological analysis of psychotherapeutic cases, connected with Ego inflation; third, review of attempts to connect religious experience of the person (community) and professional psychotherapeutic practice.

Results. When Ego is in stage of inflation, person could feel her/himself like grandiose, it could look like someone lost capability of reality testing, social adaptation could suffer too. Besides, there is another great danger, since any inflation is essentially a slip in any one of the modalities of the Self. As it is known, the intrapsychic function of the Self is to establish a balance in the psyche, and to arrange its harmonious functioning, which is manifested in establishing contradictions between the opposite sets of the psyche - conscious / unconscious, internal / external, collective / individual. Thus, any deviations in the balanced functioning of the psyche lead to the fact that the Self attempts to balance mental activity. Such a balance, is a sharp deterioration of mental or even physical health in the form of deep melancholy, depression, suicidal thoughts, psychosomatic disorders, etc.

Big danger for mental (physical) health is next stage, which follows inflation - alienation, this experience does very difficult to endure. Alienation of inflated Ego by the Self occurs with the same amplitude, with which Ego coincided with the Self. Thus, the more "inflated" Ego was, that is, the more archetypal contents it has occupied, the more traumatic the alienation will be.

According to E. Edinger (Edinger, 1992), who believes that in the Christian world, the concept of inflation is identical with the understanding of sin. However, a smaller type of inflation can be seen in the average healthy person. The biggest problem for the person is to experience the further alienation of Ego from the archetype. This condition is accompanied by a feeling of anxiety, depression and, often, accompanied by thoughts (conscious or unconscious) to harm oneself. In a situation of alienation, the level of traumatism, melancholy, lack of goals and needs, even suicidal thoughts, increases. In this case, the balance that the psyche tries to establish has a character of the arbiter of Fate, and in psychotherapeutic practice, this can be accompanied in ordinary people with words about the expectation of "God's punishment". That is why social experience how to work with such a problem could help to manage stages and to preserve person from hard experience.

Limitations and strengths of the study. Limitations of this study is absence of big empirical research. Study presents analyze of the literature and some cases-studies from practice. Strengths of the study is to present attempt to develop psychotherapeutic tool to work with Ego inflation issue.

Practical/Social value. To work with Ego inflation in psychotherapy, psychotherapist had to know not only about the fact of inflation, but about consequences of it as well. Another important issue is to be aware that when psychotherapist start to work with such a problem, he will have to work with depression, sometimes aggression, devaluation in future. According to Jungian psychoanalysis such cases are common even for healthy persons who is in his individuation process. That is why, sometimes modification of some historical, social and religious practice to manage Ego inflation could help to create pretty good tool to work with Ego inflation in psychotherapeutic practice.

Originality/Conclusions. So, the Christian practice of confession can have a great psychotherapeutic value in this case. After all, the confession, with the preservation of all its structural stages, is effective in working with 
inflation. Firstly, there is a preliminary self-analysis; secondly, there is confrontation with reality through the introduction of inflationary content in relation to an authoritative person (priest); thirdly, the detection and naming of the inflated Ego; fourthly, the identification of the archetype, with which the merger took place, and fifthly, the imposition of "penance", which is nothing else, but an inter-subjective experience of alienation without any detriment of one's own health. Thus, completion of penance is the social form of establishing a mental balance in order to avoid the interference of the forces of "Fate", and in other words "God's punishment". Summarize the contents of the paper. The article provides readers to the issue of Ego inflation which is understood as identification Ego with the Self or with the part of the Self. Confession as a psychotherapeutic tool of Ego inflation work is analyzed in the article.

Keywords: mental health, Inflation of the Ego, Self, Ego. 


\title{
Psycho-Information (Psychotronic) Technologies for Overcoming the Effects of Operative-Combat Mental Trauma: Addictive Disorders, Drug- Resistant Major Depression, Anhedonia and Alexithymia. First Report
}

\author{
(Anatolii V. Sergiienkoํㅜ, Taras A. Sergiienko², Olesia O. Kovalyk ${ }^{3}$, Taras I. Kovalyk ${ }^{4}$ ) \\ ${ }^{1}$ All-Ukrainian Association «Afghans of Chornobyl'», Kyiv, Ukraine \\ ${ }^{2}$ Major of Medicine Services, Kyiv, Ukraine \\ ${ }^{3}$ Senior Lieutenant of Medicine Services, Kyiv, Ukraine \\ ${ }^{4}$ Combat-veteran of the battalion B-2950 "Aidar", disabled war, Kyiv, Ukraine
}

\begin{abstract}
Background. In terms of operational-combat activity for the personnel of bodies and troops, the civilian population is affected by a set of intense long-acting stress-related factors leading to the tension and depletion of the adaptive systems of the organism and the emergence of a significant number of persons with operativecombat mental trauma (OCMT) (Bogomolets et al, 2015; Yena et al, 2014; Litvintsev et al, 2005; Rudoy, Sergiienko, 1990; Sergiienko, 1999; Trinka et al, 2013). Adaptation of personality to changed requirements in the performance of professional tasks and, subsequently, in specific conditions of civil life, was and remains the leading problem of medical and psychological support for effective human activities. Addictive disorders in the theater of war operations (TWO) have a distinct stressful nature, are secondary, perform a protective-adaptive function, block for a time stressful symptoms and prevent the launch of heavier registers. The hope for spontaneous, so-called "psychological" rehabilitation is utopian (Bogomolets et al, 2015; Yena et al, 2014; Litvintsev, 1997; Zapadnyuk and Sergiienko, 2004; Sergiienko, 1990; Sergiienko, 2001; Rudoy and Sergiienko, 1990).
\end{abstract}

Objective: to study psychophysiological and psychodiagnostic provision of military manpower, operative staff of the secret search, operational and technical units and operational-combat (partisan) detachments, rescuers, volunteers, in combat zones orders anti-terrorist operation (hereinafter - ATO) and civilian population of the occupied territories (more than 5000 people from April 1986 to January 2018).

Object of research: psychological qualities of servicemen, character accentuation, neuro-psychological instability, manifestations of anxiety and depressive disorders, OCMT, altered states of consciousness (A.S.C.).

Purpose: to introduce into the practical activity of the military-medical and military-psychological services of the power departments of Ukraine the results of the fundamental and theoretical studies of the former All-Union Problem No. 9, which was approved by the Resolution of the Central Committee of the CPSU and the Council of Ministers of the USSR dated 19.07.1985 No. 700-215 Top-Secret/Cosmic, corresponding to the Top-Secret Order of the KGB of the USSR No. 0060 and the Top-Secret Order of the Ministry of Defense of the USSR No. 00120, at various stages of medical evacuation in the conditions of man-made accidents, natural disasters, armed conflicts, etc.

Materials and methods. We studied a statistically significant representative group of soldiers and volunteers. The experimental and control groups were tested according to the standard procedure (16PF). Using personal questionnaire "NPI-A" (neuro-psychological instability - accentuation) of K.N. Poliakov, A.N. Glushko (1985) from standard methods of psycho-physiological selection and selection of military specialists, psycho-diagnostic methods for assessing professionally important qualities of the Navy manpower and the operational staff of the Ministry of Internal Affairs \& Security Service of Ukraine (Baranov, 1988; Yena et al, 2004; Kramarenko and Rudoy, 1984; Litvintsev, 1997; Lazutkina et al, 1999; Spivak, 2004). We measured their level of depression and anxiety. Observations were performed by psychiatrists, who took direct part in these operations.

Based on applied research of Doctor's: Meg Patterson (1983), Thomas Budzynski (1986), Eugene Peniston, Paul Kulkosky (1989), we was developed own protocol (E. Krupitsky, V. Nechyporenko, I. Smirnov, A. Safronov, A. Sergiienko et al.) (Zapadnyuk and Sergiienko, 2004; Sergiienko, 1990; Sergiienko, 2001), which, besides psycho-information (psychotronic) technologies (also known as Vibrational (Energy) Therapies), includes stimulation of the brain with a weak electric current (cranial electrostimulation, or CES), repetitive transcranial magnetic stimulation (or rTMS), magnetic resonance therapy (MRT) and audio-light stimulation (ALS), according to some authors audio-video stimulation (AVS) (Serykov et al, 1998; Smirnov and Borodkin, 1979; Smirnov, 2003) with own strategic for altered (changed) states of consciousness (ASC), based on holotropic mind and meditative practices, psychedelic (entheogenes: calypsol (ketamine), LSD-25, MDMA, DMT, ibogaine, etc.) (Kozlov, 2001; Krupitsky and Grinenko, 1992; Krupitsky, 1993; Krupitsky and Grinenko, 1993; Spivak, 2004, Tart, 2003; Cherepanova, 1983) psychoanalysis and psychotherapy by doctor's Ch. \& S. Grof, E. Krupitsky, J. Kehoe and other, subliminal/supraliminal communication of doctor E. Taylor and floating (or restricted environmental stimulation therapy - REST by J. Lilly (1977), with systems Rei-Ki (Master Dr. Mikao Usui), Tensegrity (Castaneda's Don Carlos), svasta-runic gymnastics (runic yoga), Stathagaldr (guidelines for 
Kyummer, F. Marbach, K. Shpysberher) or asanas Slavic runic, "charomutik" (magic) psycholinguistic effects (Litvintsev, 1997; Litvintsev, 2005; Lazutkina et al, 1999; Sergiienko, 1990; Rudoy, Sergiienko, 1990; Smirnov, 2003), aromatherapy (Soldatchenko, 2002), vegetotherapie (Spivak, 2004), cut more (Andari et al, 2018). Also, methods of debriefing, psychological decompression and crisis intervention, group and individual psychopsychiatric consultations were used.

Results. Studies show that the organization psychodiagnostic, medical rehabilitation and maintenance personnel in war and peace time, on such extremale and dangerous conditions, the experience ATO has the following features:

1. The effect of stress factors on combatants causing manifestations of OCMT in the form of acute reactions to stress, post-traumatic stress disorder, physical and mental disorders, chronic psychopathological personality changes, social disadapted and antisocial behavior, various variants of aesthetic and depressive syndrome with suicidal tendencies, dependence on psychoactive substances, etc.

2. Among them there is a hidden phenomenon disability, therefore particularly important preventive measures.

3. The main factors that lead to the emergence and growth of OCPT in real combat conditions are studied. Mathematical models and methods for timely recognition of such factors are developed (Andari et al, 2018; Zapadnyuk and Sergiienko, 2004; Sergiienko, 2001; Rudoy and Sergiienko, 1990).

4. Introduced military-medical psycho-informational (psychotronic) technologies A.S.C. on prevention of OCPT, in order to preserve and enhance the combat capability of the vowel and the secret apparatus of internal and external intelligence through: meditative practices, drug analysis, narcosis psychotherapy, legend programming of the future biography, holotropic transformation a worldview, intensive psycho-informative treatment recovery, and so on.

5. The participants in the activities of ATO need MPR on such phases: recruitment and training in the training center; participation in combat operations; period of output from the battle area for rest and overhaul; treatment in health facilities; adapting to civilian life.

Based on the long-term use of the own protocol in combat conditions, we can draw the following

\section{Conclusions:}

1. Feasibility of application psycho-information (psychotronic) technologies with strategic for ASC and Protocol "CES\&ALS\&MRT" in TWO have been proved.

2. CES\&ALS\&MRT with strategic for ASC are not a cure or not only cure, but brain training, which greatly expands its abilities and abilities to cope with various dysfunctions by himself.

3. CES\&ALS\&MRT with strategic for ASC cause a rapid recovery of the normal level of neuro-chemicals suppressed by combatants with drugs and alcohol. Get rid of the painful feelings of anhedonia and alexithymia.

4. CES\&ALS\&MRT in combination with psycho-information technologies for ASC allow quickly to overcome the consequences of operative-combat mental trauma in the form of drug-resistant major depression, asthenicdepressive disorders with a high level of anxiety, neutralize addictive and suicidal (homicidal) manifestations, antisocial behavior and soften distant manifestations of PTSD.

5. The CES\&ALS\&MRT with strategic for ASC method expands the traditional tools of psychologists and psychotherapists, allows them to maintain high performance, prevent mental burnout and professional deformation.

6. The method has practically no contra-indications, it does not cause addiction and dependence, it is easily accessible, after brief briefing it can be used by the combatants themselves, both directly in TWO conditions, and at the stages of medical and psychological-psychiatric rehabilitation.

Keywords: operative-combat mental trauma, anhedonia, alexithymia, psycho-information (psychotronic) technologies, altered (changed) states of consciousness, professional psycho-physiological qualities, personnel reliability, treatment resistant depression, mental burnout, combat mental trauma, mental health, trauma, military conflict.

\section{References.}

1. Andari S., Askerova T., Zdoryk I., Kovalyk O., Serhiienko T., Sergiienko A. (2018). Non-medicines strategies for overcoming the effects of operative-combat mental trauma // International and practical conference of young scientists, dedicated to the $25^{\text {th }}$ Anniversary of National Academy of Medical Science of Ukraine.March, 23 ${ }^{\text {th }}$, 2018, Kyiv, Ukraine.

2. Baranov Y. (1988). The recruits' neuropsychiatric instability and methods of detection. Actual issues of Military. Moscow

3. Bogomolets O.V., Trinka I.S., Sergiienko A.V. (2015). The impact of catastrophes and wars on mental health of personality and society. Military medicine of Ukraine. 15.- 70-79.

4. Yena A.I., Voronenko V.V., Kalnish V.V., Doroshenko M.M., Chegodar A.I., Masliuk V.V., Fartushniy E.M. (2004) Military Psychology. Textbook 
5. Yena A.I., Masliuk V.V., Sergiienko A.V. (2014) Actuality and organizational approaches of medicalpsychological rehabilitation of the ex-combatants. Scientific Journal of MH of Ukraine.- №1 (5).- 5-15.

6. Kramarenko G.I., Rudoy I.S. (1984) The recruits' nervous-mental instability: the lectures. Leningrad; 29 p.

7. Kozlov V.V. (2001) Козлов В.В. Psychotechnologies of altered states of consciousness. Second edition. Moscow - 544 p. ISBN: 5-89939-040-9.

8. Krupitsky E.M., Grinenko A.I. (1992). The use of psychedelic drugs in psychiatry: past, present and future. Survey of psychiatry and clinical psychology.- №1. 31-47.

9. Krupitsky E.M., Paley A.I., Berkaliev T.N. (1993). Psychedelic psychotherapy with the use of ketamine. Consultative psychology and psychotherapy.- Moscow.- № 2. ISSN: 2075-3470

10. Krupitsky E.M., Grinenko A.I. (1996). Stabilization of remissions with alcoholism (through ketamine therapy).- Moscow.

11. Litvintsev S., Chermyianin S., Maklakov A. (1997). Methodological aspects of assessing the nervouspsychological stability of servicemen. Navy Medical Journal.- №3.- 5-8.

12. Litvintsev S., Snedkov E., Reznik A., (2005). Combat trauma: a guide for doctors.- Moscow.

13. Methods of military professional psychological selection / Ed. Lazutkina VI, Zatsarny NN, Zarakovskiy G (1999).

14. Fundamentals of professional psychological selection of military specialists (1991).

15. Psychoinformational and psychopharmacological support of professional (operational) longevity and optimal activity of a healthy person in extreme conditions: Teaching. manual / Ed. B.V. Zapadnyuk, AV Sergiienko (2004). ISBN: 966-7474-66-6.

16. Psychoprophylactic work among personnel of law enforcement bodies. Comp. A.V. Sergiienko (1990).

17. Psychoprophylactic work among veterans of the Chernobyl disaster: Teach. manual / For the community Ed. AV Sergiienko (2001).

18. Psychodiagnostic methodologies for assessing the professionally important qualities of the Navy personnel: Methodological recommendations. (1991).

19. Psychophysiological selection of military specialists: Methodological manual (1973).

20. Rudoy I., Sergiienko A. (1990) The state of mental health of personnel in extreme conditions. Analytical review.

21. Safronov A. (2008) Psychopractices in mystical traditions from archaic to modern times.- ISBN: 978-9662079-18-0.

22. Sergiienko A., Yena A., Skaletsky Yu., Khudetsky I. (1999) To the question of the pathogenesis of combat (operational) psychic trauma. Conference Proceedings.

23. Sergiienko A., Yena A., Khmelnitsky V. (1998) On the issue of creating a unified system of psychoinformation security and psycho-physiological provision of the population, as an integral part of the national security of Ukraine. Problems of Security of the Ukrainian Nation at the Turn of the XXI Century. Materials of the All-Ukrainian Conference. - Part I.

24. Serykov A., Dremov S., Semin I., et al (1998) Audio-visual stimulation in the treatment of PTSD. Rehabilitation in Psychiatry. $170-171$.

25. Smirnov V., Borodkin Y. (1979) Artificial functional relationships. Leningrad.

26. Smirnov I. (2003) The psychoecology. Textbook. Moscow.- ISBN: 5-9900151-1-9.

27. Spivak D. (1986) The linguistic of modified states of consciousness

28. Spivak D. (1984) Early detection of military personnel with neuropsychic disorders. Moscow.

29. Spivak L.I. (1992) Modified states of consciousness. Phisiology of the human - 18 (2) -22 - 27.

30. Soldatchenko S.S., Kaschenko G.F., Pidaev A.V. (2002). Aromatherapy. Symferopol

31. Tart Ch. (2003) Modified states of consciousness. Moscow - ISBN: 5-699-03481-1.

32. Trinka I.S., Nechyporenko V.V., Sergiienko A.V., Romanenko Y.L., Sergiienko T.A. (2013) Medical and sanitary and psycho-physiological support of autonomous reconnaissance and search raids of operational-combat detachments of the Ministry of Internal Affairs and the KGB of the USSR in conditions of high mountains and mountain-desert terrain. Military Medicine of Ukraine - 13.- 96-104.

33. Cherepanova I.Y. (1986) The House of the Witch: The Beginning of Suggestive Linguistics. Perm.

34. Bennett,(2006) Stanislav Grof with Hal Zina. The holotropic mind: the three levels of human consciousness and how they shape our lives (1st paperback ed.).- San Francisco, Calif.: Harper San Francisco, - ISBN: 9780062506597.

35. Kiepenheuer \& Witsch, (1982). Diese Definition hat Reich auch in der revidierten Version des Buches (1944) beibehalten, nur stilistisch etwas verändert. Vgl. Wilhelm Reich: Genitalität in der Theorie und Therapie der Neurose.- Köln:

36. Grof S. (1985) Beyond the Brain: Birth, Death and Transcendence in Psychotherapy.- Albany, N.Y.

37. Grof Ch. (1990) The Impoverished Soul: Addiction as Spiritual Emergency // Spiritual Emergence Network.- Vol.2(1)- 20-29. 
38. Kehoe John (2013) The subconscious can do everything. Moscow. ISBN: 978-985-15-3092-8.

39. Krupitsky E., Burakov A., Romanova T., Dunaevsky I., Strassman R., Grinenko A. (2002) Ketamine psychotherapy for heroin addiction: immediate effects and two-year follow-up // Journal of substance abuse treatment.- Vol. 23.- 273-283.

40. Lilly John C. (1981) The Deep Self (Floating or Restricted Environmental Stimulation Therapy - REST): Profound Relaxation and the Tank Isolation Technique.- Warner Books. ISBN: 044-6330-23X.

41. Shanon., Benny. (2002) The antipodes of the mind: charting the phenomenology of the Ayahuasca experience (Reprinted ed.).- New York: Oxford University Press.- ISBN: 978-0-19-925292-3.

42. Stafford P. (1983) Psychedelic Encyclopedia.- Los Angeles: J.P.Tarcher, Inc.

43. Wilhelm Reich. (1969) Die Funktion des Orgasmus. Die Funktion des Orgasmus. Sexualökonomische Grundprobleme der biologischen Energie.- Köln: Kiepenheuer \& Witsch.

44. Wilhelm Reich (1970) Charakteranalyse.- Köln: Kiepenheuer \& Witsch. 


\title{
Attitude to Supervision as the Form of Professional Support: Survey Results of the Helping Professions' Specialists
}

\author{
(Diana Shtryhol ${ }^{1}$, Larysa Spitsyna ${ }^{2}$, Victoria Melman ${ }^{3}$, Oleksii Vydysh ${ }^{4}$,
} Inese Stankus-Visa ${ }^{5}$, Zilvinas Gailius ${ }^{6}$ )

${ }^{1}$ V.N.Karazin Kharkiv National University, Kharkiv, Ukraine

${ }^{2}$ Zaporizhzhia National University, Zaporizhzhia, Ukraine

${ }^{3}$ KRI NAPA, Kharkiv, Ukraine

${ }^{4}$ City Social Services Center for Family, Children and Youth, Zaporizhzhia, Ukraine

${ }^{5}$ Association of national Organisation for Supervision in Europe, Latvia

6 "Kitokie projektai", Kaunas, Lithuania

Introduction. Over the past 20 years, there has been an unprecedented growth in the use of counseling and therapeutic approaches in the field of helping professions, in part because of the transition from more traditional forms of inpatient care to "community care" for people experiencing difficult life situations and in need of support. This transition not only led to increased demands on helping professionals, but also accelerated the realization that such work should be accompanied by appropriate supervision (P. Hawkins, R. Schochet). These issues have been very actively discussed in the publications of the last three decades in the works of Carroll, Page and Wosket, Brown and Bourne, Bond and Holland, Carroll and Holloway, Gilbert and Evans, Inskipp and Proctor, Kühl, Schreyögg, Rohr, Willke. And so today we have, on the one hand, a justified need for studying, developing and applying supervision in the practice of psychotherapy and counseling, on the other - an obvious and understandable lack of knowledge of supervision both at the theoretical and practical levels.

Methodology. That is why it seems reasonable and justified for us to study the attitude towards supervision as a form of professional support for specialists in Ukraine by interviewing specialists helping professions. The methodological basis of our research was an integrative approach that combines the principles of the humanistic, systemic, psychodynamic, cognitive - behavioral approaches realized in the practice of intersubject interaction between the supervisor and supervisee. The method used is a specially developed questionnaire for studying attitudes towards various aspects of supervising of psychologists, social workers, psychotherapists, psychiatrists (a sample of more than 100 respondents).

Results. In our research, we proceed from the assumption that supervision is a form of professional counseling aimed at improving the quality of communications and cooperation in the professional context, a form of professional support in the field of helping occupations, in business, in psychological and psychotherapeutic practice, etc.

In the European model of supervision, carried out on the basis of the professional standards of the Association of national Organisation for Supervision in Europe (ANSE), the supervisor is an independent specialist, invited to the organization. In the process of group work supervisor with supervisor (group, organization) creates conditions for:

- Improvement of professional activity, first of all, due to improvement of interpersonal communication and interaction in groups;

- Solving problem, conflict situations depending on the current needs of the organization; Search for the best solution for the organization at the moment;

- Prevention of emotional burnout of employees of the organization;

- Creation of conditions for constructive communication, which involves working out and solving problems of members of the supervisory group, search and awareness of resources;

- Implementation of emotional support, achievement of understanding, allowing the client to realize the possibilities of self-help, creation of conditions for making an informed, well -balanced decision;

- Development of professional and socio-psychological competencies of employees of organizations.

Conclusions. Various aspects of the attitude of the interviewed specialists to the supervisory process, professional experience, types of problem situations and methods for their solution, experience of participation, motivation and efficiency conditions of the supervision and other aspects of supervisory interaction were analyzed on base of results of the survey.

The obtained results confirmed the earlier assumption about the important role of supervision as a regulator of professional relations in the field of helping professions in Ukraine, showed the possibilities of using resources of supervisory relations for solving various professional tasks, confirmed the motivation of professionals for participation and training in supervisory programs. And this is a unique result of our research, which raises previously completely unexplored topics of professional psychotherapeutic / psychological discourse in Ukraine. At the same time, as a result of the survey, we received confirmation that participants were not sufficiently aware of the supervisory process as a whole, as well as of certain aspects of it, about the resources of supervisory 
reflection in solving psychotherapeutic problems. And, at the same time, this problem (clearing) quite clearly indicates the direction of development and implementation of supervision in the practice of providing psychosocial support and assistance in mental health.

Keywords: supervision, psychosocial support, professional experience, professional relations, helping professions, psychotherapy, counseling. 


\title{
The Cognitive Methods of Protection the Adolescences' Mental Health in the World Wide Web
}

\author{
(Oksana Strilchuk) \\ Institute of Social and Political Sciences NAES of Ukraine
}

\begin{abstract}
Introduction. The problem of saving the mental health in the Internet appeared with the understanding the fact that a network contains both opportunities and threats and is not absolutely safe environment for the human. It is especially important in the case of the young generation. The network is the global communicative space which provides everybody's personal participation. We divide the dangers of the network into the personal and the social ones. The inner psychological problems of the Network use like the Internet Addiction Disorder refer to the personal threats and the different external influences belong to the social ones. They could have the obvious and the hidden content. The obvious social dangers in the Internet are connected with the external psychological pressure and the violence such as propaganda, cyberbulling, cyberharasment, recruiting to the terrorist organizations. The hidden ones are connected with the catching in the Network which is not noticeable for the young person. In this case we mean the mechanisms of individual influence on the user by keeping track of his digital behavior. The network content forms according to the preferences of the certain person who can get information without any additional efforts. The trust to the network grows too much and the adolescents begin to revalue the role of the Internet in their life. The own internet activity turns into the subject of the strong emotional feelings instead to stay the communicative channel.
\end{abstract}

The teen age is the crisis period of the young person development. The forming of adolescent's identity is accompanied by the dependence of the external evaluation, the seeking of own social role and the desire to be emancipated. The teenager's identity transformations are often not controlled during the virtual socialization. It is caused by the freedom of choice and behavior in the Internet and the possibility of external intervention. The adolescents become the object of the third-party influences while using the Network as the source of communication and self-realization.

Purpose. We needed to research how the teenagers were able to detect the threats of the Web through measuring the level of their reflective, critical and analytical perception. In what way they can identify such mechanisms of external influence as suggestion and infection. It was also necessary to research the power of emotional feelings about the personal Internet activity which would help us to predict teenagers' stresses caused by the Web. The final goal was to create the program of the safe interaction with the Internet which was based on reflective approach.

Design/Methodology/Approach. The theoretical analysis of the different approaches devoted to the problem of the digital safety of the youth. The study of the media culture as the source of preventing the negative media influences. The development of our own diagnostically tools according to our main purposes. The researching how the adolescents were able to regulate their personal Internet activity with using the Internet Disorder tests. The feather creating of the program devoted to the safe interaction with the Web.

Results. The data which were received had proved our assumption that the adolescents were not skilled enough to analyze the information qualitatively. They have a high level of trust to information without critical reflection. A lot of them are not able to identify the hidden influences and to resist the obvious ones. The diagnostic of the Internet Addiction Disorder showed the low level of the ability to control the own Internet activity. While investigating the emotional component we have also came to conclusion that the virtual activity was more valuable for the teenager then the real achievements. Basing on the research we have developed the program of the safe interaction with the World Wide Web which could be provided in the school curriculum.

Limitations and strengths of the study. The strength of the study is in the expanding the vision of the problematic Network use from the subject of psychotherapy to the cognitive ability to identify different external influences. Too wide circle of problems and the fast loose of actuality caused by the rapid evolution of the Web are the limitations of the research.

Practical/Social value. The policy of the mental health saving in the digital world has the limited outlook in Ukraine. It is mostly directed on the studying of the informational war threats what is not enough. Our main purpose is to create the universal program of protection the adolescents' mental health in the Web which will cover more wide range of the problems then it covers today.

Originality/Conclusions. So, the researches of the human Internet safety have been gone beyond the exploring the Internet Addiction Disorder although it is still staying actual. There are more theoretical researches and less practical work in this sphere. The state regulation and the self-limitation in the Internet use are considered to be the main preventive measures. The Web corporations try to deepen the technologies of the influence on the youth which are impossible to be learned. Despite the opinion that the new technologies give only opportunities we should remember about the risks. The disappearance of the anonymity in the World Web turned it into the 
tool of the personal hidden influence. The user of teen age doesn't realize the power of the external impact on his digital and even real behavior. The state regulation and the self-limitation are the temporary and not very effective measures. When the young person will be able to create the own cognitive filter through the developing of the reflective, critical and analytical perception of the information it will help to avoid the main dangers of The Web. The introduction of these cognitive technologies in the modern school should become the priority topic for the public social policy in Ukraine.

Keywords: adolescences, mental health, young person, identity transformation, external influence, reflective perception, public social policy. 


\title{
Is autism Spectrum Disorder (ASD) a Mind-and-Somatic State "Neuro- Managing" System Malfunction? About Some Possible Mechanisms of this Kind of Neurodevelopmental Disorder
}

\author{
(Oleksii Tanasiienko ${ }^{1}$, Olena Tanasiienko ${ }^{2}$ ) \\ ${ }^{1}$ META GENIUS TM Strategy Group, Kyiv, Ukraine \\ ${ }^{2}$ Medical Center "The Center for Neuro Diagnostics", Kyiv, Ukraine
}

\begin{abstract}
Introduction: The problem of autism spectrum disorder (ASD) is becoming more acute in the world. Traditionally, ASD is seen as a violation of the neurodevelopmental disorder, characterized by disorders of social interaction, verbal and non-verbal communication, as well as limiting the manifestation and repetition of patterns of behavior. It is not just some local mental anomaly, but a multifunctional systemic disorder, based on problems of different origins: immunological, neurological, biochemical, social, cultural, etc. Usually, signs of autism manifest themselves in the first two years of a child's life and do not completely disappear in the adult age, even under the most favorable scenarios of therapy and social rehabilitation.

Purpose: The present paper is attempt to made an interpretation of some of the latest experimental data published by another research team working in Israel that studied the misunderstanding of emotional signals, based on laboratory studies of adult subjects (both autistics and neurologically typical) and a comparative analysis of their altered responses to social chemosignals.

Design/Methodology/Approach: It has been suggested that autistic persons lack a mechanism of transferring the acquired "neuro-experience" that is "imprinted" into the neuro-network of the bearer of this neuroexperience, from one individual to another, that is not yet studied, and presumably present in neurotypical people, but suppressed (broken) in autistics. Is proposed a conceptual model based on the supposition to explain observed phenomena.
\end{abstract}

Results: The concept of the of Neuro-Landscapes Transfer (NLT) is proposed as an instrumental model for constructing further researches and interpreting the obtained data, which allows us to take a fresh look at the "mechanism" of functioning of ASD and introduce Neuro-Landscapes Cloning (NLCln), Neuro-Landscape Contamination (NLCnt) and some other models for the presentation of possible processes of intraspecific transmission of acquired neuro-experience, important in describing the significant changes taking place in the mental and somatic field, also in the field of social interaction among autistic people themselves and among both autistics and neurologically typical persons.

Limitations and strengths of the study: The paper put forward an integrative interdisciplinary hypothesis that aims to reduce the descriptions of the various often contradictory observed phenomena to a single conceptual platform which is closest conceptually to neuroinformatics and does not pretend to directly explain the whole ASD phenomena in the conceptual "apparatus" and terminological discourse of particular scientific context of applied researches including: psychiatric, immunological, neurological, biochemical, social, cultural and similar studies of the problem of autism. In other words, the paper presents the framework approach model, focusing in unifying the former particular approaches to study the field of ASD. There is the consideration of the presenters that is the more detailed functioning of the mechanism of the Neuro-Landscapes Transfer (NLT) must be remain beyond the scope of the present work, because requires a separate study for a further observation and making a deeper research in the future.

Practical/Social value: The ASD model proposed allows explaining numerous phenomena, individual symptoms and social manifestations of autism within the single conceptual approach framework using a single conceptual description based on idea of neuro-landscapes that allows researchers to move to a not imaginary oriented, but more phenomenologically centered "common language" description in the general field of ASD.

Originality/Conclusions: According to the proposed model, ASD is caused by a deficit of a specific "mechanism" for transpersonal transferring of acquired "neuro-experience" which normally forms at an early age of the child's development and further uses the individual's access to the collective "neuro-experience" of the human population, determining the individual ability of mind and somatic field in optimally respond to environmental factors, regulate the mental and physical components of physiological processes in the body, organize cognition of the environment world, planning actions and communication with other individuals in society.

Keywords: ASD, autism spectrum disorder, autism, disease of the nervous system, mental illness, neurobiology, psychiatry, psychology, social behavior, social life. 


\section{Applying The Semantic Differential to Compare the Experiences of Existential Fears}

(Kateryna Titova ${ }^{1}$, Volodymyr Savinov $\left.{ }^{2}\right)$

${ }^{1}$ Department of General Psychology, Faculty of Psychology, Taras Shevchenko National University, Kyiv, Ukraine ${ }^{2}$ Laboratory of Social Psychology of Personality, Institute for Social and Political Psychology of the National Academy of Educational Sciences of Ukraine, Kyiv, Ukraine

Introduction. In the context of the hybrid war in society, the experience of existential fears becomes more intense: being manifested in a subconscious level, they raise the problem of the coexistence of personality and fear.

Purpose. Identifying patterns of how it is perceived and displayed will facilitate seeking the ways to cope with them. Methodology. This study focuses on the comparison of the fears of death, loneliness, meaninglessness, and freedom in the structure of human consciousness. For this purpose, we turned to the semantic differential method, as it allows us to evaluate the subjective aspect of meanings associated with the personal sense, social attitudes, stereotypes, and other emotionally rich, weakly structured, and barely consciously perceived forms of generalization [3].

The procedure for constructing semantic differential occurred in two basic sequential stages: 1) identifying bipolar descriptors (125 individuals); 2) rating the descriptors (90 individuals). The questionnaire contained an open question that allowed a respondent to answer in their own words. The question was about understanding the phenomenon of fear and read as follows: "What adjectives would you use to describe fear?"

The procedure of frequency analysis of the responses yielded relevant semantic units for constructing the semantic differential of existential fears. In qualitative analysis, the total number of words was reduced from 1193 to 203. Also, we conducted sorting to remove auxiliary parts of speech, sentences, phrases, so the number of indicators dropped to 36 main descriptors.

Table 1. "Psychosemantic Portrait of Bipolar Poles of Descriptors of Fears"

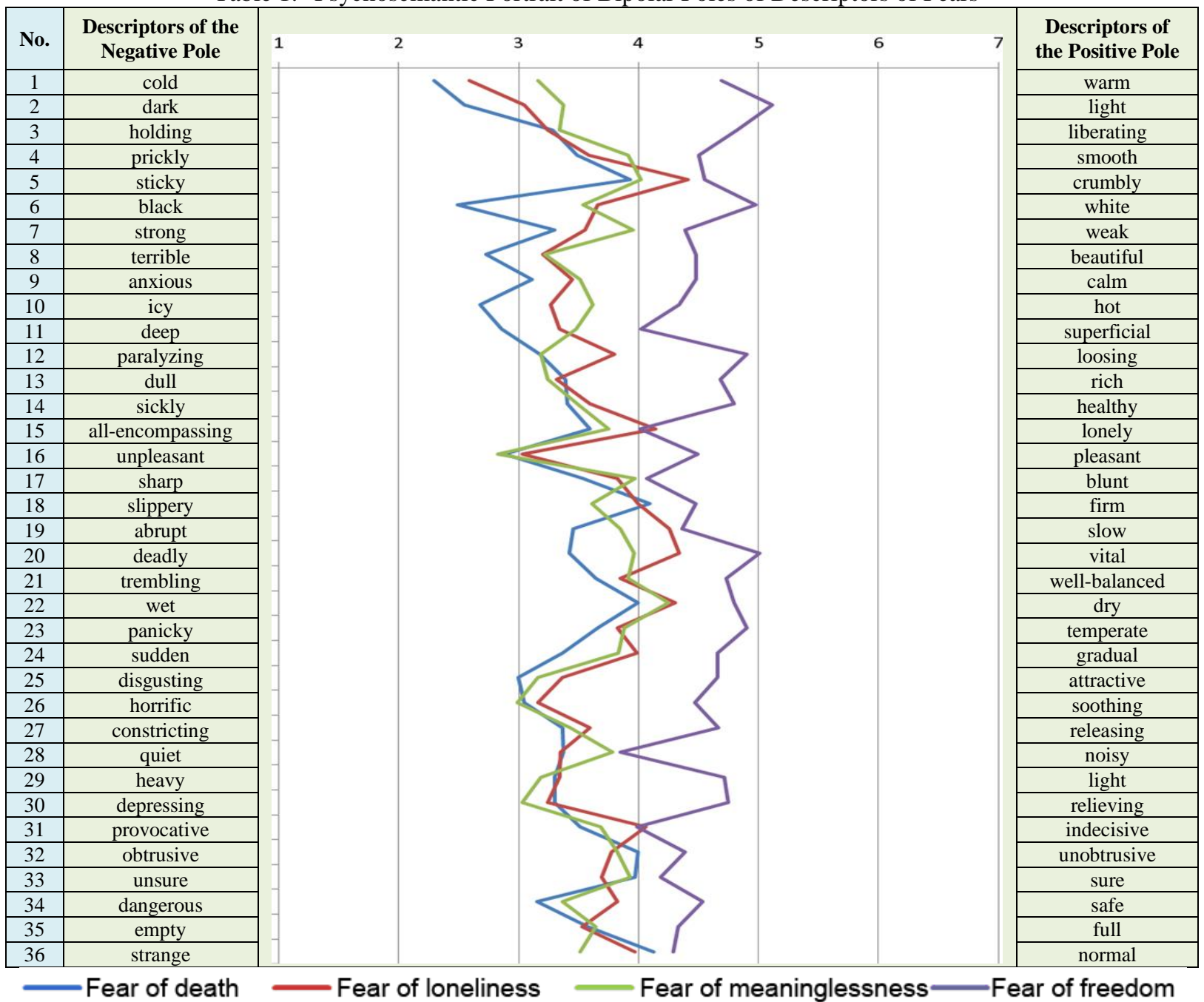


Results. The polar scales and the generalized results of the completed questionnaires (127 respondents) are presented in order of significance of descriptors in Table 1.

The chart represents the direction of change in attitude towards fears, demonstrating to which pole the subjects incline while rating the fears. It is noticeable that the curves of the three fears are very like and similar, together approaching one pole or the other. All the obvious differences can also be seen; at the same time, the interpretation of graphically shown data for each separate fear doesn't exhaust the question of its content load. Therefore, we then processed the data using the factor analysis procedure, which was carried out by the method of extracting the principal components and included rotation method of varimax with Kaiser normalization.

Factor analysis allowed us to identify the structure of the intercorrelations between the scales by classifying them. Next, we received the main semantic structures of fear as it is perceived by the subjects and excluded from the analysis less significant factors that explain least of the variance.

Then we made an attempt to compare the identified five-factor structures of each of the existential fears.

Table 2. Comparison of the factor structure of the semantic differential of the existential fears

\begin{tabular}{|l|l|l|l|l|}
\hline \multicolumn{1}{|c|}{ Factor } & \multicolumn{1}{|c|}{ Death } & \multicolumn{1}{c|}{ Loneliness } & \multicolumn{1}{c|}{ Meaninglessness } & \multicolumn{1}{c|}{ Freedom } \\
\hline First & Anxiety & Anxiety & Pressure & Safety \\
\hline Second & Safety & Safety & Stability & Estimation \\
\hline Third & Comfort & Openness & Anxiety & Stability \\
\hline Fourth & Openness & Comfort & Safety & Dynamism \\
\hline Fifth & Stability & Complexity & Comfort & Comfort \\
\hline $\begin{array}{l}\text { Total \% of } \\
\text { Variance }\end{array}$ & \multicolumn{1}{|c|}{47.06} & & 42.78 & 57.37 \\
\hline
\end{tabular}

In the semantic space, the factor structures describing the experiences of the fear of death and the fear of loneliness are almost identical, only the fifth factor is different. For the fear of death, it is stability, for loneliness it is complexity. Perhaps the fear of death is more stable, unchanging, or even inevitable. The fear of loneliness, on the contrary, is not so stable, as it changes depending on a situation and many other determinants. At the same time, it is more complex, ambiguous, as our subject [2].

While the fear of death and the fear of loneliness are almost identical, the fear of meaninglessness is different in certain ways. In the first positions, it is characterized by the factors of pressure and stability. Perhaps because experiencing meaninglessness is associated with a grave, vague state of value decline, which creates a situation of uncertainty, instability, existential vacuum. The next set of factors that comes into play is identical to the factors of the fear of death and loneliness - the factors of anxiety, security, comfort. Thus, meaninglessness may acquire vulnerable, disturbing characteristics.

The factor structures of the fears don't differ from each other significantly, except for the fear of freedom, the structure of which doesn't contain the factor of anxiety. Considering the previous results - we have traced the tendency of the subjects to ascribe fear to the positive pole. This kind of fear evokes pleasant associations in the subjects. Then, the safety factor, the first and foremost in the structure, will indicate that the loss of freedom is not so scary. There are no special consequences that can impair either physical or social existence, i.e., the fear of freedom is experienced by the subjects as safe. The next factor, estimation, indicates that the experience of the loss of freedom is heavily emotionally charged with descriptive descriptors that form a certain desired perceptual image of this fear.

The stability factor, in this case, may indicate that freedom can threaten stability, steadfastness. This process is dynamical, which is communicated by the following factor of dynamism. In other words, freedom may be desirable only in cases when it doesn't interfere with balance, peace. This point is also confirmed by the last factor of the structure - comfort. Thus, E.Fromm's idea that comfort and stability depend not on freedom, but rather on limiting it has been confirmed.

Practical value. The semantic differential became an indicator of an individual state of the personal-meaning area and the emotional sphere of the subjects. Antonymic symbols-stimuli, which had underlain each of the identified factors, determined not only the attitude towards fear but also the dynamics of experiencing it, depending to what qualities the subject is inclined and how often it happens. The positive and negative values of each group have some meaning: the negative side of fear can completely or partially repress the positive one, or shift into the positive side, and vice versa. Something that caused pleasant feelings now evokes caution, anxiety. Positive characteristics of safety and comfort can be transformed into opposite characteristics of discomfort, and increase the unpleasant context of experiencing.

Conclusions. Factor analysis of the semantic differential of existential fears showed a multilevel structure in the semantic space of which five factors have been identified: they cover from $42.78 \%$ (the fear of meaninglessness) to $57.37 \%$ (the fear of freedom) of variance. In all of them, the most prevalent are the factors of "safety," "anxiety," and "comfort." But there are still some differences between the factor structures of each of the fears. 
The fear of death is experienced by the subjects as stable, unchanging, inevitable. The fear of loneliness looks a bit different - the subjects perceive it as complex, perhaps because it may rather be situational than stable, i.e., to change over a period of time and depending on the situation.

As to the fear of meaninglessness, the most significant factors were the ones of pressure and stability, which may indicate a constant struggle of the meaning against external pressure, coercion. Perhaps the meaning doesn't have enough time to "be born" from the inside, because the modern social context increasingly requires from a personality rapid determination and ongoing action.

The fear of freedom is more desirable, "right" for the subjects. Perhaps the reason is that it's hard to experience the feeling of responsibility, traditionally associated with freedom. Obvious detachment from freedom is felt, i.e., the burden of responsibility makes us be more cautious with freedom, more afraid of it.

Thus, the semantic differential became an indicator of an individual state of the personal-meaning area and the emotional sphere of the subjects.

Abstract. The article describes the differences in the factor structure of the basic existential fears. The structures were identified in the research of existential fears using the semantic differential created specifically for this purpose.

Keywords: existential fears, semantic differential.

\section{References.}

1. Horbunova, V. V. (2007). Структура психосемантичного дослідження [Struktura psykhosemantychnoho doslidzhennia] Structure of psychosemantic research // Соціальна психологія [Sotsialna psykholohiia] Social psychology, Vol 1, 170-178 (ukr.).

2. Pyszczynski Tom, Greenberg Jeff, Koole Sander, Solomon Sheldon (2010). Experimental Existential Psychology: Coping With the Facts of Life. - NJ, US: John Wiley \& Sons Inc. - DOI: https://doi.org/10.1002/9780470561119.socpsy001020 


\title{
Psychological Factors of the Formation of Victimization of Women in the Modern World
}

\author{
(Vakulich Tetyana)
}

PhD in Psychology, Associate Professor, Kyiv, Ukraine

\begin{abstract}
Introduction. Nowadays, violence and abuse in the family is a serious and common issue. Sociological studies revealed that $97 \%$ (Christmas, 2008) of victims of family violence are women; women are 6 times more likely to fall a victim to crimes committed by the closed ones. The consequences of family violence are in the second place in the list of risk factors for mental health of a woman (after the consequences of sexual violence). The modern society has the following situation: $50 \%$ of women are falling victims to various forms of abasement and abuse and more than $20 \%$ of women experience violence on a regular basis (Zanarini, 2009). The consequences of the formation of victimization of women in the modern world in the context of social change are crucial and urgent. Hence, the purpose of the article was to theorize and test with experiment psychological mechanisms, factors and conditions of the formation of victimization of women.
\end{abstract}

Methodology. The purpose of the study required a complex of methods of empirical study to be applied. To study the personality of a woman, the following psychodiagnostic procedures have been applied: a scale of the forms of abusive behavior in a couple (specially created to study the level and forms of family violence) (I.A. Hrabska, O.D. Shynkarenko, 1999); a method of codependency diagnosing B. Weinhold; subjective scaling of self-esteem and a questionnaire for the disorders diagnostics M.Yu. Samosti, Shalneva; 16- PF questionnaire of R. Kettle; to analyze the genesis of codependent relationships associated with infantile traumatism and specifics of socialization - projective techniques: analysis of early memories (W.R. Rule) and 'enchanted family' (M. Kos, G. Biermann); a scale of differential emotions of K. Izard and ACL scale to study the defensive selfconception of personality (H.G.Gough and A.B.Heilbrun, 1965); projective techniques Hand-Test (Hand Test) to study the deep personal attributes and trends (E. Wagner, S. Piotrovsky, 1962); a questionnaire of the retrospective assessment of parents-child interaction; unstructured diagnostic interview. The study sample included 273 women. The group of interest included 134 women (women experiencing violence and abuse), the control group included 139 women (women who are not experiencing violence and abuse). The samples are coincided according to age and education.

Results, Discussion and Conclusions. Having studied the level of understanding by victimized women of their own feelings it is possible to conclude that women experiencing abuse: have disorders of affective functions in the form of misunderstanding or altered perception of their own feelings $78 \%$. They have disorders of cognitive functions in the form of misunderstanding or rationalization of own behavior, behavior of the people around and the situation: victimized women do not understand the danger impending over them, and they tend to percept the physical abuse as proof of masculinity (62\%). Possible nervous breakdowns tend to be perceived as form of rudeness. Own aggressive actions being unconsciously motivated by the feeling of fear - as evidence of own dominance, overthinking of the problematic situation - as carefulness $(46 \%)$. They tend to have altered selfperception and low self-esteem due to the transfer of the attitudes of an abuser to themselves (52\%): selfassessment as inimical person who is incapable of sympathy, a feeling of inability to get along with others. Acceptance of assessments of other people as true characteristics is a sign of the indeterminate boundaries of the ego of an abused women (43\%). Thus, it is possible to make a conclusion that the mental state of victimized women falling victims to family violence tends to have a low level of emotional control and self-confidence, low self-esteem, high level of anxiety, uncritical thinking, abnormality of the process of self-identification, lack of the ability to be assertive, feeling of guilt and shame, high conformity, low activity, fit of anger and aggression. Practicallsocial value. It is possible to use the results of the study in the course of preparation of the programs 'Psychological work with women who have been fallen victims to family violence', 'Basics of psychological work with women having behavior of a victim' in the work of crisis centers and social and psychological rehabilitation centers.

Keywords: mental health, social development, family abuse, children abuse, victim, aggressor, learned helplessness, family system theory.

\section{References.}

1. Christmas, D. (2008) Synopsis of Causation: Personality Disorder, Ministry of Defence, 1-24.

2. Zanarini, M.C. (2009) Psychotherapy of Borderline Personality Disorder. PubMed Central. Acta Psychiatrica Scandinavica, 120(5), 1-8. http://doi.org/10.1111/j.1600-0447.2009.01448. 


\section{Media-Art-Therapy for Mental Health Care}

(Olena Voznesenska)

Institute of Social and Political Psychology, National Academy of Educational Sciences of Ukraine, Kyiv, Ukraine

Introduction Media and communications play an extremely important role in our life and expand capabilities of every modern person. But informational influence can also cause mental traumatism. With an intensive media expansion in all spheres of life it is necessary to find ways to prevent possible negative media-related outcomes. Media literacy is relevant not only as means of developing media competences of a person and raising the level of one's media culture, but also as a way of preventing and overcoming the effects of mediatraumatization.

Media trauma is a psychological trauma that appears under the influence of media tools, media messages, media content as a harmful reaction to an emotionally significant event affecting the meaningful spheres of human existence. Media trauma is associated with strong stressful effects on the psyche, a life threat (destroys the sense of security) (Voznesenskaya, Sidorkina, 2016).

Purpose. The purpose of the article is to present the experience of using media-art-therapy to overcome the consequences of psychotraumatization, conflict resolution and peacemaking under the war conditions.

Design / Methodology. Media-art-therapy as an opportunity for self-expression through media creativity is an effective strategy for the preservation of mental health, the prevention of media trauma and strengthening of media-immunity is.

Media-art-therapy is the newest type of art therapy. It's basis is the usage of modern media that is a distinctive feature of the method. Media-art-therapy is more than just media art in therapy, but also concerns any media in art therapy used for the creative process (Voznesenskaya, Sknar, 2017).

Why is it necessary to create new personal assistance tools? We live at the time of informational explosion, when forms and means of communication and interaction are changing. Art as a reflection of a reality in creative way also changes. An artist goes to a new level of communication with his audience. And now every person with a simple smartphone instantly can become an artist! Media have greatly extended the possibilities of using the art therapy, have reduced the fear of one's own creativity and have helped to share ones results with others and to receive support.

The use of art-therapeutic methodology creates opportunities for facilitating the media consumers to end the role of «passive consumers» of media products. It helps to prevent the psycho-emotional disturbances and to promote the development of a reflective stance when interacting with the media. This is an important step towards creating a healthy, active and conscious personal position to media.

The mechanisms of therapeutic influence in media-art-therapy are: catharsis, creative expression (through new media), emotional support (that can grow significantly if pieces of one's own creativity are shared through Internet), awareness of one's own uniqueness, group identity (sense of belonging to the community), value of communication and joint creativity awareness, projection, reflection, awareness and construction of new meanings. The development of media competence in the process of media-creativity leads to the increase of selfevaluation and to the improvement of communication quality. This is very essential for working with psychotraumatisation.

Results. The training «Art Therapy Techniques for Conflict Resolution and Peacemaking» inside the «Women's Voice has a Power» project is implemented by the Human Rights Foundation and is funded by the Institute for International Cultural Relations (Institut für Auslandsbeziehungen) by means of the German Ministry of Foreign Affairs (Auswärtiges Amt). The training was based on the art therapy methodology in its wide sense i.e. a healing method that uses any kind of art and particularly the media-art-therapy.

The aim of the training was to understand the possibilities of the latest informational society technologies; to learn tools and methods to create the peacemaking content. The animation movie "Own Truth" (Своя правда, 2018) was one of the training results. Animation as an art appeared two decades earlier than classical cinema and up until today contributes to the modern «screen reality». Animation has fundamentally different organization of the production process than in the movies i.e. making separate shoots. It expands the experimental boundaries and the ability to embody fictional images.

The theme of the animated film was determined by the theme of the training - conflict and peacemaking. The plasticine animation was proposed for the implementation. Plasticine was chosen as the material that contributes the best as the response to the strong feelings of conflicts and traumas of war: fear, anger, aversion, etc.

Activity of creating a fine art in many cases is a very important communicational tool that enables a person to build a more harmonious relationship with the outside world. The participants tried themselves in the role of scriptwriters, directors, animators, operators, video editors, sound directors and so on. None of the training participants has tried to create animation before. It was a new experience for each of them. 
Limitations and strengths of the study. This participation experience has raised the media culture of the participants, and has allowed everyone to express their feelings related to military actions, as the participants of the training were mostly temporary displaced people from the combat zone in the East of Ukraine. Everyone could be heard, everyone has realized his or her traumatic experience, which was then translated into a symbolic form of the animated film.

Originality / Conclusions. Today art therapy as a method of healing the personality by the means of art requires understanding of new possibilities of the informational world, the emergence on a new level of understanding of healing mechanisms through the use of media in the creative process. The use of the media-art-therapy creates the environment to express the accumulated feelings including the ones that were created as the result of the interaction with media. That is an important condition to prevent the mediastraumatization and to raise the media culture of the person. Our experience has proven that media-art-therapy is an adequate method for resolving conflicts both in real groups and for the implementation of peacemaking initiatives in large communities.

Practical / Social value. Sharing of the personally created media-content enables a person to spread their message to the large audience. This contributes to the social adaptation of the temporary displaced people, and helps them to cope with the effects of mental traumatization and to integrate with the new community.

Keywords: psychology trauma, social conflict, telecommunications, resettlement of persons, peacekeeping, Ukraine, social rehabilitation, media art therapy.

\section{References.}

1. Voznesenska O., Sidorkina M. (2016). Art-therapy as treatment of mental trauma. Textbook. Kyiv. (Вознесенська, О.Л., Сидоркіна, М.Ю. (2016). Арт-терапія у подоланні психічної травми: Практичний посібник. Вид. 2е: випр. та доповн. Київ: Золоті ворота).

2. Voznesenska O., Sknar O. (2017). Encyclopedia of Art-therapy. Kуiv (Вознесенська, О.Л., Скнар, О.М. (ed.). (2017). Енциклопедичний словник з арт-терапії. Київ: Видавець ФОП Назаренко Т. В.)

3. Own truth (2018, Jule). Retrieved from www.youtube.com/watch?v=uJtCV0KfZGY (Своя правда (2018, Jule). Retrieved from www.youtube.com/watch?v=uJtCV0KfZGY) 


\title{
Traumafokus $^{\circledR}$ (TF) - Psychotherapy for Chronic Pain Regulation and Pain Syndromes
}

\author{
(Thomas Ch. Weber)
}

Institute of Neuropsychotherapy, Vienna, Austria

\section{Introduction: \\ What is Traumafokus ${ }^{\circledR}$ about?}

Traumafokus is a depth psychologic and body-focused method to treat clients with chronic diseases caused by stress, personality disorders and pain syndromes. This method enables the spontaneous, direct processing of trauma in the brain without affecting conscious memories. At the beginning of a treatment with Traumafokus, due to the observation of the client's natural eye position, there is an unconscious focus to an issue for processing. When the stress in the brain is reactivated we can start with the processing of a trauma. During the activation of stress, the involuntary breathing changes, which is consciously used by Traumafokus to regulate stress in the brain and the body. Depending on where clients look, they can sense the stress in the body stronger or less strongly.

\section{Main text:}

What do involuntary eye position imply?

When we, think about something, count, try to remember a forgotten word, or feeling pain our eye focus is spontaneous and non-systematic in the visual field. That is, we do not accommodate at this moment, but we are gazing. Clients find without consciousness natural eye positions when they are talking about a traumatic issue. During these moments they are recalling stored unconscious memories.

Per say, an eye position of a traumatic issue can be found by observing the client's face and eye positions when he or she is talking about the trauma. It is necessary to observe carefully where the eyes of a client move for gazing. It becomes the eye focus for processing - it is crucial and effective just to observe it during a therapy session. Weber detected that the highest activation chosen by a therapist using a pointer is not an optimal eye focus for an effective brain regulation. The strongest activation that a therapist chooses most often leads in people with PTSD to the effect of a hyper arousal or a dissociation. This is a useful tool only should the activation be very low, which happens less often.

How is the procedure of a Traumafokus session?

It is crucial for an effective session if a therapist is observing calmly the described phenomena (see above) of a client, especially the involuntary patterns of his/her breathing and the repeating eye positions in the visual field. If a eye focus is detected, immediately body sensations or unconscious memories or images are emerging. They can get processed directly and mindfully.

These sensations, which are sensed by the client in the body are called "Felt Sense" (E. Gendlin, 1978) this is so called the located stress in the body of a client.

Psychobiologist and neuroscientist Stephen Porges (Porges S.,2010) described in his "Polyvagal Theory" the phylogenetic development of the autonomous nervous system and its influence for humans. He found the groundbreaking new theory of dual functions of the vagus nervous system: the myelinated ventral vagus, located between the brainstem and the supra diaphragmatic area, which is activated when the client calms down. With the breathing technique that the therapist suggests to the client: "breathe comfortably to yourself, deeply and slowly" this vagus complex is activated and makes it possible to change the state of anxiety or immobilization (dissociation)into calmness. In 1932, Walter Cannon described the autonomous response of fear and death to the phenomenon of "Fight-Flight and Freeze" response.

\section{Regarding to the self-assessment of traumatic stress}

Due to the conscious breathing technique, the client enters a state in which without being at the mercy of a psychological stress. If necessary, at the beginning and at the end of the session, you can apply a stress scale according to Joseph Wolpe (1969), from "0" there is no stress to "10" maximum stress, also called SUD (Subject Units of Distress).This scale of stress seems to be convenient in some traumatherapeutic methods like EMDR, from my perspective it is of limited suitability, because clients with complex trauma have SUD, which often increases again after a while of good processing; the Felt Sense also changes simultaneously as well. We found out that it normally happens that this client experiences another traumatic part in life that opens up for processing. For inexperienced therapists, it is an unexpected surprising phenomenon, but it is not. The brain is built for regulating all emotional processes in the best way. When a part of a complex trauma is disappearing the next part is calling to be processed. That is why we should use SUDS with reservation. The most important thing is to inform clients about the principles of a SUD.

\section{Regarding the therapy of pain with Painfokus}


Inside each chronic pain there is a subjective unconscious history of pain. When treating pain due to Painfokus, an 11-level numeric rating scale is used (NRS) for valuating pain, that's indicating the rate of a client's subjective pain in the body both. Special Felt Sense techniques for pain management and Thomas Weber's manual-body-intervention (MBI) techniques are used in parts of a client's body with severe pain to release after few uses.

\section{Optimal regulation of the nervous system with Traumafokus}

Traumafokus ${ }^{\circledR}$ is an effective neuro-psychotherapeutic method, which allows to resolve mental and physical chronic stress; even in those cases where the traumatic experience happened in early childhood, during perinatal or prenatal phases, that are not consciously available. During a Traumafokus session, which regulates and calms down the brain activation, we are using multisensory resources especially in the treatment of attachment trauma. It is not therapist, who does heal a client, it is the client's regulating brain and nervous system, which gets from an impaired state into a regulatory process, and thus new neural networks are getting created in a client's brain. Chronic stress and chronic pain are constantly decreasing during each session. In order for this healing process to be maintained, we use a technique for sustainability called "progress focus" that the client can use effectively at home in order for the re-adjusted nervous system to train into a new calming state - you can say also: stress-free exercises are practiced daily repeatedly to train the brain from stress to calming. This approach goes along with the known paradigm of Donald Hebb in 1949, who said "cells that fire together wire together".

What happens with chronic pain in the brain?

From newest brain research it is known today, that chronic stress leads to a decreasing function of the hippocamp in the brain and also in the prefrontal cortex of the brain. At the same time, a cascade of stress hormones is released in the hypothalamus, pituitary gland and adrenal gland (= HPA axes). It happens the most to clients with post-traumatic stress disorder (PTSD), panic attacks, phobias, depressions, chronic emotional stress and traumatic experience of sexual abuse in childhood or with soldiers from war. These factors cause the worst traumas to occur.

\section{Therapeutic intervention using "Limbic Language"}

With the help of Traumafokus and therapeutic training system in our institute of neuropsychotherapy, clients are no longer re-traumatized and the additional indirect degree of traumatization of the therapists is kept low because we work to a large extent with the implicit memory of our clients and intervene with the help of "limbic language." This raises the effectiveness of the therapeutic approach, as we use neuro-scientific research rightbrain to right-brain interaction by Allan Schore (Schore A. N., 2010) who published an important article in 2011: the right Brain implicit self - a central mechanism of the psychotherapy change process. American Psychological Association, Division of Psychoanalysis (39), 2011.

In his article, Schore points out that the therapist's right hemisphere interacts with the right hemisphere of the client. This terrific discovery proves a brain scan. The right brain of the brain is our emotional and unconscious hemisphere.

\section{Releasing chronic pain}

A further mile stone with Painfokus was the treatment of acute and chronic pain. In 2013, Weber accidentally discovered an extremely rapid releasing of an acute pain of an acquaintance after a plunge from the stairs with severe swelling of the leg tissues and a hematoma. After an impressive rapid disappearance of symptoms, he studied the therapeutic potential of chronic somatic pain syndromes such as: migraine, cluster headache, fibromyalgia, chronic pain of the musculoskeletal system (knee, thigh, joint, back) and stated that chronic pain may completely resolve when we are getting access to the history painful memories are worked out. With Traumafokus $^{\circledR}$, we have found an effective access to the subconscious history of painful experiences. Thus the pain matrix (the cycle of pain in the brain) is changing by regulating and the pain in the body decreases until relief. Because of this approach seems to be promising, we started in 2016 a long-term pre- post study with trained Traumafokus therapists in a clinic for psychosomatic and psychotherapy in Germany.

\section{Combining Traumafokus ${ }^{\circledR}$ with other methods}

The goal of the method is a healing of blocked arousal in the brain and in the human body. Traumafokus made for an integration with other scientific validated psychotherapeutic methods.

\section{The origin of Traumafokus ${ }^{\circledR}$}

The methods Traumafokus ${ }^{\circledR}$ and Painfokus, were developed by Thomas Weber, head of the Neuropsychotherapy Institute, who worked for many years with traumatized clients and for several years he worked as master trainer beside David Grand, the founder of Brainspotting ${ }^{\mathrm{TM}}$. Grand, former trainer beside Francine Shapiro, who founded EMDR (eye movement desensitization and reprocessing). Traumafokus uses insights of: Focusing (Gendlin) (Gendlin E. T.,2014), Pranayama, current neurobiological pain research (Bushnell, Egle, Melzack\& Wall, Engel, etc.), Hypno Systemic approach (Schmidt), Brainspotting (Grand, Schwarz, Weisz), MBEP (Weisz), neurobiological studies (Porges, Schore, Damasio, Hirsch, Schiepeck, Hüther, and others) (Porges. S.,2017, Schore, A. N., 2000, Hirsch, M.C.,2000, Van der Kolk, B.,2016, Watkins, J. \& Watkins, H.,2008). 


\section{Practical Value:}

\section{Areas of application of traumafocus}

With Traumafokus we normally can treat people having a single trauma with 2-3 sessions. For complex traumatized clients we need with Traumafokus more sessions.

Traumafokus can be used effectively in psychotherapy with children and adolescents: in cases of preverbal traumas, chronic stress experience in early childhood, dissociation disorders, ADD / ADHD, enuresis, encopresis, stammer, depression, drug addiction, anxiety disorders, truancy, obsessive compulsive disorder, bipolar disorder, phobias. The use of Traumafokusin the treatment of children and adolescents works in a shorter time of a session.

Traumafokus can be used successfully with: acute, complex and single trauma, post-traumatic stress disorder, panic attacks, generalized fears, depressions, obsessive compulsive disorders, addiction, chronic psychosomatic diseases, allergies, attachment disorder, borderline personality disorder, sleeping disorders, eating disorders, chronic headaches, migraines, fibromyalgia, pains of the musculoskeletal system, cluster headaches and various forms of dissociative disorder as dissociative identity disorder. Many of the psychiatric symptoms of ICD-10 and DSM-V appear to be consistent sequel of childhood injuries and are treated effectively with Traumafokus and Painfokus.

Keywords: mental stress, psychology, regulation, trauma.

\section{References.}

1. BADENOCH, B. (2018): The Heart of Trauma. Norton, New York.

2. DOIDGE, N. (2008): Neustartim Kopf. Campus, Frankfurt a.M.

3. DOIDGE, N. (2015): Wie das Gehirn heilt. Neueste Erkenntnisse aus der Neurowissenschaft. Campus, Frankfurt.

4. FLIEß, C. \& IGNEY, C. (2010): Handbuch Rituelle Gewalt. Pabst, Wien.

5. GENDLIN E. T. (2014): Focusing-orientierte Psychotherapie. Ein Handbuch der erlebensbezogenen Methode. Klett-Cotta, Stuttgart.

6. HIRSCH, M.C. (2000): Glossar der Neuroanatomie. Springer, Berlin.

7. KRÖNER-HERWIG B., FRETTLÖH J. et al. (2017) 8. Aufl.: Schmerzpsychotherapie - Grundlagen, Diagnostik, Krankheitsbilder, Behandlung. Springer, Paderborn.

8. LE DOUX, J. (2016): Angst. Wie wir Furcht und Angst begreifen und therapieren können, wenn wir das Gehirn verstehen. Ecowin, Wals b. Salzburg.

9. LOHNINGER A. (2017): Herzratenvariabilität - Das HRV-Praxis-Lehrbuch. Facultas, Wien.

10. Mc GILCHRIST, I. (2009): The Master and his Emissary. The divided brain and the making ofthe western world. Yale University Press, London.

11. PORGES, S. (2010): Die Polyvagal-Theorie. Neurophysiologische Grundlagen der Therapie. Junfermann, Paderborn

12. PORGES, S. (2017): Die Polyvagal Theorie und die Suche nach Sicherheit: Traumabehandlung, soziales Engagement und Bindung. Probst, Lichtenau.

13. SCHORE, A. N. (1994): Affectregulationandtheoriginoftheself. Mahwah, NJ: Erlbaum

14. SCHORE, A. N. (2000): Attachment and the regulation of the right brain. Attachment \& Human Development Vol. 2 No 1, p. 23-27.

15. SCHORE, A. N. (1997): Early organization of the nonline a rright brain and development of a predisposition to psychiatric disorders. Development and Psychopathology, Vol. 9, p. 595-631.

16. VAN DER KOLK, B. (2016): Verkörperter Schrecken - Traumaspuren in Gehirn, Geist und Körper und wie man sie heilen kann. Probst, Lichtenau.

17. WATKINS, J. \& WATKINS, H. (2008): Ego States - Theorie und Therapie. Carl Auer, Heidelberg. 


\title{
Ethical Grounds of Psychological Help as a Means of Preserving Mental Health of a Person
}

(Tetiana Yablonska, Natalia Bulatevych)

Taras Shevchenko National University of Kyiv (Ukraine)

\begin{abstract}
Introduction. Practical psychological service is actual and significant field of psychologists' activity in modern society. Society is becoming more and more aware of the importance of psychological assistance and human support in various spheres of its life: in the educational process, in professional activity, in solving personal and family problems, in overcoming difficulties in severe life situations.

Social changes in Ukraine in recent years have led to an increase in the number of people who need professional psychological help, which is called to support in preserving their mental help. This puts difficult tasks for psychologists and they need to improve their professional skills and adhere high professional standards in work, above all ethical ones.

It is obvious that professional standards, professional ethics ensure the quality of psychological services, and protection of the interests of both a psychologist and their clients.
\end{abstract}

Purpose. The purpose of this article is to analyse the ethical dimensions of psychologists' professional activity through the prism of psychologists' perceptions of the ethical aspects of psychological counselling

Methodology. Professional ethics means a system of moral norms, values, principles of behaviour that specify the requirements for objectives, tasks and conditions of a certain type of work, and serve as an internal regulator of behaviour and relationships in the community of professionals (Myagotin, 2011). The ethics of psychologists' work is based on universal moral values, including free and comprehensive development of a person and respect for him/her, intimacy of people, creation of a just, humanitarian, and prosperous society. The ethical principles and rules of the psychologists' work form the conditions under which their professionalism, humanity of their actions, respect for people, and the real value of their efforts are preserved and increased (Krylov, Yuryev, 2000).

In addition to general ethical principles, specific ethical standards are developed for psychologists' activity. In particular, the EFPPA Code of Ethics (European Federation of Professional Psychological Associations). Ukraine become a member of EFPPA in 2017. Code of Ethics of EFPPA includes provisions governing the professional activities of psychologists which are united into 4 general principles:

Respect for a person's rights and dignity means awareness of and respect for the knowledge, insight, experience, and avoidance of practices as a result of unfair bias, which may lead to unjust discrimination; confidentiality; work based on a client's informed consent.

Competence means awareness of the limits of competence derived from education, training and experience, awareness of the limits of procedures for particular tasks, and the limits of conclusions that can be derived in different circumstances and for different purposes; professional development; obligation not to practice when ability or judgement is adversely affected, including temporary problems.

Responsibility means psychologists' responsibility for the quality and consequences of their professional actions, promotion and maintenance of high standards; avoidance of the misuse of psychological knowledge or practice; responsibility towards a client, which continues after the formal termination of the professional relationship.

Integrity means honesty and accuracy, accuracy in presenting information, hypotheses, conclusions, and opinions expressed in professional reports and statements; avoiding double relationships with a client in financial issues of counselling / psychotherapy, (Meta-Code of Ethics) ${ }^{1}$.

The issues of the ethical principles of psychologists' activities, the underpinning values of their work are actively discussed in psychological studies (Bondarenko, 2012; Bocheliuk, Zaritska, 2007; Bulatevych, 2015; Corey, Corey \& Callanan, P., 2007) Vorobyeva, 2009). The scientists note that psychologists' professional activities are bound to work with a person's inner world and personality, which requires observance of special principles and rules of ethics.

According to the researchers (Karandashev, 2000), the most important principles of psychologists' professional ethics are: professional competence (a psychologist must know their rights and duties, professional capability and act only within their professional competency); non-infliction of harm to a person (psychologist's activities should not harm the health and interests of a person); objectivity (a psychologist must hold an objective position, in particular by applying standardized, reliable, valid adapted techniques as well as use adapted methods for data processing and interpretation); respect toward a client (a psychologist must respect the dignity of their clients and show honesty in communicating with them); professional confidentiality.

\footnotetext{
${ }^{1} \mathrm{http} / / /$ ethics.efpa.eu/metaand-model-code/meta-code/ 
In modern psychological practice many ethical problems of psychologists' activities remain unresolved. Thus, excessive regulation of such activities leads to psychologists' decisions being too formalized. The psychologists' professional ethics is divided into "mandatory ethics", which is the minimum of ethical rules and guidelines to be followed by psychologists, and "aspirational ethics", which is that level of compliance with ethical guidelines when a psychologist acts in the client's best interest (Corvey, 2016). There are other aspects of psychologists' activities related to ethical issues:

- incorrect assessment and psychological diagnostics in counselling (psychotherapy) may result in wrong diagnosis and accordingly his/her stigmatization;

- a formalized, technological approach involving short and standardized interventions;

- an insufficiently defined attitude of the professional community to multiple relationships in counselling (combining the roles of a teacher and a therapist, a supervisor and a therapist, counselling of friends, employees, relatives, common business with a client, etc.), which is the basis for the emergence of ethical dilemmas in the psychologists'activity (Corvey, 2016).

In order to empirically study the views of psychologists and clients on ethical norms, the author's questionnaire was used, in which statements were formulated based on the psychologists' ethical code. The questionnaire includes the questions requiring open answers of the respondents (in the form of unfinished sentences), and the wording reflecting the basic requirements of the ethical code with the proposal for their evaluation.

The four categories from the Ethical Code of the European Federation of Professional Psychological Associations (EFPPA) ${ }^{2}$ were used in content-analysis of the psychologists' and clients' statements: respect for a person's rights and dignity, competence, responsibility, integrity. The methods of content analysis of unfinished sentences were used for data processing, together with linguistic and semantic analysis of a statement frequency (Glukhov, 2008; Tarasova, Cheremukhin, 2017), Student's t-criterion, and Pearson correlation coefficient.

Results. The psychologists' views on the important ethical aspects of psychologists' professional activities were studied. The empirical study was carried out on 46 psychologists aged 22 to 59 years, an average of 38.7 years, having a work experience of 1 to 34 years, average experience of 12.6 years.

Peculiarities of psychologists' representations about ethical values and standards in their professional activity were singled out as a result of the survey analysis. Thus, the majority of polled psychologists (78\%) consider confidentiality and respect for a client as the basis of professional activity. Another important basis for professional activity, is understanding of the limits of psychologists' competence (60\% of respondents). The third place in the frequency of references is the subjective well-being of the psychologist and the inadmissibility of the use of directives, instructions, tips (30\% of those polled). $26 \%$ of the respondents considered important psychologist's work with their own personal problems and subjective well-being of a psychologist, observance of the limits during counselling (a contract), responsibility for used techniques. Less important, but often mentioned are such aspects of activity such as good organization of counselling conditions and customer safety ( $21 \%$ of respondents), creating conditions for a client's personal development (21\%).

As a result of the content-analysis, it was found out that the statements related to the category of "respect for a person's rights and dignity" constitute $37.2 \%$ of all statements, they are mentioned by $95.7 \%$ of the surveyed psychologists.

As much as $25.62 \%$ of the statements were categorized as "competence", and $78.3 \%$ of the surveyed psychologists pointed out the importance of standards pertaining to competence.

Only $7.43 \%$ of all the statements belong to the category of "responsibility". The psychologists' responsibility as the ethical value and standard of professional work is highlighted in the responses of $47.8 \%$ of the surveyed psychologists.

The statement belonging to the "integrity" category make up $23.14 \%$ of all statements and $82.7 \%$ of the surveyed psychologists mentioned them.

The analysis of frequency of statements classified into a certain category allows us to speak of a peculiar "rating" that represents the values and ethical norms of professional activities in the psychologists' views. Hence, the standards related to respect for a client are the most important, the principles and standards described by the categories of competence and integrity are rated a bit lower, and responsibility has the lowest importance.

The performed analysis has revealed statements difficult for categorization and describing an emotional, "human" side of the relations between psychologists and their clients. These are the following concepts: indifference, trust, emotional comfort, a stable emotional state, emotional and mental inclusion, openness, acceptance, and faith in a client. These statements make $6.61 \%$, but they are mentioned by $47.8 \%$ of psychologists, which indicates the significance of emotional aspects of their activities.

Limitations and strengths of the study. The research performed shows that the ethical code of a psychologist is a sufficiently reliable basis for effective interaction with the client, but, at the same time, it does not solve all

\footnotetext{
${ }^{2}$ http://ethics.efpa.eu/metaand-model-code/meta-code/ 
practical contradictions of the process of providing psychological assistance, and sometimes stands in opposition with the organization of such practice.

Practical/Social value. The consequences of communicating with a psychologist have a great personal significance for the client. Compliance or not with the ethical principles of professional activities influence the counselling results, developing or destroying client's identity.

The significance of this study of views about professional ethics and the prospect of further researches is seen in the perspective of increasing the professional competence of future psychologists regarding the issue of mental health and improving the quality of providing psychological assistance to clients.

Conclusions. The ethical principles of psychologists' professional activities are aimed at the establishment of universal humanitarian and social values; the main ethical principles are respect for a person, protection of human rights, sense of responsibility, honesty and sincerity with respect to a client, professional competence, commitment to the counselling purpose and confidence in its scientific basis.

It has been empirically discovered that psychologists' views on ethical principles in their activities are fairly logical and consistent, the correspond with the provisions of the ethical code. It has been discovered that psychologists' views on ethical principles' importance (respect for person's rights and dignity, competence, responsibility, integrity) and emotional aspects of interaction determinated by psychologists' orientation on a certain "framework" and the rules of interaction. At the same time, ethical requirements, not being the subject of work with the client, provide security, trust, and cooperation, exactly the conditions that are the basis of effective psychological assistance.

Keywords: mental health, psychologists’ professional ethics, ethical values, psychological counseling.

\section{References (Transliteration).}

1. Bochelyuk V. I., Zaritska V.V. (2007). Psihologiya: vstup do spetsialnosti: navch.posibnyk / V.I. Bochelyuk, V.V. Zaritska. - K., 2007. - 288s.

2. Bondarenko A.F. (2007). Psychological help: theory and practice / A.F. Bondarenko, K.: Osvita Ukraini, 2007. -332 s.

3. Bulatevich N.M. (2015). Organizatsiya diyalnosti psihologichnoyi sluzhby: navch. Posibnyk / N.M. Bulatevich. Sumy. SumDPU im. A.S.Makarenka, 2015. - 445s.

4. Vorobeva L.I. (2009). Psihoterapiya I etika // Konsultativnaya psihologiya I psihoterapiya. - 2009. - №1. S.80-98.

5. Gluhov V.P. (2008). Osnovyi psiholingvistiki / V.P.Gluhov. - M.: AST: Astrel, 2008. 352s.

6. Gorbunova V.V. (2005). Etichni ta pravovi aspekti psihologichnyh doslidzhen // Praktichna psihologiya ta sotsialna robota / V.V.Gorbunova. - № 3. - 2005. - S. 18-23.

7. Krylov A.A., Yurev A.I. (2000). Praktikum po obschey I eksperimentalnoy psihologii / Pod red. Krylova A.A., Manicheva S.A., 2-e izd. - SPb., Moskva, Harkov, Minsk, 2000. - S.545-552.

8. Myagotin A.V. (2011). Professionalnaya etika: sovremennyie tsennosti I smyislyi // Tsennosti I smyislyi. 2011. - №2. - S.74-80.

9. Corey G. (2016). Theory and Practice of counceling and psychotherapy. Brooks Cole, 2016. - 490 p., 10 edition.

10. Meta-Code of Ethics, http://ethics.efpa.eu/metaand-model-code/meta-code/ (accessed on 16.06.2018)

11. Tarasova K., Cheremukhin A. (2017). Representation of psychologist-consultant on ethical values, professional sustainability and resilience in professional activities. Universum Psychology and Education. 4 (34), http://7universum.com/ru/psy/archieve/item/4615 


\title{
Neurofitness as a Method of Psychotherapy for Children with Psychoneurological Pathologies
}

\author{
(Olga Yashna ${ }^{1}$, Olexandr Makarenko ${ }^{1}$, Alla Shapovalova $\left.{ }^{2}\right)$
}

${ }^{1}$ National Pedagogical Dragomanov University, Kyiv, Ukraine

${ }^{2}$ Kyiv, Ukraine

\begin{abstract}
Introduction. Child psychoneurology is focused on the bases of such sciences as neurology, psychiatry and neurosurgery. The founders of it were N.N. Burdenko, A.S. Shmar'yan, G.E. Sukharev, J. M. Pellock and E.K. Mayer. It got further development in the works of V.S. Podkorytova, L.A. Bulakhovoy, S.N. Zinchenko, O.M. Sagan, E.Bondarenko, G.G. Shanko, M. Holder, D. Geta, R. Mayo, and others.

The main causes of neuropsychiatric pathologies in children are: craniocerebral trauma, tumors, abscesses, hematomas, vascular diseases, hydrocephalus, hypoxia and infections. This, in turn, causes focuses, synechias, worsens brain nutrition and complicates the construction of new neural connections. The child has various delusional, gauchenric, catatonic, perverse states with which it is very difficult to fight.

Some of recognized non-drug therapies are physiotherapy, electrotherapy, light therapy, magnetotherapy, ultrasound, balneotherapy, massage, physical therapy exercises, psychotherapy, art therapy, bodily therapy and psychoanalysis. However, these methods do not take into account the psychoemotional characteristics of childhood, where systematic procedures and treatment can overload and further injure the child. Therefore, we propose a method of pediatric neurofitness therapy.
\end{abstract}

In the presented scientific literature, there are no sources describing this method.

Results. T.A. Dobrokhotova and N.N. Bragina in their clinical studies pay attention to the fact that when the brain is damaged, there are disturbances in consciousness with a passing perception of the surrounding world and himself - with right-sided localization of the lesion; with the defeat of the left hemisphere - they preempt speech disorder and mental processes based on it (verbal, thinking and memory) motor processes. In the opinion of the authors, the withdrawal from the condition of an attack can be represented as the restoration of the full volume of consciousness due to the normalization of the psychomotor sphere in patients with left hemisphere and psychosensory lesion - with damage of the right hemisphere, as well as the resumption of space-time indices in these patients.

However, in the early stages of child development, its nerve centers are not specialized in functions, a weakened level of afferent-efferent connections, unregulated cortico-subcortical levels of impulses and overlap between different areas of the brain. In childhood, pathology has more serious consequences than in adults, since the adult basic functions of life are already laid. During infancy, along with primary pathology, secondary deviations are more clearly arised, which have more negative consequences for the development of the child's personality than the pathology itself. Even when the primary pathology was eliminated, secondary abnormalities can already form their basis of psychophysical deficiencies.

It should also be noted that the psychomotor and psychosensory spheres of integral psyche are realized: 1) in different present times (individual and world); 2) in opposite directions of time (from the present to the past and from the present to the future); 3) simultaneously - simultaneously and consistently - consistently. In such a way the asymmetry of the consciousness of the spatio-temporal organization of psychosensory and psychomotor spheres appears. Therefore, in neurofitnesses the central method is played by a game that allows us to solve the problem of restoring consciousness and the psychoemotional sphere of the child. The game activity combines both movement and actual sensory stimuluses, it presupposes the necessary chronology of the sequence of actions. In the game, children easily release traumatic patterns and gradually get rid of them.

In addition, the neurofitness includes neuroimaging complexes developed in the 90s by P. Denis, which are structurally divided into two types: the first is the movements that cross the middle line of the human body. They activate the natural mechanisms of interhemispheric interaction, optimize the work of nervous processes, establish the processes of psychophysical functions, and form cognitive activity. The second type is the asymmetric movements aimed at controlling the movements. Such exercises require considerable effort and energy. As a rule, these are static movements that depend on the concentration of consciousness.

Neurofitness exercises which are aimed at stimulating higher mental functions through the sensorimotor level got further development. Such gymnastics obviously contains breathing exercises, massage and self-massage, finger gymnastics and exercise games to form attention and overcome stereotypes of different directions, study your own corporeality and temporal-spatial representations, develop auditory cognition (sense of rhythm, understanding speech and onomatopoeia), exercises, developing tactile, visual, motor and auditory memory. Moreover there is work with muscle blocks in the form of stretching, relaxation, etc.

I. P. Pavlov believed that the result of any thought is movement. As a result of the movement during mental activity, neural networks are built, allowing to fix new knowledge. In this case, the neurotransmitter 
acetylcholine is released through the synapses of activated neurons, which contributes to the growth of dendrites and the development of the nervous network.

The peculiarity of the children's neurofitness is that the method combines the psychomotor complexes of the gaming orientation that affect the neurodynamic processes and the characteristics of their activity.

It is known that children who missed the vital stage of development - crawling, experience learning difficulties. The fact is that during the crawl, cross movements of the hands, legs and eyes are used, which activate the development of the corpus callosum.

With the regular performance of reciprocal movements, a large number of neural pathways connecting the cerebral hemispheres are formed and myelinated, which promotes the development of mental functions. Slowly performing cross-motions contributes to the activation of the vestibular apparatus and frontal lobes of the brain. A series of consecutive movements must be carried from the head and neck to the lower limbs, from the neck and shoulders to the hands and separate fingers and from the knees to the toes. The regulation of the strength of the muscle tonus can also take place in accordance with the laws of the development of movements: from the muscles of the head and neck to the muscles of the trunk and then to the muscles of the lower limbs; from the muscles of the neck and shoulders to the forearms, hands, fingers and, respectively, from the muscles of the thighs to the toes.

The more small muscles of the body are involved, the more nerve paths are built between the frontal parts of the brain, the basal ganglia of the limbic system and the cerebellum.

Conclusions. The use of neurofitness can improve interhemispheric neural connections, and strengthen afferentefferent pathways, increase the neurodynamics of the process of nervousness of nervous activity, which is an important aspect of the maturation of the nervous system at a child's age and the restoration of mental health.

Keywords: children, neurofitness, sensorimotorics, psychomotorics, psychotherapy.

(C) NDSAN (MFC - coordinator of the NDSAN), Italy, 2018 